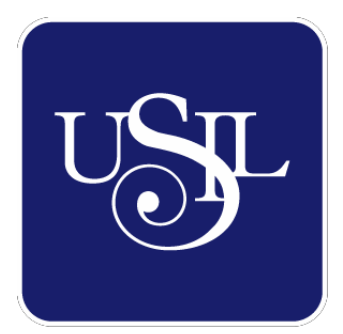

UNIVERSIDAD

SAN IGNACIO

DE LOYOLA

ESCUELA DE POSTGRADO

\title{
“PLAN DE MARKETING DE AMÉRICA DELUXE HEALTH PARA LA EMPRESA AMÉRICA SALUD EN LIMA 2020"
}

Trabajo de Investigación para optar el grado de:

ANGELICA SUSANA CANCHAN HERMOZA Maestro en Dirección de Marketing y Gestión Comercial.

NATHALIE ANDREA RIVERA FLORES

Maestro en Dirección de Marketing y Gestión Comercial.

Asesor:

Dr. José Miguel Solano Morales

Lima - Perú

2020 


\section{DEDICATORIA}

Con admiración y gratitud a mis padres

A mis hijos Matthew y Steve, que son

el regalo más bello que la vida me pudo

dar.

Susana Canchan.

Dedico a mis padres que me dieron la vida, educación apoyo y consejos. A mis compañeros, a mis maestros y amigos. A todos ellos le agradezco desde el fondo de mi alma.

Para todos ellos hago esta dedicatoria y a Dios.

Nathalie Rivera. 


\section{INDICE}

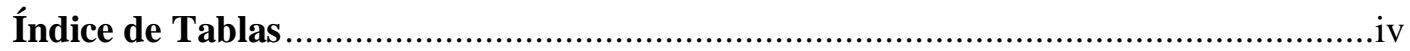

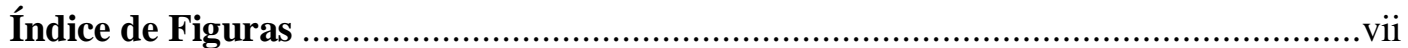

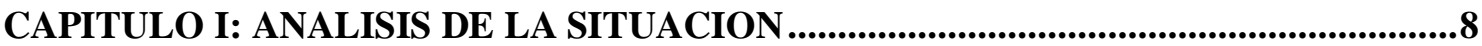

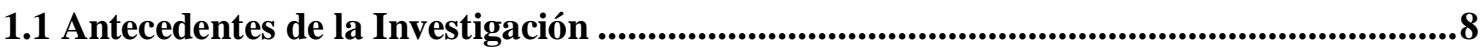

1.2 Determinación del problema u oportunidad ..........................................................................12

1.3 Justificación del proyecto.........................................................................................................13

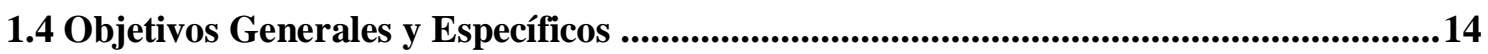

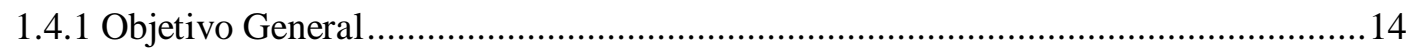

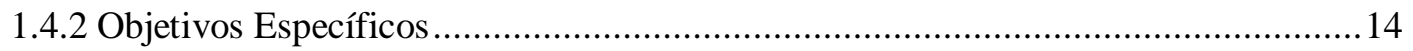

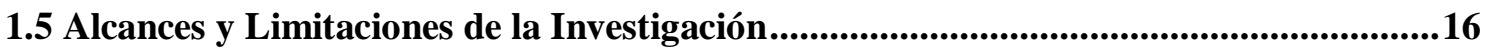

1.6 Antecedentes de la empresa .........................................................................................................16

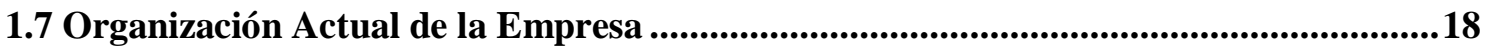

1.8 Situación del Mercado y Financiera Actual de la Empresa ........................................25

1.9 Misión, Visión y Valores de la Empresa ...................................................................28

1.10 Análisis Externo: entorno, sector, mercado y competencia ......................................28

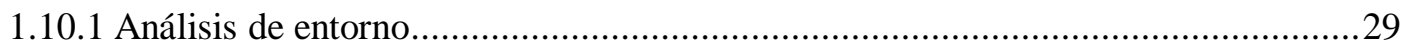

1.10.2 Análisis del Sector (Cinco Fuerzas de Porter) …..................................................40

1.10.3 Análisis de Mercado y la Competencia ...............................................................42

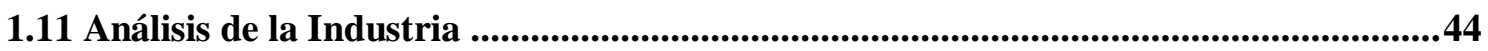

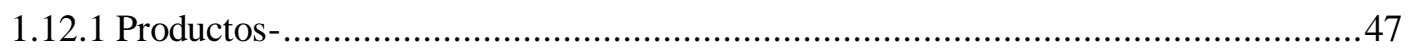

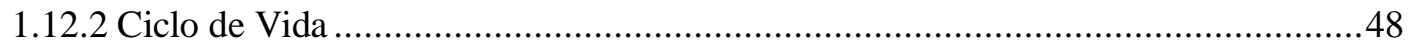

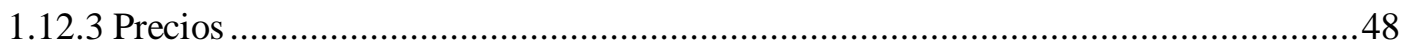

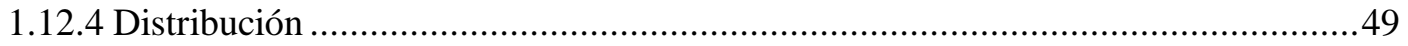

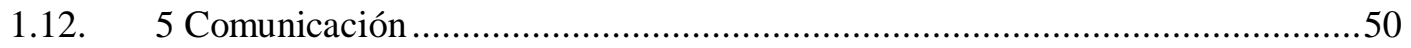

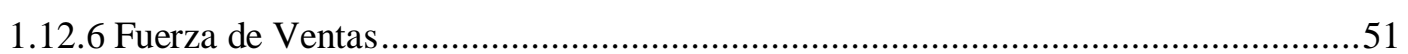

1.13 Descripción del producto (bien o servicio) de la empresa ........................................53

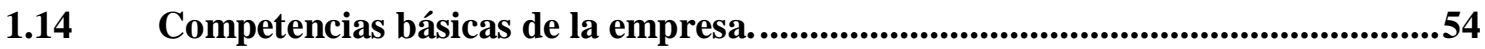

1.15 Capacidades de marketing de la empresa...........................................................55

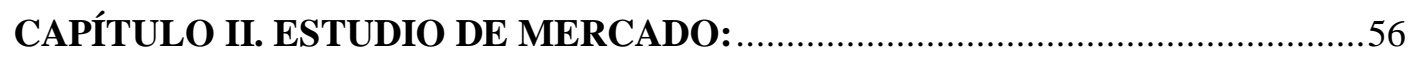

2.1 Problema de investigación ...................................................................................................58

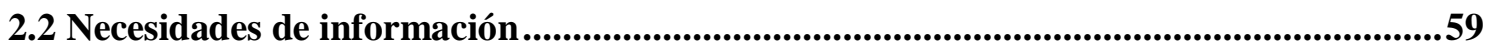

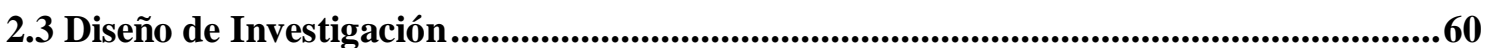

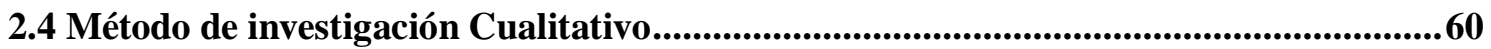

2.4.1 Entrevista a profundidad: Expertos del Sector ..........................................................60 
2.4.2 Ficha técnica investigación cualitativa: focus......................................................62

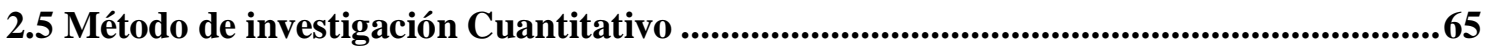

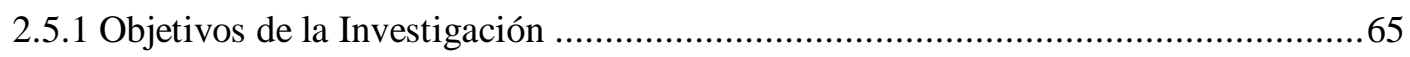

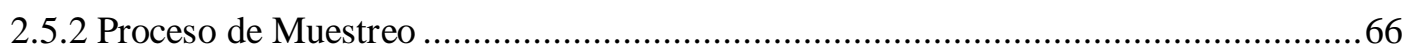

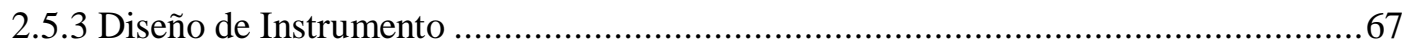

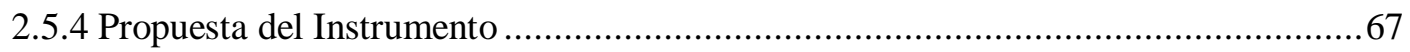

2.6. Análisis del producto ...............................................................................................68

2.7. Tendencias del producto..................................................................................................68

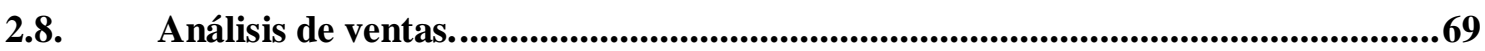

2.9. Tendencias del comportamiento del consumidor ............................................70

2.10. Tendencias de medios, distribución, precio.........................................................71

2.11. Segmentos del mercado que compran el producto .........................................................72

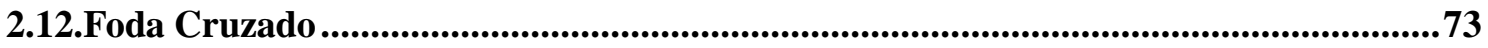

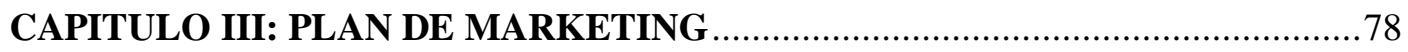

3.1. Relación entre el Plan Estratégico y el Plan de marketing (objetivos estratégicos y

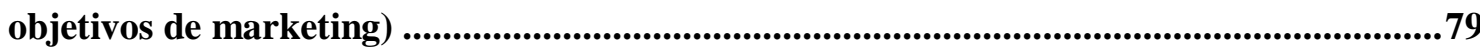

3.2. Formulación de objetivos: venta, margen, comerciales, de producto, comunicación. . .80

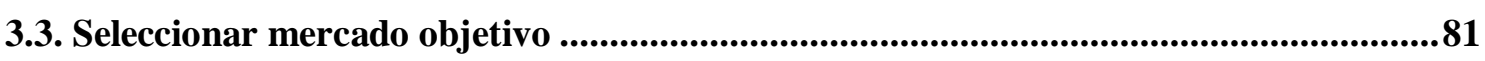

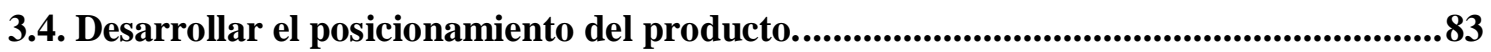

3.5. Macro estrategias ............................................................................................................................83

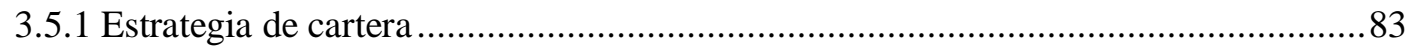

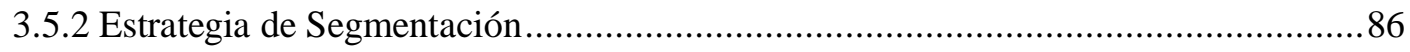

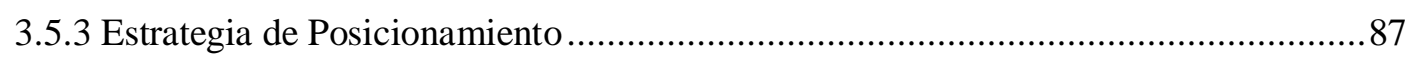

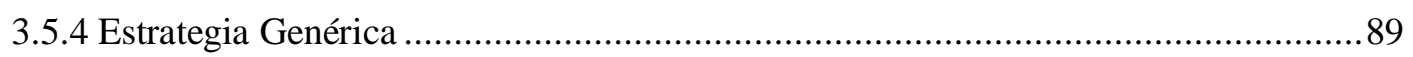

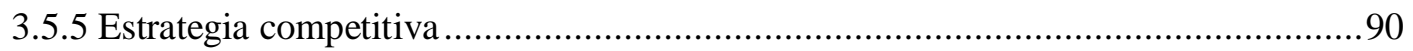

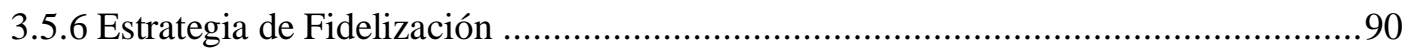

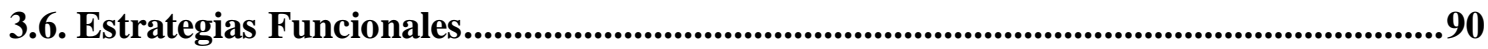

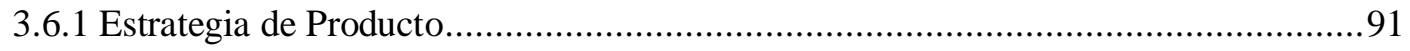

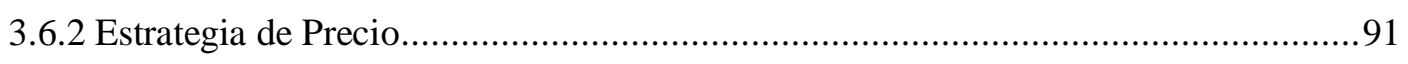

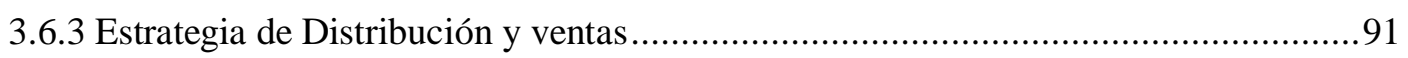

3.6.4 Estrategia de Promoción y Comunicación de Marca ..................................................91

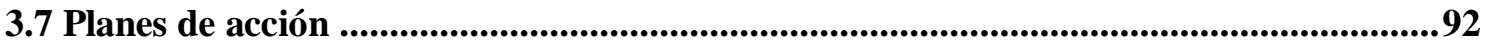

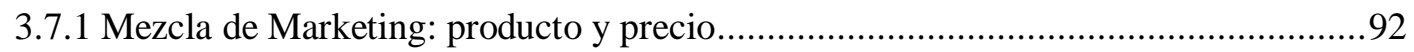

Mezcla de Marketing: Distribución, y promoción..............................................................96

CAPITULO IV: PROYECCIONES FINANCIERAS ....................................................106

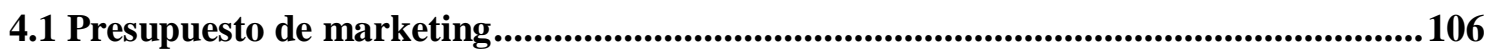

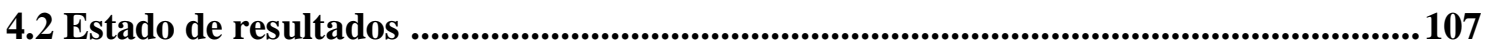


4.3 Evaluación Financiera del Plan ..................................................................................................108

CAPÍTULO V IMPLEMENTACION Y CONTROL .............................................. 109

5.1. Sistema de Información y Control ..........................................................................109

5.2. Plan de Contingencia .....................................................................................112

$5.3 \quad$ Calendario de ejecución del plan ...............................................................112

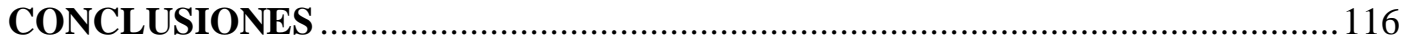

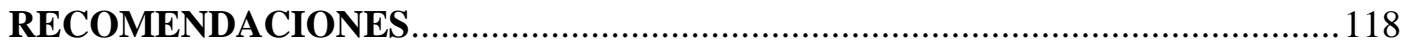

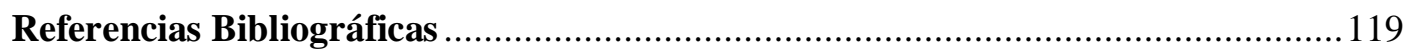

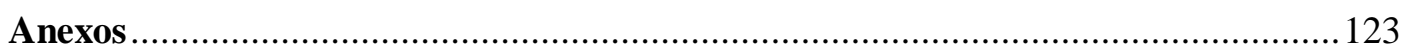

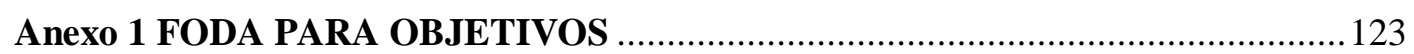

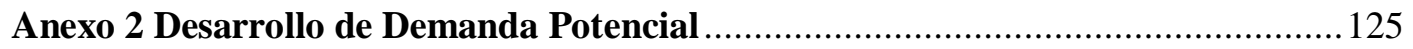

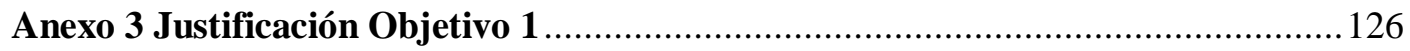

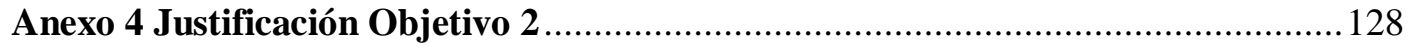

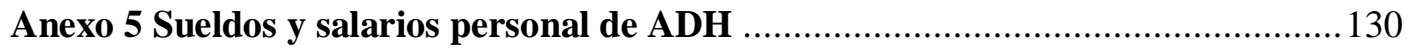

Anexo 6 Mapa de Operaciones Personal ADH por horario de Trabajo ................... 131

Anexo 7 Guía de Entrevistas en Profundidad ............................................................... 132

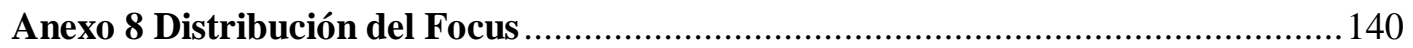

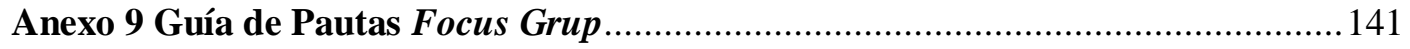

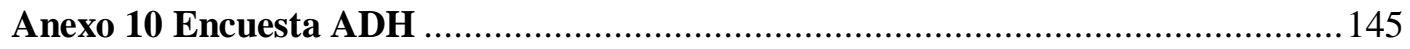

Anexo 11 Distribución de Productos y Márgenes de venta ADH ............................. 149

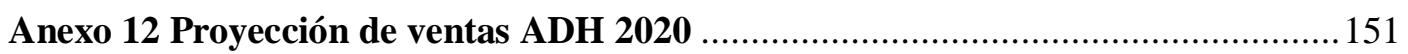

Anexo 13 Inversión Inicial................................................................................. 152

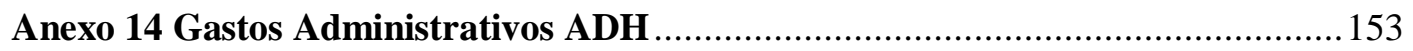

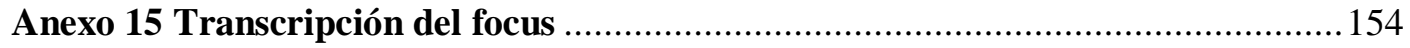

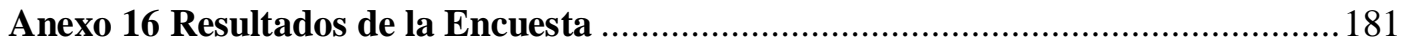

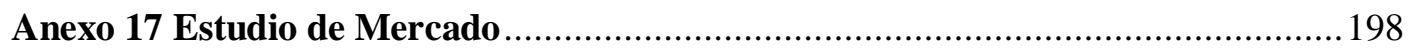




\section{Índice de Tablas}

Tabla 1 Objetivos Corporación 2020..................................................... 15

Tabla 2. Objetivos América Deluxe Health ........................................ 15

Tabla 3 Locales comerciales América Salud .................................... $\quad 17$

Tabla 4 Actividades Comerciales y CIIU....................................... 18

Tabla 5 Perfil del Supervisor ................................................ 20

Tabla 6 Perfil del Jefe de Contabilidad ............................................. 20

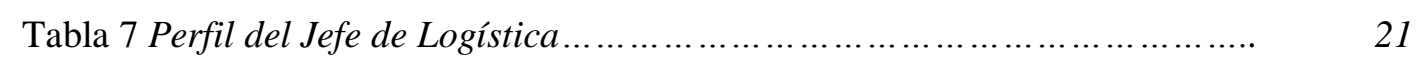

Tabla 8 Perfil del Jefe de Marketing.............................................. 21

Tabla 9 Perfil del Almacenero.................................................. $\quad 22$

Tabla 10 Perfil del Comprador ................................................. 23

Tabla 11 Perfil del Administrador de Farmacia.................................... 23

Tabla 12 Personal operativo ADH........................................ 24

Tabla 13 Competencia Sector Farmacéutico..................................... 25

Tabla 14 Situación Financiera de América Deluxe Health (expresada en dólares

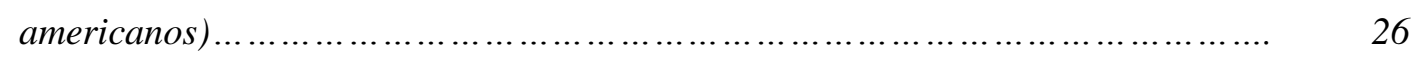

Tabla 15 Ventas y Utilidades Operativas 2016-2018.............................. 27

Tabla 16. Población Económicamente Activa en Lima.............................. 30

Tabla 17. PBI Total y PBI Per Cápita 2013-2018.................................. 31

Tabla 18. Tasa de Desempleo Lima Metropolitana 2015-2019..................... 32

Tabla 19. Canasta Familiar en Lima Metropolitana 2018-2019................... 32

Tabla 20. Tasa de Inflación en Lima Metropolitana 2010-2018..................... 33

Tabla 21 .Tasas de Interés Activa Promedio de Mercado 2014-2019 (al 15 de octubre de

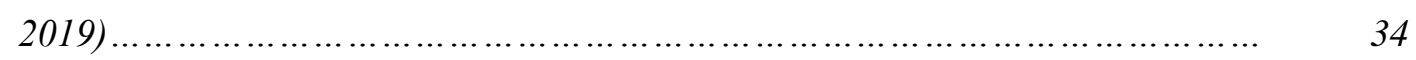

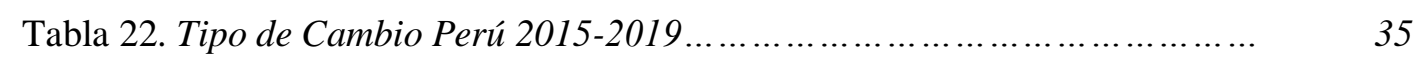

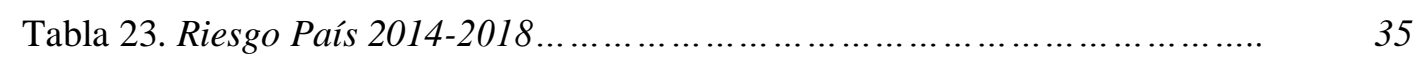

Tabla 24. Ratios Macro y Microeconómicos Economía Peruana 2019-2022....... 36 
Tabla 25. Resumen del Atractivo Global del Sector

Tabla 26 Competencia y participación estimada de mercado año 2019............. 43

Tabla 27 Participación de mercado 2020.................................... 43

Tabla 28 Definición de la Industria............................................ 44

Tabla 29 Demanda Estimada.................................................

Tabla 30. Matriz de Factores Externos .............................................. 46

Tabla 31 Participación de Ventas de Productos Ofrecidos por América Salud...... $\quad 47$

Tabla 32 Márgenes Aproximados por Línea de Productos América Salud........... 49

Tabla 33 Propuesta de Comunicación ADH...................................... 51

Tabla 34 Cantidad de vendedores y Ratio América Salud............................ 52

Tabla 35 Matriz de Factores Internos .............................................

Tabla 36 Línea de productos y ejemplos de marcas.................................

Tabla 37 Formación de Grupos para Focus.......................................... 63

Tabla 38 Mix de Productos América Deluxe Health........................................ 69

Tabla 39 Comportamiento del Consumidor.................................... $\quad 70$

Tabla 40 Características de los Sofisticados.................................. 71

Tabla 41 Matriz FODA ...........................................................

Tabla 42 Relación Objetivos Plan de Marketing versus................................... 80

Tabla 43 Participación de Mercado América Salud...................................... $\quad 80$

Tabla 44 Objetivos de marketing ADH.................................... 81

Tabla 45 Mercado Objetivo para ADH........................................ 82

Tabla 46 Estrategias de Crecimiento en el tiempo.................................. 86

Tabla 47 Estrategia de Segmentación................................................ 87

Tabla 48 Segmentación Esperada por tipo de clientes.................... 87 
Tabla 49 Respuesta al Posicionamiento

Tabla 50 Presupuesto de Marketing ADH... 106

Tabla 51 Porcentaje de participación del Mix de Marketing primer año.... 107

Tabla 52 Estado de resultados.

Tabla 53 Resultados del Primer año ADH

Tabla 54 Control de indicadores de gestión... 109

Tabla 55 Segmentación de actividades por tipo de clientes...

Tabla 56Planes de contingencia ADH.

Tabla 57 Calendario Ejecución Mix Producto Plan de Marketing primer año.

Tabla 58 Calendario Ejecución Mix Precio Plan de Marketing primer año 113

Tabla 59 Calendario Ejecución Mix Plaza Plan de Marketing primer año

Tabla 60 Calendario Ejecución Mix Promoción y Comunicación Plan de Marketing primer año 


\section{Índice de Figuras}

Figura 1 Organigrama América Salud...................................... 18

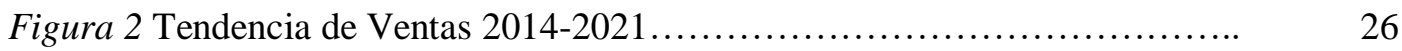

Figura 3 Utilidades/Ventas totales América Salud 2016-2018_................ 27

Figura 4 Ciclo de Vida de Productos de América Salud......................... 48

Figura 5 Diagrama de Distribución......................................... 50

Figura 6 Ubicación ADH San Isidro.......................................

Figura 7 Matriz de expansión Producto/Mercado................................... $\quad 84$

Figura 8 Matriz BCG..................................................... 85

Figura 9 Cartera de Productos....................................... 93

Figura 10 Personal ADH.......................................... 93

Figura 11 Promoción de Producto .................................... 94

Figura 12 Modelo Campaña Ventas Virtuales.......................... 96

Figura 13: Modelo de Local ADH...................................... 97

Figura 14 Lay Out ADH................................................ 97

Figura 15 Ejemplo de Dermatruck ADH.............................. 98

Figura 16 Modelo Panel ADH............................................ 99

Figura 17 Desarrollo Base de Datos ADH............................. $\quad 100$

Figura 18 Ejemplo de Espacio VIP ADH........................... 101

Figura 19 Servicio de venta a Domicilio............................... 101

Figura 20 Organización Conferencias ADH........................... 102

Figura 21 Selección Inversión Selectiva de Marketing.................... 103

Figura 22 Auspicio Eventos Selectivos .............................. 104

Figura 23 Ejemplo Modelo Campaña “Customer Day Off”.................. 104

Figura 24 Ejemplo Activaciones eventos especiales....................... 105

Figura 25 Ejemplo Lanzamiento de marca ADH ........................ 105 


\section{CAPITULO I: ANALISIS DE LA SITUACION}

A consecuencia que, en Lima, aproximadamente el $4.7 \%$ de sus habitantes pertenecen al nivel socioeconómico A y estos no encuentran servicios y/o productos exclusivos de salud y belleza en un solo lugar de la capital, se abre una oportunidad de negocio que se puede aprovechar desarrollando un plan de marketing para la implementación de una unidad que permita brindar dicho productos y servicios.

Por ello la pregunta de investigación es ¿Cómo desarrollar el plan de Marketing de una Botica Exclusiva en Lima Metropolitana como una alternativa a los usuarios que buscan constantemente productos dermatológicos exclusivos médicos y de belleza en un solo lugar?

En consecuencia el objetivo general del plan de Marketing de la corporación es obtener ventas el 2020 por \$ 6,702,067 dólares superiores en $20 \%$ al 2019 y se cuenta con tres objetivos específicos que son: mejorar la rentabilidad de la Corporación de $15 \%$ al 18\% con el funcionamiento de América Deluxe Health en el 2020, ser líderes de sector al 2020 y modificar la cartera de productos a productos orgánicos en $25 \%$

\subsection{Antecedentes de la Investigación}

De acuerdo al estudio presentado por Global Cosmetics Products Market Analysis of Growth, Trends and Forescast 2018-2023 la industria de belleza movió 532 mil millones de dólares durante el 2017 y se espera que en el 2023 este sector esté valorizado en 605 mil millones representando un crecimiento de $7.14 \%$ en el mundo (PromPerú, 2018). Por otro lado, de acuerdo a Peru Retail (2017) el mercado farmacéutico peruano genera un valor de 918 millones en el PBI pero está creciendo a tasas menores a las del 2016 sin embargo el mercado de belleza de lujo ha crecido 14\% durante el 2018 principalmente impulsado por la marca Estee Lauder (Fashion Network, 2018). 
En las principales calles de las ciudades destino del mundo, Nueva York, Tokio, Londres o Madrid se encuentran boutiques de lujo. Una tienda de lujo es el lugar para vivir una experiencia. Ya no es un destino para hacer una transacción que se puede realizar online. La tienda como destino exige razones más allá de la necesidad de comprar algo. Son tiendas que dejan recuerdos memorables contando historias que interesan. Hablan de su legado artesanal como la tienda de Loewe en Madrid diseñada por Jonathan Anderson que muestra en horizontal los videos de las manos artesanas. En la que enseñan la obra de artesanos del barro, de la madera, de los textiles. La tienda es el escenario de representación de los valores de la marca. Como lo es la tienda de Burberrys en Regent street en Londres en la que ponen de manifiesto su vocación tecnológica con pantallas, probadores virtuales y tabletas en manos en cada vendedor. Möet Hennessy ha transformado un apartamento en Paris cercano a los Campos Elíseos en una pequeña boutique muy discreta para sus mejores clientes. Sus más caras y mejores botellas de Dom Perignon o Hennessy están disponibles para ser descubiertas en el entorno más privado. En una boutique de lujo saben quién es el cliente y cuál es su nombre proporcionando un trato y un servicio personalizado. Los algoritmos de inteligencia artificial pueden anticipar que es lo que se quiere comprar esta vez basado en el comportamiento previo del cliente. Por ello las tiendas de lujo aspiran no solo a personalizar el servicio, pero también los productos que se compran. En este espíritu de exclusividad, las tiendas de las marcas más deseables en algunos casos muestran sus procesos como el "Palazzo Fendi" en Roma donde los clientes son testigos desde la tienda y a través de un cristal, de un taller de fabricación artesanal de peletería que es real. (Forbes, 2017)

La moda de las boutiques de lujo es mundial como lo demuestra El Vaticano que inauguró un nuevo departamento de cosmética de lujo en la farmacia de la ciudad del 
Vaticano. Según explica la cabecera de la Santa Sede, el motivo de introducir esta nueva línea de productos se debe al creciente deseo de las personas que buscan alcanzar un buen estado de salud. Asimismo, asegura que en el centro de la iniciativa están las personas que con sus necesidades no solo buscan curar una enfermedad, sino también alcanzar un bienestar individual y social por lo que se quiere brindar un espacio único a la línea de cosméticos para ofrecer al cliente una más fácil e inmediata oferta de los productos. De esta manera la farmacia tendrá la posibilidad de ampliar notablemente el espacio de exposición y el espacio laboral, con el objetivo de mejorar y de hacer más rápida la elección de los productos expuestos y las operaciones de venta para lo que ofrece artículos de lujo como Yves Saint Lauren, Lancome y Armani. (Infovaticana, 2019)

$\mathrm{Al}$ ser productos de alto valor adquisitivo se hace necesario evaluar si las mujeres limeñas de nivel socioeconómico A estarían dispuestas a visitar una super boutique en la ciudad de Lima donde se les brindaría un servicio exclusivo y personalizado acorde con sus requerimientos.

\section{Antecedentes Internacionales}

Chacón (2015) en el trabajo de investigación "Propuesta de un plan de mercadeo para la expansión de la cadena de farmacias Santiago en la gran área metropolitana" tesis para optar el grado de y título de Maestría Profesional en Ventas y Mercadeo de la Universidad de Costa Rica desarrolló un análisis del mercado farmacéutico latinoamericano en el que concluye que existen oportunidades de desarrollo para propuestas innovadoras dentro del sector. El desarrollo de la investigación metodológico utilizó instrumentos cuantitativos y cualitativos, basándose en muestras representativas de la población y obteniendo un perfil del consumidor objetivo caracterizando los hábitos de compra, el grado de satisfacción y sus preferencias. Finalmente propone 
recomendaciones sobre los servicios a ofrecer, la política de precios y promoción, la distribución de los productos, la estructura y orden del lugar de trabajo para facilitar el flujo normal del negocio y mejorar el servicio al cliente.

Rallón (2016) en el trabajo de investigación "Plan de Negocios Oasis SPA Campestre" para optar el título de administrador en la Universidad Cooperativa de Colombia ante el agotamiento y estrés de la sociedad actual es factible brindar un servicio de bienestar al cuerpo y mente de los clientes. En el estudio de mercado un $92 \%$ de personas estaría dispuesto a adquirir servicios exclusivos en un ambiente natural, atención personalizada y múltiples servicios de relajación. El proyecto presenta viabilidad ya que el VAN es de \$ 63.448 .502 siendo la tasa de descuento de 11,17\%. El proyecto se financia con $4,65 \%$ recursos propios y $95,35 \%$ provenientes de un crédito financiero.

En la proyección de ventas se indexaron un spread en las diferentes líneas de negocio para completar la oferta (masajes, aroma terapias, mascarillas, depilación, baño turco, caminata ecológica).

\section{Antecedentes Nacionales}

Ccanahuire y Fuentes (2017) en el trabajo de investigación "Innovación estratégica comercial en una empresa de cuidados de belleza y salud, 2016" tesis para obtener el título profesional de licenciado en Administración de la Universidad Santa María de Arequipa sostiene que en el Perú el crecimiento del mercado de bienestar y salud se ha efectivizado de manera acelerada debido a que la población cuenta con los medios y el tiempo para utilizarla. Esto conlleva al desarrollo de una competencia que intenta complacer las exigencias del mercado. Para ello realiza un análisis de la empresa Montalvo Salón \& Spa que cuenta con una importante participación de mercado por la innovación de servicios y productos focalizado en la calidad que aplica en diferentes 
operaciones de su cadena de valor en respuesta a la creciente competencia que manejan los mismos servicios y está enfocado al segmento de jóvenes.

Para ello recomienda enfocarse en el Marketing Estratégico generando una mentalidad de cambio orientada al cliente para alcanzar los objetivos planteados. Se debe considerar que América Deluxe Health brinda servicios exclusivos orientados a mujeres de Nivel A de Lima Metropolitana por lo que el plan de Marketing debe considerar el público objetivo. Mendez (2017) en el trabajo "Análisis estratégico del plan de marketing de la Botica GC Farma, en el distrito de Independencia, año 2016" para optar el grado de Maestra en Administración de Negocios de la Universidad Cesar Vallejo realiza un análisis estratégico de una botica orientada a un sector BC en Lima en la que el objetivo es determinar el análisis del nivel de estrategias del plan de Marketing de la farmacia. Para ello desarrolla una metodología cuantitativa cuyos resultados permitieron comprobar que existe diferencia en el plan estratégico del marketing de la Botica encontrando diferencias significativas en cada una de las dimensiones. Ello le permite hacer recomendaciones orientadas a la mejora del plan estratégico de Marketing por lo que a pesar de tratarse de un trabajo orientado a un público objetivo diferente al de América Deluxe Health permite concluir que existen herramientas que permiten cuantificar los servicios que la empresa puede ofrecer al mercado.

\subsection{Determinación del problema u oportunidad}

Considerando que, de acuerdo al estudio Niveles Socio Económicos 2018 realizado por la Asociación Peruana de Empresas de Investigación de Mercados -APEIM (2018) en Lima, aproximadamente el $4.7 \%$ de los habitantes pertenecen al nivel socioeconómico A y estos no encuentran servicios y/o productos exclusivos de salud y belleza en un solo lugar de la capital, como si existen en urbes desarrolladas como Nueva York, Los Ángeles, Paris o Tokio, se abre una oportunidad de negocio que se puede 
aprovechar desarrollando un plan de marketing para la implementación de una unidad que permita brindar dicho productos y servicios.

América Salud Cadenas de Boticas es una empresa comercializadora de productos farmacéuticos, perfumería y cuidado personal que inicia actividades en el distrito de Miraflores en Lima el año 2000. Actualmente cuenta con 15 locales de los cuales 13 están en Lima y dos en provincias con ventas aproximadas por quince millones de soles anuales. Está dirigido a todo tipo de sectores por lo que compite con otras farmacias y servicios de cuidado personal sin diferenciarse por exclusividad por lo que, ante el crecimiento del mercado y la necesidad identificada, se hace importante la creación de una nueva unidad de Negocios que se dedique exclusivamente a clientes de ambos sexos de nivel A ofreciendo servicios dermatológicos y de belleza exclusivos en un solo lugar.

Por ello el problema a ser resuelto es

¿Cómo desarrollar el plan de Marketing de una Botica Exclusiva en Lima Metropolitana como una alternativa a los usuarios que buscan constantemente productos dermatológicos exclusivos médicos y de belleza en un solo lugar?

\subsection{Justificación del proyecto}

\section{Social}

Rallón (2016) afirma que debido al estilo de vida que llevan las personas en la actualidad se ha incrementado el nivel de estrés y deterioro en la salud, causada principalmente por la presión laboral, la ansiedad y la tensión por lo que se identifica la necesidad de crear una súper botica exclusiva que permita un ambiente de relajamiento y descanso a mujeres jóvenes y mayores que puedan encontrar productos exclusivos de belleza para la piel y el rostro, insumos médicos para otras partes del cuerpo, insumos de mejoramiento odontológico, vitaminas, complementos y tratamientos exclusivos de rejuvenecimiento en un solo lugar siendo atendidas por personal médico especializado.

\section{Económica}


Este tipo de negocios existen en metrópolis desarrolladas como Nueva York, Paris y Los Ángeles por lo que, ante la mejora de las condiciones económicas en el Perú, se puede ofrecer un negocio de esta clase aprovechando la infraestructura con la que cuenta la empresa América Salud.

\section{Educativa}

Este trabajo de investigación permitirá a las autoras obtener el grado de Magister en Marketing.

Considerando el problema y la justificación del proyecto la propuesta de valor es

"Somos un centro exclusivo de salud y belleza personalizada que brinda una alternativa para la generación de bienestar del cuerpo y la mente de las usuarias mediante productos dermatológicos y de belleza exclusivos en un solo lugar de Lima Metropolitana”

\subsection{Objetivos Generales y Específicos}

De acuerdo a David (2013) los objetivos se pueden definir como los resultados específicos que pretende alcanzar una organización por medio del cumplimiento de su misión. Estos permiten establecer un curso de acción, ayuda a la evaluación y revelan prioridades.

\subsubsection{Objetivo General}

El objetivo general del plan de Marketing de la corporación es:

Obtener ventas el 2020 por \$ 6,702,067 dólares superiores en $20 \%$ al año 2019

\subsubsection{Objetivos Específicos}

Los objetivos específicos del plan son los siguientes: 
Mejorar la rentabilidad de la Corporación de $15 \%$ al 18\% con el funcionamiento de América Deluxe Health en el 2020.

Obtener el posicionamiento de ADH como "líder" en el primer año de operación

Reconvertir la cartera de cremas como productos orgánicos consiguiendo que el $25 \%$ de la venta de cremas sea orgánica

En la Tabla 1 se observan los objetivos 2020 cuantificados para la corporación

\section{Tabla 1}

Objetivos Corporación 2020

\begin{tabular}{cl}
\hline & \multicolumn{1}{c}{ OBJETIVOS CORPORACION 2020 } \\
\hline i. & Obtener ventas ascendientes a $\$ 6,702,067$ en el 2020 \\
\hline ii. & $\begin{array}{l}\text { Mejorar la rentabilidad de la Corporación del 15\% al 18\% con } \\
\text { el funcionamiento de América Deluxe Health. }\end{array}$ \\
\hline iii. $\quad \begin{array}{l}\text { Conseguir que la nueva unidad de negocio ADH sea líder en } \\
\text { su nicho de mercado. }\end{array}$ \\
\hline iv. & $\begin{array}{l}\text { Reconversión de la cartera de cremas a productos orgánicos en } \\
25 \% .\end{array}$ \\
\hline
\end{tabular}

Fuente: Elaboración propia (2019)

En consecuencia los objetivos para América Deluxe Health se muestran en la Tabla 2.

\section{Tabla 2.}

Objetivos América Deluxe Health

\begin{tabular}{l}
\hline OBJETIVO AMERICA DELUXE HEALTH 2020 \\
\hline Obtener ventas por $\$ 556,017$ \\
\hline Obtener una rentabilidad del $26 \%$ que permita una \\
rentabilidad de $18 \%$ a la corporación \\
Posicionarse como líder de mercado en su primer año de \\
operación \\
Reconversión de cremas en productos orgánicos para que el \\
$25 \%$ de cremas sea de origen orgánico \\
\hline
\end{tabular}

Fuente: Elaboración propia (2019) 


\subsection{Alcances y Limitaciones de la Investigación}

\section{Alcances}

El presente proyecto se desarrollará como una unidad de negocios para la empresa América Salud. Abarca la creación de una nueva unidad en la que se fijaran los objetivos para viabilizar el plan de marketing del negocio. Además, el proyecto puede ser utilizado para empresas con rubros similares ya que el desarrollo del plan es el de una nueva unidad de negocio.

\section{Limitaciones}

El proyecto de estudio está limitado a su desarrollo en el local de San Isidro por lo que la delimitación del espacio se limita a dicho local. El periodo de estudio es de ocho meses hasta la finalización del plan de Marketing y se debe considerar que la empresa es nueva en el sector de Belleza de lujo.

\subsection{Antecedentes de la empresa}

América Salud es una empresa familiar comercializadora de productos farmacéuticos, perfumería y cuidado personal orientada a un mercado socio económico de todo nivel debido a los productos que ofrece. Debido a que los propietarios cuentan con una empresa mayorista de productos de dicha categoría, se vieron en la necesidad de crear un canal minorista de venta, iniciando sus actividades el año 2003 en un local en Miraflores.

En el año 2019 cuentan con operaciones en 16 locales a nivel nacional y un call center; de los cuales catorce se encuentran en Lima y dos en provincia. Estos se pueden apreciar en la Tabla 3 


\section{Tabla 3}

Locales comerciales América Salud

\begin{tabular}{lll}
\hline $\mathrm{N}^{\circ}$ & Locales & Lugar de Operaciones \\
\hline 1 & Miraflores1 & Av. Armendáriz 215 \\
2 & Miraflores2 & Av. Comandante Espinar 830 \\
3 & San Isidro & Av. Pezet 930 \\
4 & Magdalena & Av. Brasil 3390 \\
5 & La Molina & Av. Raúl Ferrero 1155 \\
6 & San Miguel & Av. Brígida Silva de Ochoa 364 \\
7 & Jesús María & Arnaldo Márquez 1300 \\
8 & San Borja & Av. Aviación 2958 \\
9 & San Miguel & Av. Faucett 483 \\
10 & Santiago de Surco & Av. El Polo 506 \\
11 & San Isidro2 & Javier Prado 390 \\
12 & Independencia & Av. Carlos Izaguirre 149 \\
13 & San Juan de Miraflores & Hernando Lavalle 240 \\
14 & Tacna & San Martin 404 \\
15 & Chimbote & MZ S Lote 1 Urb. 21 de abril \\
16 & Central (San Miguel) & Av Insurgentes 1074 \\
\hline
\end{tabular}

Fuente: Plan de Marketing América Salud (2019)

El negocio se enfoca a brindar un servicio cálido buscando generar alta satisfacción al cliente. Para ello cuentan con un servicio de atención de 24 horas y delivery en todo Lima.

Su competencia son las cadenas de farmacias que brindan servicios similares como Boticas y Salud, Boticas Perú, Inka farma y Mifarma, los que han creado una rivalidad extremadamente alta ya que ninguna se encuentra diferenciada y están dirigidas a todo tipo de público.

Su objetivo es lograr la satisfacción del cliente, brindándole productos de excelente calidad, buenos precios, una atención personalizada y servicios gratuitos. 
Las actividades comerciales y la clasificación industrial internacional uniforme (CIIU) de América Salud se aprecian en la Tabla 4

\section{Tabla 4}

Actividades Comerciales y CIIU

\begin{tabular}{ll}
\hline Definición & Detalle \\
\hline Actividad 1 & Venta minorista de Productos Farmacéuticos y artículos de \\
& tocador \\
Actividad 2 & Otro tipo de ventas al por menor \\
CIIU & 4772 \\
\hline
\end{tabular}

Fuente: SUNAT (2019)

Actualmente tiene ventas por doce millones anuales y 100 empleados a nivel de la cadena.

\subsection{Organización Actual de la Empresa}

La empresa actualmente cuenta con un organigrama tradicional que se aprecia en la figura 1

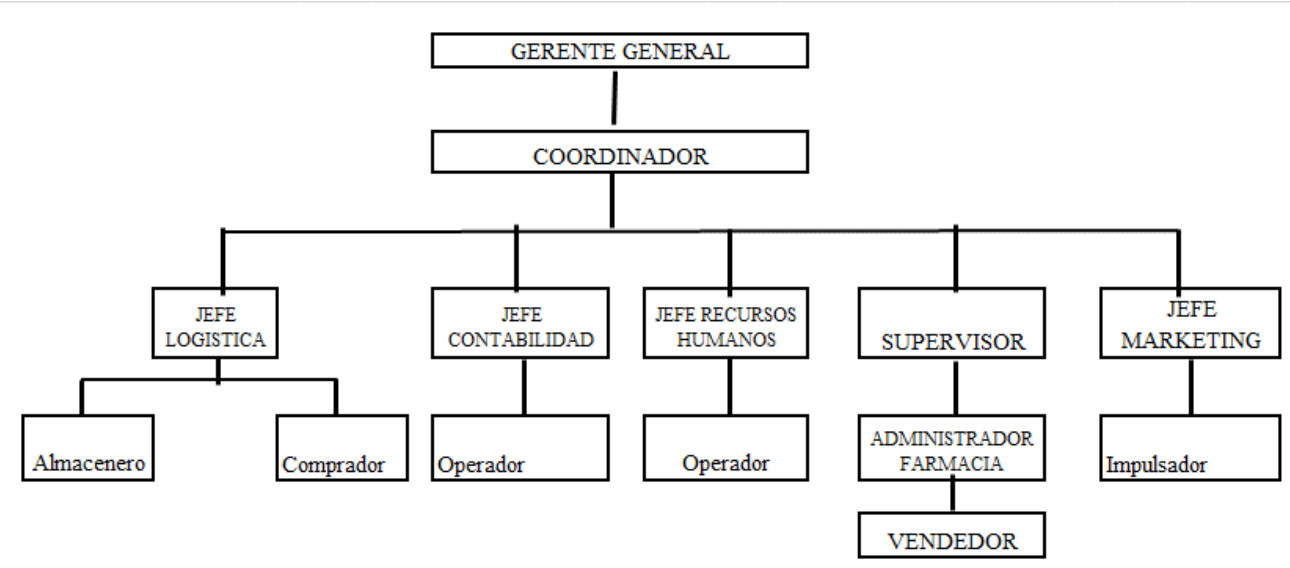

Figura 1

Organigrama América Salud

Fuente: America Salud (2019) 
Dicha organización está dirigida por la familia Alfaro siendo el Gerente General, el coordinador y el jefe de Marketing miembros de dicha familia por lo que dichos puestos se consideran de confianza.

Las funciones del Gerente General son las siguientes:

Asumir la representación legal de la empresa ante las autoridades

Representar a América Salud ante los accionistas y los aliados estratégicos

Las funciones del Coordinador son las siguientes:

$\checkmark$ Dirigir, controlar y tomar decisiones estratégicas que conlleven al crecimiento de la misma a fin de alcanzar los objetivos previstos.

$\checkmark$ Administrar los flujos del efectivo y suministrar los fondos necesarios para la operación.

$\checkmark$ Brindar la información administrativa actualizada de la situación de la empresa a las instituciones /accionistas que lo requieran.

$\checkmark$ Contratar los servicios externos que se requieran para el cumplimiento de las funciones

Las funciones del Jefe de Personal son:

Evaluar y autorizar los pagos del personal

Autorizar la programación del personal requerida para cada unidad de negocio.

Responder las observaciones laborales del Ministerio de Trabajo

$\checkmark$ Autorizar las actividades de integración para el personal.

En la Tabla 5 se muestra el perfil del supervisor. 
Tabla 5 Perfil del Supervisor

\begin{tabular}{ll}
\hline Puesto & Supervisor \\
\hline Área & Comercial/Operaciones \\
\hline Vacantes & 02 \\
\hline Personal bajo su mando & Administradores de Farmacia \\
\hline Perfil requerido & Ingeniero Industrial/Administrador/Químico \\
\hline
\end{tabular}

Fuente: Elaboración Propia (2019)

Las funciones del puesto son las siguientes:

Servir como nexo entre las farmacias y la Coordinación General

Autorizar los programas de trabajo de las Farmacias

Visar las órdenes de pedido, los requerimientos, la propuesta comercial y todas las actividades

$\checkmark$ Programar los horarios de servicio de las farmacias.

Coordinar los requerimientos de las farmacias con las áreas de operaciones.

En la Tabla 6 se muestra el perfil del jefe de contabilidad

\section{Tabla 6}

Perfil del Jefe de Contabilidad

\begin{tabular}{ll}
\hline Puesto & Jefe de Contabilidad \\
\hline Área & Administración \\
\hline Vacantes & 01 \\
\hline $\begin{array}{l}\text { Personal bajo } \\
\text { mando }\end{array}$ & Operadores contables \\
\hline Perfil requerido & Contador colegiado \\
\hline
\end{tabular}

Fuente: Elaboración Propia (2019)

Sus funciones son:

Llevar la contabilidad mensual de la empresa

Desarrollar el balance anual de América Salud

$\checkmark$ Integrar el balance de América Salud a la Corporación Alfaro. 
Determinar el Estado de Pérdidas y Ganancias de la empresa individualizando cada unidad de negocio

En la Tabla 7 se muestra el perfil del jefe de logística

\section{Tabla 7}

Perfil del Jefe de Logística

\begin{tabular}{ll}
\hline Puesto & Jefe de Logística \\
\hline Área & Administración \\
\hline Vacantes & 01 \\
\hline Personal bajo su mando & Almacenero/Comprador \\
\hline Perfil requerido & Ingeniero Industrial
\end{tabular}

Fuente: Elaboración Propia (2019)

Sus funciones son:

Determinar los stocks e inventarios deseables para América Salud

Ocuparse del envío de los insumos a cada una de las farmacias

Desarrollar el plan anual de inventarios en base a las proyecciones de ventas.

Autorizar los pedidos programados por el comprador.

En la Tabla 8 se muestra el perfil del jefe de marketing.

Tabla 8 Perfil del Jefe de Marketing

\begin{tabular}{ll}
\hline Puesto & Jefe de marketing \\
\hline Área & Administración \\
\hline Vacantes & 01 \\
\hline $\begin{array}{l}\text { Personal } \\
\text { bajo su } \\
\text { mando }\end{array}$ & Impulsadores \\
\hline $\begin{array}{l}\text { Perfil } \\
\text { requerido }\end{array}$ & Administración/Marketing \\
Fuente: Elaboración Propia (2019)
\end{tabular}

Sus funciones son: 
Desarrollar el Plan de marketing de la empresa

Dirigir las actividades de activación en cada una de las farmacias

Monitorear los resultados de las campañas de marketing de América Salud

Proponer el Trade Marketing de la cadena

Proponer el presupuesto de Marketing a la Alta dirección

En la Tabla 9 se muestra el perfil del almacenero

\section{Tabla 9}

Perfil del Almacenero

\begin{tabular}{ll}
\hline Puesto & Almacenero \\
\hline Área & Administración \\
\hline Vacantes & 02 \\
\hline Personal bajo su mando & Ninguno \\
\hline Perfil requerido & Experiencia en el manejo de almacenes, transporte \\
& de insumos médicos y Kardex. De preferencia \\
& carrera técnica
\end{tabular}

Fuente: Elaboración Propia (2019)

Sus funciones son las siguientes:

Controlar la entrada y salida de los insumos de América Salud

Despachar y controlar la entrega de los productos a cada una de las farmacias de la corporación

$\checkmark$ Remitir a las áreas respectivas los inventarios valorizados para que estas realicen sus funciones.

Controlar los inventarios en cada una de los centros de negocios

Llevar el control de los cambios y devoluciones

En la Tabla 10 se detalla el perfil del comprador. 


\section{Tabla 10}

Perfil del Comprador

\begin{tabular}{|c|c|}
\hline Posición & Comprador \\
\hline Área Laboral & Administración \\
\hline Cantidad de Vacantes & 01 \\
\hline Posiciones bajo su mando & Ninguno \\
\hline Descripción de capacidades & $\begin{array}{l}\text { Experiencia en el manejo y pedido de insumos } \\
\text { farmacéuticos médicos y de tocador De preferencia } \\
\text { carrera técnica }\end{array}$ \\
\hline
\end{tabular}

Fuente: Elaboración Propia (2019)

Sus funciones son las siguientes:

Realizar las compras de América Salud en base a los reportes de las unidades de negocio y almacén.

$\checkmark$ Generar las órdenes de compra de los requerimientos solicitados por las farmacias.

En la Tabla 11 se muestra el perfil del administrador de farmacia

\section{Tabla 11}

Perfil del Administrador de Farmacia

\begin{tabular}{ll}
\hline Puesto & Administrador de Farmacia \\
\hline Área & Operaciones \\
\hline Vacantes & 15 \\
\hline Personal bajo su mando & Vendedor \\
\hline Perfil requerido & \multicolumn{1}{c}{ Químico Farmacéutico } \\
& Experiencia en la venta, manejo y pedido \\
& de insumos farmacéuticos médicos y de \\
& tocador
\end{tabular}

Elaboración Propia (2019)

Sus funciones son las siguientes: 
$\checkmark$ Administrar las farmacias revisando los inventarios, las ventas y la operatividad de los vendedores

$\checkmark$ Velar por el mobiliario y la limpieza del local de América Salud

$\checkmark$ Proponer campañas al área de Marketing para mejorar las ventas

Realizar los requerimientos coordinando con las áreas funcionales

Comunicar al coordinador cualquier ocurrencia dentro de la zona de operaciones.

Remitir los ingresos y salidas del personal para los pagos respectivos.

Los otros puestos no se describen porque son puestos operativos y no se requiere estudios especializados para apoyar a los jefes salvo los estudios de su especialidad.

Se aprecia que la organización es una estructura en la cual es necesario coordinar funcionalmente con todas las áreas por lo que la información y comunicación debe ser eficiente para el funcionamiento de cada unidad de negocio.

Para atender $\mathrm{ADH}$ la estructura para dicha tienda está compuesta por el personal que se muestra en la Tabla 12

\section{Tabla 12}

Personal operativo ADH

\section{Colabor} adores Admin Dermatólog CM Asisten Recepc Anfitri Vig. Deliv total

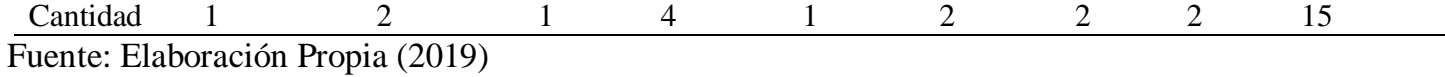

En el anexo 5 se muestra los sueldos del personal que labora en $\mathrm{ADH}$.

Asimismo en el anexo 6 se observa el mapa de operaciones de los 15 trabajadores de ADH durante el día. 


\subsection{Situación del Mercado y Financiera Actual de la Empresa}

América Deluxe Health es una empresa que forma parte de la corporación América Salud que se encuentra ubicada dentro del sector farmacéutico en el mercado peruano.

La competencia de la corporación se observa en la Tabla 13

\section{Tabla 13}

Competencia Sector Farmacéutico

\begin{tabular}{lll}
\hline Empresa Farmacéutica & Número de Locales & Alcance \\
\hline Inka Farma & Más de 1,000 & Nivel Nacional \\
BTL & Menos de 100 & Nivel Lima \\
MIFARMA & 640 & Nivel Nacional \\
FASA & Menos de 100 & Nivel Lima \\
Boticas Arcangel & 344 & Nivel Nacional \\
B\&S & Menos de 100 & Nivel Lima
\end{tabular}

Fuente: Investigación Propia (2019)

Inkafarma al año 2019 es el líder del mercado con más de 1,000 boticas a nivel nacional siendo su meta a fin de año de 1107. Entre sus estrategias brinda distintos servicios tales como ofrecer sus productos farmacéuticos, perfumería y tocador, buscando brindar precios módicos los 365 días del año incentivando que se compren en grandes cantidades favoreciendo una mejora de precios y venta a menor escala.

Por otra parte Quicorp, empresa chilena compró en el año 2018 las boticas BTL y Mi Farma por lo que se espera que esta empresa invierta en el posicionamiento de dichas empresas.

La situación financiera de la Corporación al año 2020 se muestra en la Tabla 14 


\section{Tabla 14}

Situación Financiera de América Deluxe Health (expresada en dólares americanos)

\begin{tabular}{|c|c|c|c|c|c|c|c|}
\hline OPERACIÓN & $\begin{array}{c}2014 \\
\text { Suma de Ventas }\end{array}$ & $\begin{array}{c}2015 \\
\text { Suma de Ventas }\end{array}$ & $\begin{array}{c}2016 \\
\text { Suma de Ventas }\end{array}$ & $\begin{array}{c}2017 \\
\text { Suma de Ventas }\end{array}$ & $\begin{array}{c}2018 \\
\text { Suma de Ventas }\end{array}$ & $\begin{array}{c}219 \\
\text { Suma de Ventas }\end{array}$ & $\begin{array}{c}\text { Total Suma de } \\
\text { Ventas }\end{array}$ \\
\hline ABANCAY & $\$ 101,857$ & $\$ 115,021$ & $\$ 104,580$ & $\$ 5,197$ & $\$ 0$ & $\$ 0$ & $\$ 326,655$ \\
\hline ARMENDARIZ & $\$ 674,514$ & $\$ 659,651$ & $\$ 703,720$ & $\$ 649,456$ & $\$ 432,047$ & $\$ 433,451$ & $\$ 3,552,838$ \\
\hline AVIACION & $\$ 222,707$ & $\$ 201,439$ & $\$ 175,884$ & $\$ 175,233$ & $\$ 131,524$ & $\$ 135,518$ & $\$ 1,042,305$ \\
\hline BRASIL & $\$ 285,907$ & $\$ 267,871$ & $\$ 230,048$ & $\$ 229,663$ & $\$ 183,852$ & $\$ 197,529$ & $\$ 1,394,870$ \\
\hline Call center & $\$ 0$ & $\$ 0$ & $\$ 0$ & $\$ 0$ & $\$ 0$ & $\$ 1,230,928$ & $\$ 1,197,341$ \\
\hline CENTRAL & $\$ 0$ & \$0 & $\$ 0$ & \$0 & $\$ 0$ & $\$ 1,230,928$ & $\$ 1,230,928$ \\
\hline CHIMBOTE & $\$ 227,887$ & $\$ 1,311,123$ & $\$ 2,236,662$ & $\$ 1,016,779$ & $\$ 1,032,138$ & $\$ 708,695$ & $\$ 6,533,284$ \\
\hline EL POLO & $\$ 157,708$ & $\$ 150,410$ & $\$ 107,263$ & $\$ 94,397$ & $\$ 78,108$ & $\$ 92,024$ & $\$ 679,910$ \\
\hline ESPINAR & $\$ 300,491$ & $\$ 329,395$ & $\$ 303,035$ & $\$ 249,210$ & $\$ 160,371$ & $\$ 197,488$ & $\$ 1,539,989$ \\
\hline FAUCETT & $\$ 377,866$ & $\$ 406,430$ & $\$ 324,010$ & $\$ 243,189$ & $\$ 161,917$ & $\$ 145,180$ & $\$ 1,658,592$ \\
\hline FERRERO & $\$ 620,267$ & $\$ 313,616$ & $\$ 299,411$ & $\$ 295,521$ & $\$ 250,652$ & $\$ 226,847$ & $\$ 2,006,315$ \\
\hline IZAGUIRRE & $\$ 219,017$ & $\$ 218,507$ & $\$ 184,569$ & $\$ 175,700$ & $\$ 135,185$ & $\$ 38,995$ & $\$ 971,972$ \\
\hline JAVIER PRADO & $\$ 242,318$ & $\$ 250,966$ & $\$ 193,022$ & $\$ 170,516$ & $\$ 143,947$ & $\$ 157,129$ & $\$ 1,157,898$ \\
\hline JESUS MARIA & $\$ 233,248$ & $\$ 248,244$ & $\$ 229,200$ & $\$ 233,001$ & $\$ 172,342$ & $\$ 160,388$ & $\$ 1,276,422$ \\
\hline PEZET & $\$ 471,175$ & $\$ 446,060$ & $\$ 401,363$ & $\$ 402,071$ & $\$ 311,953$ & $\$ 349,510$ & $\$ 2,382,133$ \\
\hline PRIMAVERA & $\$ 679,816$ & $\$ 435,193$ & $\$ 364,937$ & $\$ 414,628$ & $\$ 223,282$ & $\$ 137,226$ & $\$ 2,255,082$ \\
\hline PUEBLO LIBRE & $\$ 127,889$ & $\$ 125,365$ & $\$ 109,686$ & $\$ 70,748$ & $\$ 0$ & $\$ 0$ & $\$ 433,688$ \\
\hline BELAUNDE & $\$ 76,307$ & $\$ 53,415$ & $\$ 55,990$ & $\$ 35,597$ & $\$ 1,074$ & $\$ 0$ & $\$ 222,383$ \\
\hline SAN JUAN DE MIRAFLORES & $\$ 3,849$ & $\$ 0$ & $\$ 0$ & $\$ 0$ & $\$ 0$ & $\$ 0$ & $\$ 3,849$ \\
\hline SAN MIGUEL & \$0 & $\$ 0$ & \$0 & $\$ 0$ & $\$ 41,880$ & $\$ 60,946$ & $\$ 102,826$ \\
\hline TACNA & $\$ 137,367$ & $\$ 140,723$ & $\$ 122,337$ & $\$ 102,450$ & $\$ 88,685$ & $\$ 82,277$ & $\$ 673,839$ \\
\hline Total general & $\$ \quad 5,160,189$ & $\$ \quad \mathbf{5 , 6 7 3 , 4 2 9}$ & $6,145,717$ & $4,563,357$ & $3,548,957$ & $\mathbf{5 , 5 8 5 , 0 5 6}$ & $30,643,119$ \\
\hline
\end{tabular}

Fuente: América Salud (2020)

En la figura 2 se muestra la tendencia de ventas de la Corporación en caso seguir la tendencia de ventas que mantiene la empresa en el sector.

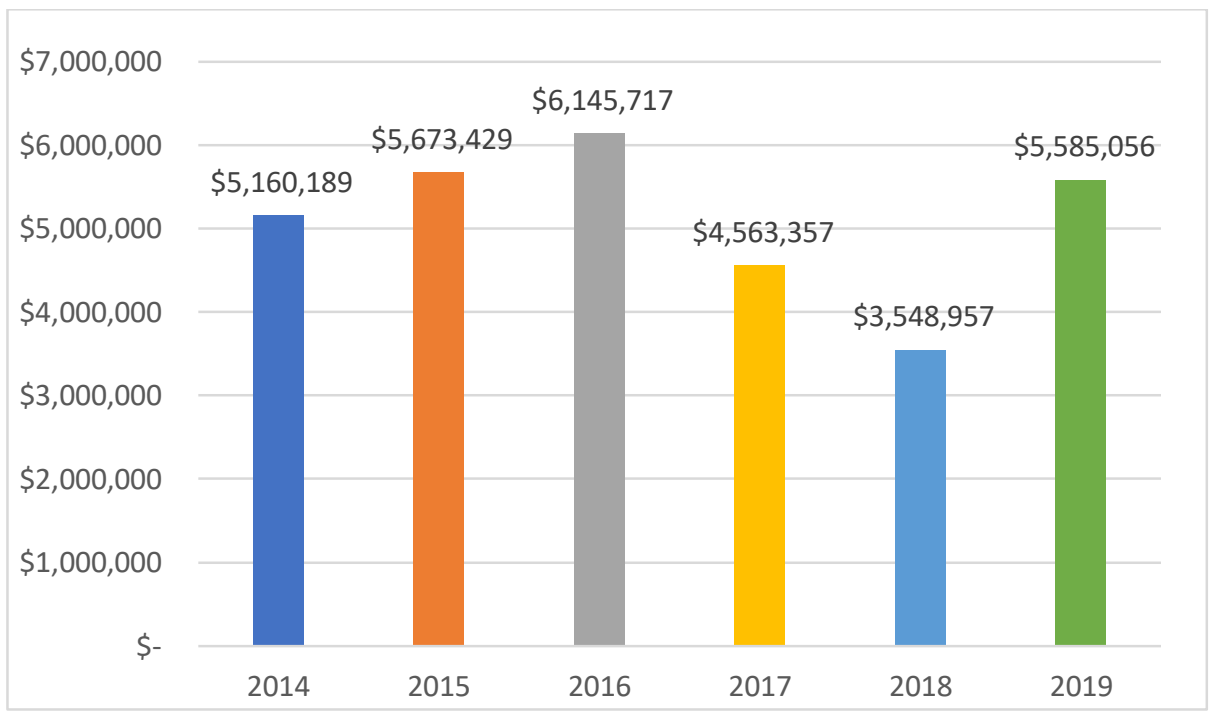

Figura 2

Tendencia de Ventas 2014-2021

Fuente: America Salud (2019) 
En la Tabla 15 se aprecia las ventas y utilidades operativas de la Corporación hasta el 2018.

\section{Tabla 15}

Ventas y Utilidades Operativas 2016-2018

\begin{tabular}{|c|c|c|c|c|c|c|c|c|}
\hline \multirow[b]{2}{*}{ tiendas } & \multirow{2}{*}{\multicolumn{2}{|c|}{$\begin{array}{c}2016 \\
\text { Suma de Ventas Suma de Uti }\end{array}$}} & \multirow{2}{*}{$\begin{array}{c}2017 \\
\text { Suma de Ventas }\end{array}$} & \multicolumn{3}{|c|}{2018} & \multicolumn{2}{|c|}{ Total Suma de V Total Suma de Uti } \\
\hline & & & & Suma de Uti & Suma de Venta & Ima de Uti & & \\
\hline & & & & & & & & \\
\hline ARMENDARIZ & $\$ 703,720$ & $\$ 133,375$ & $\$ 649,456$ & $\$ 122,720$ & $\$ 432,047$ & $\$ 86,311$ & $\$ 1,785,223$ & $\$ 342,405$ \\
\hline AVIACION & $\$ 175,884$ & $\$ 34,443$ & $\$ 175,233$ & $\$ 31,608$ & $\$ 131,524$ & $\$ 23,928$ & $\$ 482,641$ & $\$ 89,979$ \\
\hline BRASIL & $\$ 230,048$ & $\$ 49,634$ & $\$ 229,663$ & $\$ 51,018$ & $\$ 183,852$ & $\$ 40,736$ & $\$ 643,563$ & $\$ 141,388$ \\
\hline CENTRAL & $\$ 2,236,662$ & $\$ 70,264$ & $\$ 1,016,779$ & $\$ 83,242$ & $\$ 1,032,138$ & $\$ 143,889$ & $\$ 4,285,579$ & $\$ 297,395$ \\
\hline CHIMBOTE & $\$ 107,263$ & $\$ 24,312$ & $\$ 94,397$ & $\$ 20,896$ & $\$ 78,108$ & $\$ 18,230$ & $\$ 279,768$ & $\$ 63,438$ \\
\hline EL POLO & $\$ 303,035$ & $\$ 42,004$ & $\$ 249,210$ & $\$ 37,142$ & $\$ 160,371$ & $\$ 25,690$ & $\$ 712,616$ & $\$ 104,835$ \\
\hline ESPINAR & $\$ 324,010$ & $\$ 46,959$ & $\$ 243,189$ & $\$ 33,381$ & $\$ 161,917$ & $\$ 21,494$ & $\$ 729,116$ & $\$ 101,835$ \\
\hline FAUCETT & $\$ 299,411$ & $\$ 56,563$ & $\$ 295,521$ & $\$ 52,365$ & $\$ 250,652$ & $\$ 44,443$ & $\$ 845,585$ & $\$ 153,372$ \\
\hline FERRERO & $\$ 184,569$ & $\$ 32,241$ & $\$ 175,700$ & $\$ 30,276$ & $\$ 135,185$ & $\$ 22,900$ & $\$ 495,453$ & $\$ 85,417$ \\
\hline IZAGUIRRE & $\$ 193,022$ & $\$ 41,027$ & $\$ 170,516$ & $\$ 33,054$ & $\$ 143,947$ & $\$ 28,966$ & $\$ 507,486$ & $\$ 103,047$ \\
\hline JAVIER PRADO & $\$ 229,200$ & $\$ 50,679$ & $\$ 233,001$ & $\$ 51,073$ & $\$ 172,342$ & $\$ 36,133$ & $\$ 634,542$ & $\$ 137,884$ \\
\hline JESUS MARIA & $\$ 401,363$ & $\$ 64,481$ & $\$ 402,071$ & $\$ 62,095$ & $\$ 311,953$ & $\$ 47,119$ & $\$ 1,115,387$ & $\$ 173,695$ \\
\hline PEZET & $\$ 364,937$ & $\$ 44,416$ & $\$ 414,628$ & $\$ 43,458$ & $\$ 223,282$ & $\$ 27,309$ & $\$ 1,002,847$ & $\$ 115,183$ \\
\hline PRIMAVERA & $\$ 109,686$ & $\$ 21,254$ & $\$ 70,748$ & $\$ 14,206$ & $\$ 0$ & $\$ 0$ & $\$ 180,434$ & $\$ 35,459$ \\
\hline PUEBLO LIBRE & $\$ 55,990$ & $\$ 10,574$ & $\$ 35,597$ & $\$ 7,895$ & $\$ 1,074$ & $\$ 249$ & $\$ 92,661$ & $\$ 18,718$ \\
\hline SAN JUAN DE MIRAFLORES & $\$ 0$ & $\$ 0$ & $\$ 0$ & $\$ 0$ & $\$ 41,880$ & $\$ 8,794$ & $\$ 41,880$ & $\$ 8,794$ \\
\hline SAN MIGUEL & $\$ 122,337$ & $\$ 24,999$ & $\$ 102,450$ & $\$ 20,659$ & $\$ 88,685$ & $\$ 16,989$ & $\$ 313,472$ & $\$ 62,647$ \\
\hline TACNA & $\$ 178,149$ & $\$ 37,174$ & $\$ 179,446$ & $\$ 31,022$ & $\$ 157,825$ & $\$ 29,145$ & $\$ 515,421$ & $\$ 97,341$ \\
\hline Total general & $\$ 6,323,866$ & $\$ 784,399$ & $\$ 4,737,606$ & $\$ 726,107$ & $\$ 3,706,782$ & $\$ 622,325$ & $\$ 14,663,675$ & $\$ 2,132,831$ \\
\hline
\end{tabular}

Fuente: América Salud (2019)

A pesar de disminuir los niveles de ventas las utilidades se han incrementado porcentualmente como se aprecia en la Figura 3

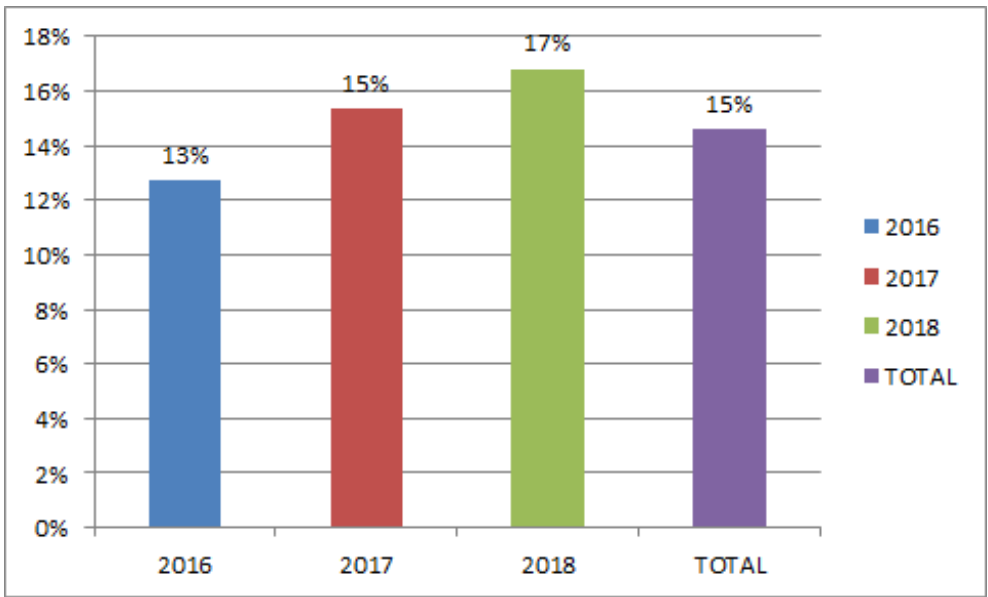

Figura 3

Utilidades/Ventas totales América Salud 2016-2018

Fuente: America Salud (2019) 


\subsection{Misión, Visión y Valores de la Empresa}

La Misión, Visión y valores de América Deluxe Health son los mismos de América Salud, ya que forman parte de la corporación por lo que estos son:

Misión: “Ofrecerle a nuestros clientes variedad y calidad en los productos acompañados del mejor servicio".

Visión: "En el 2029 ser la mejor cadena peruana del sector farmacéutico"

Los valores sobre los que se basa la organización son los siguientes:

Honestidad: Garantizar que todos los empleados de la corporación sean veraces y cumplan su trabajo de acuerdo a los lineamientos esperados de la misma.

$>$ Compromiso: Cada uno de los empleados de la Corporación deben sentirse parte de la misma a fin que los logros y metas obtenidas sean también compartidos por cada colaborador de la empresa.

Trabajo en Equipo: Pilar fundamental para el crecimiento de la Corporación ya que cada área y estamento de la empresa requiere el apoyo de cada colaborador dentro de su puesto de trabajo para que los objetivos se cumplan.

Responsabilidad: Cada empleado es significativo en el cumplimiento de las metas de la Corporación. Con dicho esfuerzo se garantiza que los objetivos serán alcanzados de la mano de cada colaborador.

\subsection{Análisis Externo: entorno, sector, mercado y competencia}

El análisis del sector arroja un valor de 2.69 para la matriz de factores externos la cual está afectada sobre todo por la inestabilidad política del Perú pero el crecimiento y la tendencia positiva del sector artículos de lujo permiten entrever un panorama positivo. 


\subsubsection{Análisis de entorno}

\section{Fuerzas políticas, gubernamentales y legales (P)}

Las fuerzas políticas se encontraban alteradas circunstancialmente por los cambios electorales y cambio de gobierno del año 2016. Dicha reconfiguración finalizó con la disolución del congreso que le otorga poderes especiales al Presidente de la República Martin Vizcarra y una situación de inestabilidad política creada por escándalos de corrupción que se manifiestan a todos los niveles de gobierno: Odebretch a nivel gobierno central con las obras del gasoducto del sur y la interoceánica, la línea Amarilla y los peajes a nivel Lima, las relaciones con los cuellos blancos a nivel judicial han ocasionado que toda la clase política esté involucrado en procesos pendientes y que el partido político que tenía la mayor cantidad de congresista tenga a su lideresa en la cárcel desde octubre del 2018 con prisión preventiva por presunción de lavado de activos generan una situación especial en el Perú.

Esto, como consecuencia, desacelera el aparato estatal, puesto que muchas instituciones, optan por ralentizar sus procesos esperando las decisiones del gobierno. La aprobación de la gestión del Presidente de la República Martín Vizcarra se encuentra en 68\% según sondeo de Ipsos realizado el 4 de octubre del 2019 motivado especialmente por la disolución del Congreso de la República, que contaba con una desaprobación de 90\% (El Comercio, 2019).

Dicha inestabilidad política constituye una amenaza para el sector.

\section{Fuerzas económicas y financieras (E)}

Al 31 de diciembre de 2018, el sistema financiero peruano está conformado por un total de 62 empresas, entre bancos, financieras, micro financieras y sistemas no bancarios. (Ministerio de Relaciones Exteriores, 2019). 
Los factores económicos y financieros se analizan dentro del Marco Económico Multianual 2019-2022 por lo que cada factor se evaluará en prospectiva hacia dicho año.

\section{Población económicamente activa}

La población económicamente activa (PEA) está integrada por personas que están ocupadas y por los que buscan estarlo representando el $68,5 \%$ de la población en edad de trabajar (PET). La información muestra que, en la ciudad hay un incremento constante de la población de personas que generan ingresos y tienen poder adquisitivo lo cual es favorable para la industria y se aprecia en la Tabla 16

Tabla 16

Población Económicamente Activa en Lima

\begin{tabular}{|c|c|c|c|}
\hline Año & $\begin{array}{ll}\text { PET nivel } \\
\text { nacional }\end{array}$ & PEA Lima & $\%$ \\
\hline 2013 & $16,328,800$ & $4,625,200$ & 28.33 \\
\hline 2014 & $16,396,377$ & $4,701,025$ & 28.67 \\
\hline 2015 & $16,443,600$ & $4,750,620$ & 28.89 \\
\hline 2016 & $16,856,252$ & $5,120,700$ & 30.38 \\
\hline 2017 & $17,070,100$ & $5,204,300$ & 30.39 \\
\hline
\end{tabular}

Fuente: Instituto Nacional de Estadística e Informática, población y crecimiento de Lima Metropolitana (2018)

\section{Producto Bruto Interno}

El Producto Bruto Interno es una medida de valor de la producción de bienes o servicios de un país durante un periodo, mostrando el crecimiento o decrecimiento del mismo (INEI, 2019) 
Entre el 2013 y el 2018 el ingreso per cápita ha crecido, a una tasa que gira alrededor del 3.0\% como se aprecia en la Tabla 17, indicando un crecimiento económico favorable para el entorno del proyecto, porque un mayor ingreso permite que aumente la capacidad de elección de las personas por su mayor poder de compra y presumiblemente de ahorro.

Tabla 17.

PBI Total y PBI Per Cápita 2013-2018

PBI PBI per cápita

\begin{tabular}{llll}
\hline & Millones & & \\
Año & Euros & Var PBI & Euros \\
\hline $\mathbf{2 0 1 4}$ & 152,199 & $2.4 \%$ & 4,936 \\
$\mathbf{2 0 1 5}$ & 172,614 & $3.3 \%$ & 5,541 \\
$\mathbf{2 0 1 6}$ & 175,689 & $4.0 \%$ & 5,579 \\
$\mathbf{2 0 1 7}$ & 189,544 & $2.5 \%$ & 5,956 \\
$\mathbf{2 0 1 8}$ & 190,688 & $4 \%$ & 5,961 \\
\hline
\end{tabular}

Tasa de Desempleo

La tasa de desempleo se mide mensualmente, pero se refleja trimestralmente como se muestra en la Tabla 18. 
Tabla 18.

Tasa de Desempleo Lima Metropolitana 2015-2019

\begin{tabular}{lll}
\hline Trimestre & Tasa de Desempleo & Personas sin empleo \\
\hline Enero 2019-Agosto2019 & $6.5 \%$ & 341,700 \\
Enero 2018-Agosto 2018 & $7.3 \%$ & 382,200 \\
Enero 2017- Agosto 2017 & $7.2 \%$ & 374,600 \\
Enero 2016-Agosto 2016 & $6.6 \%$ & 335,300 \\
Enero 2015-Agosto 2015 & $6.4 \%$ & 314,500 \\
\hline
\end{tabular}

Fuente: INEI Informe de Empleo (2019)

La tasa de desempleo se ha mantenido relativamente constante por lo que al aumentar la población aumenta la cantidad de desempleados en la misma proporción. Ello no afecta al sector de artículos de lujo debido a que se cuenta con trabajadores calificados a precio económico para la implementación del sector.

Canasta Básica

Durante el mes de agosto de 2019 se aprecia la variación de la canasta familiar en Lima Metropolitana en los ocho grupos de consumo como se muestra en la Tabla 19.

Tabla 19.

Canasta Familiar en Lima Metropolitana 2018-2019

\begin{tabular}{llll}
\hline Índice General & Ponderado & $\begin{array}{l}\text { Agosto } \\
2019\end{array}$ & Anual18-19 \\
& & 2019 \\
\cline { 2 - 4 } & $100 \%$ & 0.07 & 2.13 \\
\hline Alimentos y bebidas & 37.8 & -0.07 & 1.53 \\
Calzado y vestido & 5.4 & 0.06 & 0.87 \\
Vivienda Combustible & 9.3 & 1.45 & 2.72 \\
Muebles y enseres & 5.8 & 0.09 & 1.52 \\
Conservación de la Salud & 3.7 & 0.13 & 1.42 \\
\hline
\end{tabular}




\begin{tabular}{|c|c|c|c|}
\hline Transportes & y 16.5 & -0.66 & 2.63 \\
\hline \multicolumn{4}{|l|}{ Comunicaciones } \\
\hline Enseñanza y Cultura & 14.9 & 0.19 & 3.76 \\
\hline Otros bienes y servicios & 6.7 & 0.17 & 1.92 \\
\hline
\end{tabular}

Fuente: INEI (2019)

Se aprecia que lo invertido por la canasta familiar para la conservación de la salud representa el $3.7 \%$ del gasto total de las familias.

\section{Tasa de Inflación}

La Inflación es un proceso económico provocado por el desequilibrio existente entre la producción y la demanda; causa una subida continuada de los precios de la mayor parte de los productos y servicios, y una pérdida del valor del dinero para poder adquirirlos. La inflación se mantiene en el tiempo, sin embargo, en el año 2016 comenzó a disminuir a niveles de 2\% manteniéndose debajo de dicho parámetro como se aprecia en la Tabla 20

\section{Tabla 20}

Tasa de Inflación en Lima Metropolitana 2010-2018

\begin{tabular}{ll}
\hline Año & Porcentaje \\
\hline 2014 & 3.3 \\
2015 & 3.5 \\
2016 & 3.23 \\
2017 & 1.36 \\
2018 & 2.19 \\
\hline
\end{tabular}

Fuente: INEI (2019) 


\section{Tasa de interés}

La tasa de Interés es el precio del dinero o pago estipulado, por encima del valor depositado, que un inversionista debe recibir, por unidad de tiempo determinado, del deudor a raíz de haber usado su dinero durante ese tiempo. La tasa de interés bancario se muestra en la Tabla 21

Tabla 21

Tasas de Interés Activa Promedio de Mercado 2014-2019 (al 15 de octubre de 2019)

\begin{tabular}{lll}
\hline Año & Moneda Nacional & Moneda Extranjera \\
\hline 2014 & 15.74 & 7.88 \\
2015 & 16.18 & 7.82 \\
2016 & 16.03 & 8.09 \\
2017 & 17.03 & 7.49 \\
2018 & 15.67 & 7.12 \\
2019 & 14.38 & 8.42 \\
\hline
\end{tabular}

Nota: Superintendencia de Banca y Seguros (2019)

Tipo de cambio

El tipo de cambio en el Perú se ha mantenido relativamente constante; sin embargo, hay sectores donde solo se hacen venta con moneda extranjera lo cual hace que se vean afectados los del mercado local. Sin embargo, en el sector el precio no es un factor limitante. El tipo de cambio se observa en la Tabla 22. 
Tabla 22.

Tipo de Cambio Perú 2015-2019

\begin{tabular}{ll}
\hline Año & Promedio Anual \\
\hline 2015 & 3.18 \\
2016 & 3.35 \\
2017 & 3.33 \\
2018 & 3.25 \\
2019 & 3.38 \\
\hline
\end{tabular}

Nota: Superintendencia de Banca y Seguro (2019)

\section{Riesgo país}

El riesgo país está definido como factores políticos, económicos y sociales referentes a las características específicas de cada país. De esta manera, un país más riesgoso pagará un mayor costo de capital y, por el contrario, el menos riesgoso pagará menos. En el Perú el riesgo país se muestra en la Tabla 23.

Tabla 23.

Riesgo País 2014-2018

\begin{tabular}{ll}
\hline Año & Riesgo País \\
\hline 2014 & 162 \\
2015 & 247 \\
2016 & 136 \\
2017 & 121 \\
2018 & 133
\end{tabular}

Fuente: Banco Central de Reserva del Perú( 2019) Estadísticas anuales 
Proyección al 2022

De acuerdo al Marco Multieconómico Multianual (MMM) 2019-2022 se debe destacar que las proyecciones multianuales se brindan en un contexto de mayor volatilidad siendo los factores de riesgo los siguientes:

Tensiones comerciales ante medidas Arancelarias implementadas por los Estados Unidos de Norteamérica

$\checkmark$ Desequilibrios Financieros generados por el retiro del estímulo monetario de países del primer mundo

Populismo Global

Alto Nivel de endeudamiento de gobiernos Locales de China

Los ratios macro y micro económicos más relevantes se muestran en la Tabla 24.

Tabla 24

Ratios Macro y Microeconómicos Economía Peruana 2019-2022

\begin{tabular}{lll}
\hline Ratios & 2019 & $2020-2022$ \\
\hline Demanda Interna & 4.5 & 4.8 \\
PBI & 3.2 & 3.4 \\
Tasa Desempleo & 6.2 & 5.8 \\
Tasa Inflación & $2.5 \%$ & $2.5 \%$ \\
Tasa de Interés & 2.75 & 2.6 \\
Tipo de Cambio & 3.30 & N.D \\
\hline Fuente: MMM 2019-2022 \& Banco Central de Reserva (2019)
\end{tabular}




\section{Fuerzas sociales, culturales y demográficas (S)}

Las condiciones de vida de los peruanos ha mejorado en términos de indicadores del acceso a bienes y servicios básicos, estos incluyen los accesos a servicios desde salud, educación hasta infraestructura sanitaria. El Perú es uno de los dos países latinoamericanos que más avanzó entre el 2000 y el 2010 en cuestión de igualdad de género, ingresos, pobreza, empleo formal, salud y educación. (ONU, 2013).

De acuerdo al estudio presentado por Global Cosmetics Products Market Analysis of Growth, Trends and Forescast 2018-2023 en el mundo la industria de belleza movió 532 mil millones de dólares durante el 2017 y se espera que en el 2023 este sector esté valorizado en 605 mil millones representando un crecimiento de 7.14\% (PromPerú, 2018). Por otro lado de acuerdo a Perú Retail (2017) el mercado farmacéutico peruano genera un valor de 918 millones en el PBI pero está creciendo a tasas menores a las del 2016 sin embargo el mercado de belleza de lujo ha crecido 14\% durante el 2018 principalmente impulsado por la marca Estee Lauder (Fashion Network, 2018). Dicho crecimiento del mercado peruano de belleza es una oportunidad en el sector

Según Vargas (2015) una de las características principales de las personas que pertenecen al nivel socio económico A es su forma de ver la vida. Con sus necesidades financieras cubiertas, estando a su alcance todas las cosas materiales que desearan, acumular deja de ser una prioridad en casi todos los casos. La demanda de bienes de lujo en el Perú ha aumentado a pesar que en algunas partes del mundo esta se ha desacelerado compensándose con mercados emergentes como China, algunos países africanos y América Latina, en donde el sector del lujo ocupa puestos nunca soñados - por ventashace tan solo una década. México, Colombia, Chile y recientemente Perú cuentan no solo con una clase alta consumidora de productos premium, sino con una creciente clase media/alta aspiracional que está consumiendo prácticamente el doble que a principios de 
la década de los 2000. lo que permite establecer que los criterios del público objetivo constituyen una amenaza para el sector ya que el público objetivo es altamente selectivo y tiene los medios para elegir el proveedor adecuado.

Asimismo, de acuerdo a Olarte (2018), dicho público objetivo maneja los siguientes drivers que son exclusividad, disponibilidad inmediata de servicio, atributos o beneficios de productos especializados, el cuidado de la salud y verse para sentirse bien que son factores que ayudan a identificar y mejorar la posición competitiva en la mente del consumidor . Dichos drivers no son permanentes y varían por diversas causas por lo que es importante efectuar periódicamente los costumer experience journey mapping para identificarlas dimensiones de los drivers y no constituya un riesgo en el sector.

\section{Fuerzas tecnológicas y científicas ( $T$ )}

Las fuerzas tecnológicas provienen del mundo globalizado, al lograr acceso de nuevas tendencias a través de fuentes como YouTube y redes sociales, el interés en el uso de tanto los dispositivos móviles como computadoras personales y Tablets para acceder a aplicativos que mejoren la calidad de vida y acerquen al usuario diversos servicios, ha traducido en un creciente uso de ellos.El incremento en el uso de internet se puede atribuir al mayor acceso que se tiene a equipos tecnológicos, ya sea computadores, celulares, tablets, entre otros. De acuerdo a ESAN (2019) los consumidores digitales en Perú han evolucionado con el tiempo ya que no se sienten atraídos por una marca en especial y sus búsquedas ahora se centran en la relación precio-calidad del producto que desean comprar. Además, son personas interesadas en el avance de la tecnología y las nuevas tendencias, viéndose influenciadas por el mercado americano y europeo. Las principales características del consumidor digital es que emplea las redes sociales ya que dicho medio le permite conocer esos nuevos avances tecnológicos siendo la tendencia de moda Facebook. Esta red social sigue siendo el medio digital de más alcance, por encima de 
Google y de YouTube, ya que los usuarios del país pasan en promedio más de cuatro horas al día conectados. Además de ello utiliza varios canales de comunicación ya que espera contactarse con la marca que le interesa desde varios canales, en cualquier momento. Si el sitio web que visita no le proporciona la facilidad de autoayuda durante el proceso de compra, lo abandonará y buscará otra opción más accesible esperando una experiencia de compra completa ya que a través de todos sus canales digitales, y especialmente en sus redes sociales, las marcas deben alentar activamente a los usuarios a compartir sus experiencias, hacer encuestas de opinión e invitarlos a que proporcionen su feedback. Al interactuar con ellos en todos los canales y puntos de venta online, obtendrán su confianza y fidelidad. El consumidor digital en Perú sigue evolucionando al mismo ritmo que el avance tecnológico así que detectar los cambios con anticipación permitirán una diferenciación en el sector.

\section{Fuerzas ecológicas y ambientales (E)}

La consultora Grand View Research prevé para la cosmética natural y ecológica a nivel mundial en 2025 un consumo de 25,110 millones dólares, según su último informe sobre el sector, un mercado que en 2017 alcanzó los 12.190 millones. Con un crecimiento anual que oscila entre el 8 y el 10\%, la fiebre por este tipo de cosméticos parece imparable. Existen diferencias entre la cosmética natural y la ecológica ya que mientras la primera se refiere a productos formulados con ingredientes de origen natural, la segunda se fija también en el respeto al medio ambiente. La cosmética natural incluye en su formulación un $90 \%$ de materias primas de origen vegetal o animal, por lo tanto, no es vegana, La otra debe probar que un mínimo de su formulación proviene de la agricultura ecológica, y no se experimenta en animales. Debido a que el público objetivo no escatima en precios se convierte en el producto ideal para estos ya que fabricar sin químicos y tan solo con productos naturales encarece los costes por lo que se debe asumir que el precio va a ser 
casi siempre mayor al de otros productos específicos en el mercado (Caballero, 2019). Ello constituye una oportunidad en el sector ya que el público objetivo pagará el justo precio por el producto.

\subsubsection{Análisis del Sector (Cinco Fuerzas de Porter)}

Para desarrollar el análisis del sector se utiliza las cinco fuerzas de Porter

\section{Participantes nuevos.}

Los factores que constituyen barreras de Ingreso al Mercado son la legislación, la economía de escala de costos, el tamaño de mercado y el costo de implementación del servicio.

El poder de los nuevos participantes es bajo ya que ninguno de dichos factores es una barrera de ingreso inviable por lo que este sector permite el ingreso de nueva competencia. A pesar que no una existe legislación rígida para el servicio de productos de lujo dicho servicio podría ser normado en cualquier momento lo que a futuro puede aumentar la barrera de ingreso. El tamaño de mercado peruano todavía no es importante pero la tendencia creciente puede inducir al ingreso de corporaciones internacionales en un futuro.

Proveedores.

Los proveedores que intervienen en la cadena son los especialistas farmacéuticos, personal experto en belleza, las cadenas mayoristas de importación y los vendedores internacionales de artículos de lujo. El poder de negociación de los proveedores es medio porque estos son especializados y no están organizados. Se debe tener en cuenta que los precios de alquiler son altos por lo que es importante contar con un local propio. Al ser los proveedores muy especializados esta contribuye a aumentar el precio del servicio por 
lo que éste está orientado a nichos exclusivos de personas que pueden cubrir el negocio a cualquier valor.

\section{Sustitutos.}

Los sustitutos son empresas que brindan servicios de cirugía plástica de lujo específico en Lima y en el exterior en ciudades como Nueva York, Miami, Milán u otra ciudad sofisticada. Esta fuerza es media ya que la costumbre del cliente y la adaptabilidad a los costos le permiten al cliente utilizarlo en desmedro de los servicios que puede brindar un servicio nacional. Al no ser el precio de los productos un condicionante el diferenciador debe ser la novedad que el servicio que se debe brindar.

\section{Clientes.}

Los clientes del sector son mujeres y hombres de clase social A que requieren un servicio exclusivo, personalizado y orientado a satisfacer sus necesidades. Su poder de negociación es alto ya que cuentan con suficientes opciones para poder decidir el tipo de servicio a utilizar siendo el servicio altamente especializado lo que permite que estas opten por la alternativa que prefieran.

\section{Competidores.}

En este mercado compiten las cadenas de farmacias, los Centros Spa de belleza y salud del exterior ya que no existe en el país empresa que brinde el servicio ofrecido por America Deluxe Health. Esta rivalidad es baja ya que el mercado peruano es muy pequeño y en dichos negocios se atienden millonarios de todo el mundo. La aparición de nuevas tecnologías puede provocar que la rivalidad a futuro aumente para que la competencia se especialice en nichos de mercado.

El resumen del atractivo de cada fuerza para el sector se aprecia en la Tabla 25. 
Tabla 25.

Resumen del Atractivo Global del Sector.

\begin{tabular}{ll}
\hline Fuerza & Atractivo \\
\hline Proveedores & Medio \\
Clientes & Alto \\
Nuevos competidores & Bajo \\
Competidores actuales & Bajo \\
Sustitutos & Media \\
\hline
\end{tabular}

Fuente: Porter M (2009) Estrategias Competitivas: Técnicas para el Análisis de la empresa y sus competidores.

Para el sector se considera que mayor importancia relativa tienen los clientes, ya que ellos deciden la compra y los proveedores ya que estos deciden la cantidad y calidad del servicio.

\subsubsection{Análisis de Mercado y la Competencia}

$\mathrm{ADH}$ se encuentra dentro del sector de la belleza saludable.

Vale precisar que en el Perú no existe un centro dermatológico que brinde el servicio de venta de artículos de belleza dermatológica saludable de lujo, por lo que dicha atención es brindada parcialmente por diversas farmacias de cadena y clínicas especializadas que cuentan con artículos para diversos niveles socio económicos, así como un porcentaje de participación estimada de mercado. Estos se aprecian en la tabla 26 
Tabla 26

Competencia y participación estimada de mercado año 2019

\begin{tabular}{cc}
\hline Competidor & $\begin{array}{c}\text { Participación relativa de } \\
\text { Mercado }\end{array}$ \\
\hline Cadena de Farmacias & $55 \%$ \\
Nacionales & \\
\hline Clínicas y Centros & $25 \%$ \\
Estéticos Nacionales & \\
\hline Negocios de Belleza & $20 \%$ \\
Internacionales &
\end{tabular}

Fuente: Investigación preliminar de mercado (2019)

Asimismo se puede apreciar las características de la competencia y el market share esperado para el año 2020 en la Tabla 27

Tabla 27

Características de la competencia y Participación de mercado 2020

\begin{tabular}{|c|c|c|c|c|}
\hline Competidor & \% Participación & Productos & Precios & Caracteristicas \\
\hline $\begin{array}{l}\text { Clínicas Particulares } \\
\text { Exclusivas Nacionales }\end{array}$ & $20 \%$ & Cremas & $\begin{array}{l}10 \% \\
\text { debajo }\end{array}$ & $\begin{array}{ll}\text { Solo } & \text { se } \\
\text { especializa } & \text { en } \\
\text { productos } & \\
\text { médicos } & \end{array}$ \\
\hline $\begin{array}{lll}\text { Farmacias de } & \text { Cadena } \\
\text { Nacional } & & \\
\end{array}$ & $20 \%$ & $\begin{array}{l}\text { Maquillaje } \\
\text { Perfumería } \\
\text { Cremas }\end{array}$ & $\begin{array}{l}30 \% \\
\text { debajo }\end{array}$ & $\begin{array}{l}\text { Cuenta con } \\
\text { pocas marcas } \\
\text { sin atención } \\
\text { personalizada }\end{array}$ \\
\hline $\mathrm{ADH}$ & $30 \%$ & & & \\
\hline $\begin{array}{l}\text { Negocios de Belleza } \\
\text { Internacionales }\end{array}$ & $30 \%$ & $\begin{array}{l}\text { Maquillaje } \\
\text { Perfumería } \\
\text { Cremas }\end{array}$ & Igual & $\begin{array}{l}\text { Se encuentran } \\
\text { en el exterior }\end{array}$ \\
\hline
\end{tabular}

Total

Fuente: Investigación Grupo (2019) 
Es importante precisar que la creación de $\mathrm{ADH}$ dentro de la corporación se debe a que la marca America Salud está orientada a un target diferente lo que no atraería al público objetivo esperado lo que obra negativamente en la demanda ya que los drivers de ambos mercados son completamente diferentes.

Por otro lado Aruma, empresa orientada a productos de belleza no se considera competencia para $\mathrm{ADH}$ por tres razones:

— Está orientada a un target diferente al de ADH masificando sus locales (ya que cuenta con cinco).

— No brinda atención personalizada para sus productos

- No cuenta con productos premium exclusivos en los sectores maquillaje, perfumes y cremas.

\subsection{Análisis de la Industria}

\subsubsection{Definición de la Industria}

El sector de estudio corresponde a las actividades de atención de productos farmacéuticos y de belleza cuyas características se observan en la Tabla 28

\section{Tabla 28.}

Definición de la Industria

\begin{tabular}{lllll}
$\begin{array}{l}\text { Identificación de } \\
\text { CIIU }\end{array}$ & Grupo & Clase & Descripción \\
\hline 47 & 477 & 4772 & $\begin{array}{l}\text { Productos farmacéuticos } \\
\text { belleza al por menor en te } \\
\text { especializadas }\end{array}$ \\
\hline Fuente: SUNAT (2019) Clasificación Industrial Internacional Uniforme
\end{tabular}

\subsubsection{Evolución de la Demanda}

En el Perú no se tiene establecido estudios de la demanda de artículos de salud de lujo por lo que se ha establecido un marco referencial que será demostrado en la investigación cuantitativa del presente trabajo. Referencialmente se establece una 
demanda estimada del público objetivo en los distritos de influencia y se muestran en la Tabla 29

\section{Tabla 29}

Demanda estimada

\begin{tabular}{llll}
\hline & Población & Total & \\
Distrito & $20-70$ & NIVEL A & TOTAL \\
\hline MIRAFLORES & 82,805 & 0.346 & \\
LAMOLINA & 166,912 & \\
SAN BORJA & 111,808 & \\
SAN ISIDRO & 55,006 & \\
SANTIAGO & DE & \\
SURCO & 338,509 & \\
\hline TOTAL & 755,040 & $\mathbf{2 6 1 , 2 4 3}$
\end{tabular}

Fuente: APEIM(2018) Estudio Nivel Socio Económico Lima 2018

El estudio de mercado se detalla en el anexo 17 y para un escenario pesimista $(2.5 \%)$ determina.una atención de 845 personas con seis atenciones anuales lo que significan 5,070 atenciones en ADH.

Para evaluar los factores externos se utiliza la Matriz de factores externos mediante la cual se evalúa las oportunidades y amenazas, con la cual se obtiene un valor dentro de una escala comprendida entre 1 y 5, que representa el grado de respuesta que tiene el sector analizando el entorno de la industria. (D`Alessio 2013). El valor de 5 representa que la empresa reacciona muy bien dentro del sector frente a la oportunidad y/o amenaza mientras que el valor de 1 significa que la empresa no tiene capacidad de reacción frente a la oportunidad y/o amenaza. Los resultados se muestran en la Tabla 30.

Las oportunidades y amenazas se han encontrado en el análisis de sector externo habiéndolas calificado de acuerdo al grado de importancia para el negocio. 
Tabla 30.

Matriz de Factores Externos

FACTORES DETERMINANTES DE ÉXITO OPORTUNIDADES

Crecimiento del mercado peruano de belleza PESO Puntaje Ponderad

Globalización del mercado de belleza

$\begin{array}{lll}0.12 & 3 & 0.36\end{array}$

Crecimiento de mercado objetivo

$\begin{array}{lll}0.08 & 3 & 0.24\end{array}$

Pago justo por el servicio ofrecido

$\begin{array}{lll}0.12 & 4 & 0.48\end{array}$

Desarrollo de tecnología

$\begin{array}{lll}0.08 & 2 & 0.16\end{array}$

Subtotal

$0.10 \quad 3$

AMENAZAS

Alta Oferta Mundial de belleza de lujo

0.5

0.3

Escasas posibilidades de diferenciación

$\begin{array}{lll}0.10 & 2 & 0.20\end{array}$

Fuerte demanda por personal especializado

$\begin{array}{lll}0.08 & 2 & 0.16\end{array}$

Selectividad del Mercado Objetivo

$\begin{array}{lll}0.12 & 2 & 0.24\end{array}$

Inestabilidad Política disolución congreso

$0.15 \quad 2$

0.30

SubTotal

$0.05 \quad 5$

0.25

Total 1.15

2.69

Fuente: Investigación propia (2019)

1.12. Análisis Interno: productos, ciclo de vida, precios, distribución, comunicación y fuerza de ventas

AMERICA SALUD es una Cadena Peruana de Boticas, formada en el año 2003, dedicada íntegramente a la comercialización de productos de farmacia, artículos de perfumería y de tocador. Cuenta con quince locales a nivel nacional, un almacén central y un servicio de call center con competencias básicas como atención las 24 horas, una amplia línea de productos el servicio de reparto de salud entre otras. Ello le permite establecer un valor de 2.35 para la matriz de factores internos en el cual las fortalezas superan a las debilidades. 
Las acciones de marketing para las líneas que produce y comercializa América Salud son básicas y se realizan programas de Servicio al cliente, activaciones en los puntos de venta, concursos y premios por campaña y publicidad promocional en las quince tiendas En el análisis interno se evaluará los productos con los que cuenta América Salud, el ciclo de vida de los mismos, los precios de dichos productos así como las variables de distribución, comunicación y fuerza de ventas para concluir con un análisis de la matriz de factores internos

\subsubsection{Productos}

América Salud ofrece una diversa línea de productos que se aprecian en la tabla 31

Tabla 31

Participación de Ventas de Productos Ofrecidos por América Salud

\begin{tabular}{lc}
\hline Producto/Servicio & Participación en la Estructura de Ventas (\%) \\
\hline Farmacia & 34 \\
Productos Oncológicos & 2 \\
Material médico Quirúrgico & 5 \\
Productos Galénicos & 4 \\
Homeopatía & 2 \\
Productos para diabéticos & 5 \\
Productos Naturales & 8 \\
Cremas, maquillajes y perfumes & 18 \\
de lujo & 12 \\
Perfumería & 8 \\
Bazar & \\
Productos para Bebes &
\end{tabular}

Fuente: Informe de Ventas América Salud (2019) 


\subsubsection{Ciclo de Vida}

En la figura 4 se muestra el ciclo de vida en que se encuentran la línea de los productos expedidos por América Salud así como la nueva oferta de América Deluxe Health (ADH)

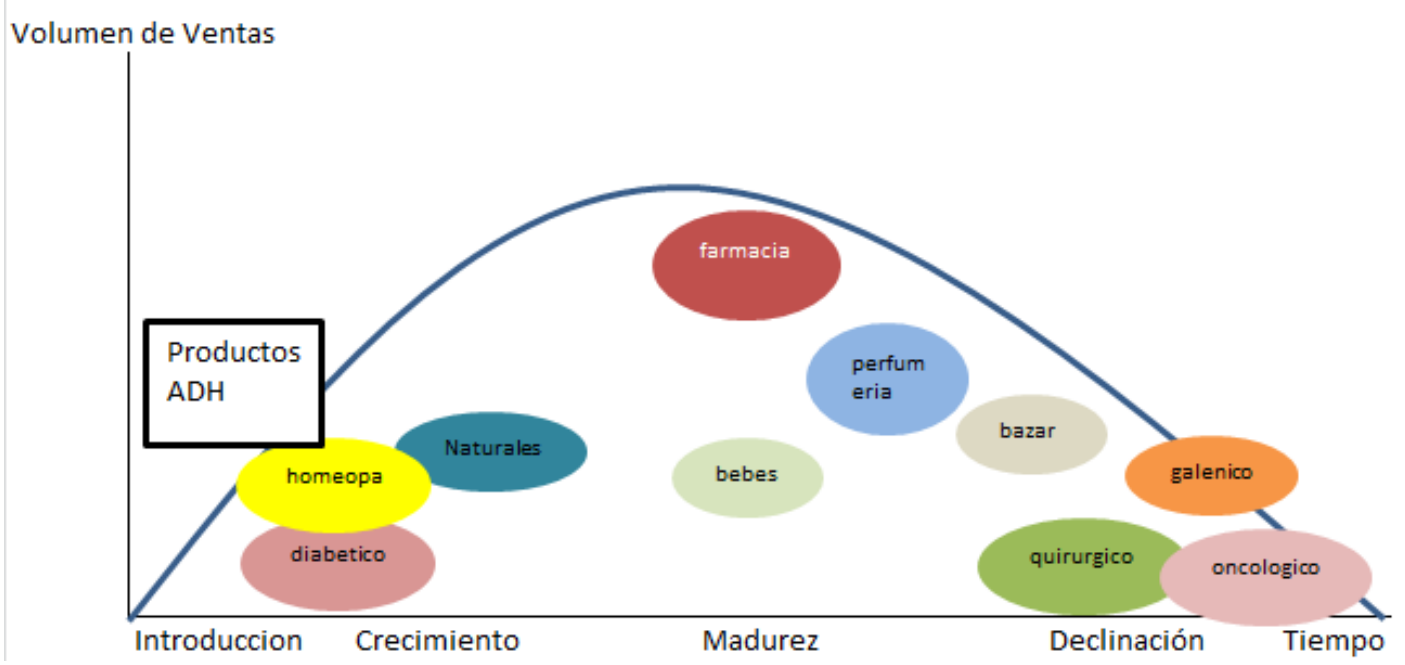

Figura 4

Ciclo de Vida de Productos de América Salud

Fuente: Adaptado de Kotler \&Keller (2012)

En dicha figura se observa que los productos quirúrgicos, galénicos y oncológicos constituyen productos que la corporación está dejando de ofertar manteniéndolos por la costumbre.

\subsubsection{Precios}

En la Tabla 32 se aprecia se aprecian los márgenes aproximados por línea de productos 
Tabla 32

Márgenes Aproximados por Línea de Productos América Salud

\begin{tabular}{lc}
\hline Producto/Servicio & Margen Bruto promedio (\%) \\
\hline Farmacia & 30 \\
Productos Oncológicos & 10 \\
Material médico Quirúrgico & 15 \\
Productos Galénicos & 15 \\
Homeopatía & 15 \\
Cremas, $\quad$ maquillajes & 100 \\
perfumes de lujo & \\
Productos para diabéticos & 15 \\
Productos Naturales & 15 \\
Perfumería & 25 \\
Bazar & 15 \\
Productos para Bebes & 10
\end{tabular}

Fuente: Informe de Ventas América Salud (2019)

Dichos márgenes brutos promedio arrojan al final del ejercicio un margen neto para América Salud de 15\%

\subsubsection{Distribución}

América Salud cuenta con 15 tiendas; trece ubicadas en Lima y dos en provincia además de contar con un callcenter y un almacén central que realiza venta mayorista por lo que el diagrama de distribución se observa en la figura 5 


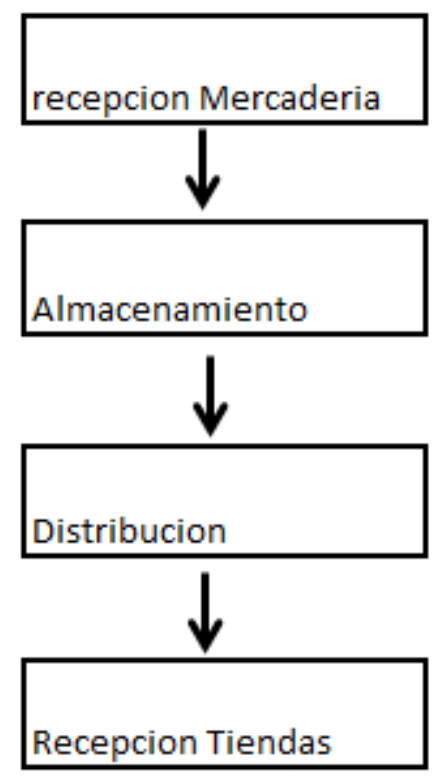

\section{Figura 5}

Diagrama de Distribución

Fuente: América Salud (2019)

América Salud realiza las compras corporativas de acuerdo a los requerimientos mensuales de cada tienda; los productos son recibidos en un almacén central donde son codificados y destinados para ser entregados a cada tienda vía terrestre.

\subsubsection{Comunicación}

Los objetivos de comunicación son publicitar la marca América Salud como una botica multiusos asociando diversas marcas a la oferta de la farmacia siendo reconocidos en el Perú como una tienda especializada de la salud.

Para ello utiliza una propuesta detallada en la Tabla 33 
Tabla 33

Propuesta de Comunicación ADH

\begin{tabular}{lll}
\hline Medio & Frecuencia & Propuesta \\
\hline Redes & Por campaña & Se utiliza Face Book , Instagram y la página \\
& WEB para publicitar fechas especiales \\
Activaciones & Por campaña & Se utilizan fechas especiales para promociones \\
& y concursos orientadas a los puntos de venta así \\
& como la participación de Ferias.
\end{tabular}

Fuente: América Salud (2019) Plan de Marketing Perú

\subsubsection{Fuerza de Ventas}

América Salud dispone de vendedores especializados en cada una de las tiendas los cuales laboran bajo un esquema de sueldo básico; estos reportan a cada administrador de tienda. En la Tabla 34 se muestra la cantidad de vendedores por tienda y el ratio ventas/vendedor. 
Tabla 34

Cantidad de vendedores y Ratio América Salud

\begin{tabular}{llccc}
\hline $\mathrm{N}^{\circ}$ & Locales & \multicolumn{2}{c}{ Ventas 2018 } & \multicolumn{2}{c}{ Vendedores Ratio } \\
\hline 1 & Miraflores1 & $\$ 432,046.54$ & 8 & 54006 \\
2 & Miraflores2 & $\$ 161,917.00$ & 6 & 26986 \\
3 & San Isidro & $\$ 223,282.46$ & 6 & 37214 \\
4 & Magdalena & $\$ 183,852.35$ & 4 & 45963 \\
5 & La Molina & $\$ 135,184.73$ & 4 & 33796 \\
6 & San Miguel & $\$ 88,685.48$ & 4 & 22171 \\
7 & Jesús María & $\$ 311,953.43$ & 4 & 77988 \\
8 & San Borja & $\$ 131,523.71$ & 3 & 43841 \\
9 & San Miguel & $\$ 250,652.05$ & 4 & 62663 \\
10 & Santiago de Surco & $\$ 160,370.73$ & 5 & 32074 \\
11 & San Isidro2 & $\$ 172,341.63$ & 4 & 43085 \\
12 & Independencia & $\$ 143,946.71$ & 4 & 35987 \\
13 & San Juan de Miraflores & $\$ 41,880.09$ & 3 & 13960 \\
14 & Tacna & $\$ 77,531.18$ & 4 & 19383 \\
15 & Chimbote & $\$ 78,108.13$ & 4 & 19527 \\
\hline & & & 67 &
\end{tabular}

Fuente: América Salud (2019) Informe de Ventas

Para evaluar los factores internos se utiliza la Matriz de factores externos (MEFI) mediante la cual se evalúa las fortalezas y debilidades, con la cual se obtiene un valor dentro de una escala comprendida entre 1 y 4, que representa el grado de respuesta que tiene la empresa aplicada en el sector (D`Alessio, 2013). El valor de 4 representa que la empresa reacciona muy bien dentro del sector mientras que el valor de 1 significa que la empresa no tiene capacidad de reacción. Los resultados se muestran en la Tabla 35. 
Tabla 35

Matriz de Factores Internos

\begin{tabular}{lrrr} 
FACTORES DETERMINANTES DE ÉXITO & & \\
FORTALEZAS & PESO & Puntaje Ponderad \\
\hline Conocimiento del Negocio & 0.15 & 3 & 0.45 \\
Experiencia en el Mercado & 0.1 & 2 & 0.2 \\
Locales Propios & 0.15 & 2 & 0.3 \\
Integración Vertical como Negocio & 0.1 & 3 & 0.3 \\
\hline Subtotal & 0.5 & & 1.25 \\
\hline DEBILIDADES & & & \\
\hline Ingresante en Mercado de Belleza de Lujo & 0.15 & 2 & 0.3 \\
Nula Diversificación en el mercado Perú & 0.15 & 2 & 0.3 \\
Requiere Fuerte Inversión en Infraestructura & 0.1 & 3 & 0.3 \\
Requiere relaciones exclusivas para el Marketing & 0.1 & 2 & 0.2 \\
\hline SubTotal & & & 1.1 \\
\hline Total & & & 2.35
\end{tabular}

Fuente: Investigación propia (2019)

\subsection{Descripción del producto (bien o servicio) de la empresa}

AMERICA SALUD es una Cadena Peruana de Boticas, formada en el año 2003, dedicada íntegramente a la comercialización de productos de farmacia, artículos de perfumería y tocador, ofreciendo para ello la más alta calidad y garantía de sus productos y su esmerado servicio de atención al cliente. Dichos productos están ordenados por líneas y se muestran en la Tabla 36

\section{Tabla 36}

Línea de productos y ejemplos de marcas

\begin{tabular}{ll}
\hline Producto/Servicio & Ejemplos de Marca y/o nombre \\
\hline Farmacia & Pfizer, Bayer, Abbot \\
Productos Oncológicos & Oncovital, Janssen \\
Material médico Quirúrgico & Quirumed, bisturís
\end{tabular}




\begin{tabular}{ll}
\hline Productos Galénicos & Alkofarma (Agua de Azahar, Vinagre Wuyi) \\
Homeopatía & Grupo Huriach, Heel \\
Productos para diabéticos & Glocosem, Glucosamin, \\
Productos Naturales & Stevia,Sábila, \\
Perfumería & Shakira, Antonio Banderas, Adidas \\
Bazar & Loreal, Jhonson \\
Productos para Bebes & Jhonson, Pañales Huggies \\
\hline Fuente: Informe de Ventas América Salud (2019)
\end{tabular}

Fuente: Informe de Ventas América Salud (2019)

\subsection{Competencias básicas de la empresa.}

En base a los drivers que define el público objetivo las competencias básicas de América Salud y serán utilizadas por América Deluxe Health (ADH) son la permanente atención profesional de químicos farmacéuticos que para el caso de $\mathrm{ADH}$ serán profesionales dermatólogos y personal altamente calificado para venta de productos de lujo de belleza, personal altamente capacitado en la Línea de farmacia y perfumería para la venta de productos exclusivos, un horario amplio de atención cubierto por las 24 horas del día, un servicio de reparto a domicilio de acuerdo a la categoría del cliente, campañas de salud exclusivas y promociones y premios acorde a la categoría de las clientes. Ello permite fundamentar que los drivers de $\mathrm{ADH}$ son la Exclusividad del servicio personalizado, la exclusividad de los productos de lujo y los beneficios al cuidado de la salud que percibe el cliente.

- Servicio exclusivo personalizado

— Productos exclusivos

- Campañas exclusivas orientadas al cliente 


\subsection{Capacidades de marketing de la empresa.}

Las acciones de marketing para las líneas que produce y comercializa América Salud son básicas y se realizan en las quince tiendas. Estas cuentan con una gerente de Marketing que realiza las siguientes acciones

$\checkmark$ Programa de Servicio al cliente

$\checkmark$ Activaciones en los puntos de venta

$\checkmark$ Concursos y premios por campaña

$\checkmark$ Publicidad promocional

Para ello cuentan con un presupuesto de $\$ 35,000$ anuales y planes de acción que deben multiplicarse para el lanzamiento del nuevo servicio y orientarse al público objetivo 


\section{CAPÍTULO II. ESTUDIO DE MERCADO:}

El estudio de mercado del presente plan de marketing busca obtener información de las preferencias del público objetivo sobre los servicios ofrecidos, definir los parámetros de servicio, la propuesta de valor y la demanda potencial de América Deluxe Health en Lima Metropolitana. Para ello se desarrolló un estudio que comprendió métodos cualitativos (cuatro entrevistas en profundidad y cuatro focus group) y métodos cuantitativos(una encuesta orientada a 385 personas pertenecientes al público objetivo basada en 17 preguntas). Los resultados de la investigación cualitativa permitieron determinar que el público objetivo de American Deluxe Health es muy exigente tanto en la atención como en los requerimientos de pedido. Dicho público está concentrado en el cuidado de la piel y las limpiezas faciales. Para ello requiere que el local cuente con todos los productos que busca; eso incluye la variedad, el surtido y la calidad requerida ya que en Lima no existe un único local que expenda productos de lujo. Valora la atención, el trato y la ayuda requerida por el cliente y considera el servicio como una de las variables a medir ya que la atención no es personalizada, los vendedores ofrecen su marca y hay mucho público en las tiendas. Ellos expresan que la tendencia para la comercialización de productos dermatológicos es creciente en el Perú. Asimismo sostienen que la competencia en el mercado es alta siendo la facturación aproximada de aproximadamente 20 dólares siendo el sector mucho más dinámico los fines de semana. Los tres distribuidores mayoristas concentran el $85 \%$ de la importación ofreciendo promociones, ofertas y precios por volumen. El público objetivo relacionó la idea del negocio con exclusividad y poder encontrar variedad de productos en un solo lugar .Sugirieron que la tienda cuente con personal propio para atención y lugares de espera donde puedan ser atendidos por personal de negocio y por personal de servicio. Apreciaron que exista un lugar exclusivo para pruebas y el delivery. Además el local debe ser amplio y bonito. En cuanto a que la 
tienda sea únicamente dermatológica no fue resaltado en ninguno de los focus. Resaltaron adicionalmente que el personal esté preparado y capacitado para una buena atención con amabilidad y paciencia tomando en cuenta las personas que están en espera los que deben contar con algún entretenimiento. En cuanto a la propuesta de negocio opinan que es innovadora, interesante y llamativa y que el diferenciador principal es que el negocio este enfocado en el cliente mediante un servicio personalizado. Algunos sugirieron que cuente con un dermatólogo que ofrezca realizar un buen servicio de limpieza contando con todos los productos, se cuente con valet parking y que el local sea pet friendly

Los resultados de la investigación cuantitativa permitieron definir que los productos preferidos por el público objetivo son las cremas dermatológicas (62\%).Debido a ello $\mathrm{ADH}$ debe enfocarse en promover la venta de cremas dermatológicas que han sido las preferidas por el público objetivo sin descuidar los maquillajes y las colonias. Los usuarios utilizan una gran variedad de productos dermatológicos adquiridos en el Perú y el extranjero. La compra la realizan generalmente cada mes y/o cuando lo requieren. En cuanto al precio la inversión podría ser superior a $\$ 300$ el ticket promedio si los productos lo ameritan. Todos los participantes pagarían con tarjeta de crédito y la mayoría estaría dispuesta a participar en las activaciones para lo cual preferirían ser invitados por correo electrónico y/o redes sociales. En cuanto a la ubicación del local prefieren San Isidro y la promoción debería mediante redes.

La demanda esperada de acuerdo a la investigación de mercado es de 845 clientes que representan el $2.5 \%$ de la demanda total cubriendo el total esperado de operaciones que es de 5,070 atenciones.

Dichos resultados permitieron establecer estrategias a ser desarrolladas en el mix de marketing de América Deluxe Health y son las siguientes:

$\checkmark$ Brindar un panel especializado de prueba de artículos de belleza en el local de ventas 
Contar con un producto de lujo del mes para testeo aplicado a las clientes de $A D H$

Desarrollar la base de clientes y la actualización periódica del mismo.

$\checkmark$ Ejecutar la Campaña "Customer Day Off".

Ventas virtuales con promociones especiales

Activaciones exclusivas en eventos especiales.

Contar con un espacio dentro del local para clientes VIP con productos exclusivos

Lanzamiento de $\mathrm{ADH}$ mediante el auspicio de marcas exclusivas

Implementar las ventas a domicilio para productos exclusivos

Implementar DermaTrucks ADH en clubes privados por invitación

Firmar convenios con centros mundiales de belleza para el entrenamiento del personal de $\mathrm{ADH}$

$\checkmark$ Auspiciar eventos exclusivos fuera de Lima con productos especiales

$\checkmark$ Contar con Carteras de Productos Exclusivos ADH

$\checkmark$ Bench Marking con Centros Mundiales de belleza para la decoración del local.

$\checkmark$ Organizar Eventos exclusivos con Gurús del Sector.

$\checkmark$ Inversión selectiva de Marketing para público objetivo ya que es necesario potenciar la marca a fin de que el target conozca la propuesta de valor que brinda $\mathrm{ADH}$

$\checkmark$ Reconvertir progresivamente la cartera de cremas dermatológicos a productos orgánicos

\subsection{Problema de investigación}

Se debe resolver los siguientes problemas de investigación:

$\checkmark$ ¿Cómo obtener información de las preferencias del público objetivo sobre los servicios ofrecidos por ADH?

$\checkmark$ ¿Cómo definir los parámetros de servicio y la propuesta de valor de ADH?

$\checkmark \quad$ ¿Cuál es la demanda potencial de América Deluxe Health en Lima Metropolitana 


\subsection{Necesidades de información}

\section{Metodología cualitativa}

\section{Entrevista a Profundidad.}

— Información sobre el público objetivo

— Productos más buscados por el público objetivo

— Información sobre factores críticos de éxito del negocio

- Conocimiento de la competencia y el mercado.

- Averiguar quiénes son los proveedores más importantes en el sector

- Servicios claves para el público objetivo

— Información para definir la Propuesta inicial de valor para el negocio

- Conocer los procesos y tiempos de importación de artículos de belleza y salud de lujo

— Conocer los precios y márgenes de los productos de belleza y salud de lujo.

- Conocer la distribución y logística de los productos de lujo de belleza y salud.

\section{FOCUS}

- Definición de las características de Negocio

- Medición de la idea del negocio

- Medición de la Propuesta de valor

\section{Metodología Cuantitativa}

\section{Encuesta}

— Definición del atractivo de la oferta del negocio

— Determinación de la demanda potencial

— Información sobre el mix de la comunicación 


\subsection{Diseño de Investigación}

De acuerdo a Hernández (2014) la investigación es de tipo Mixta descriptiva ya que utiliza instrumentos cualitativos y cuantitativos para resolver los problemas de la Investigación.

\subsection{Método de investigación Cualitativo}

Se ha desarrollado los siguientes instrumentos cualitativos

\subsubsection{Entrevista a profundidad: Expertos del Sector}

\subsubsection{Objetivos de la Investigación}

Los objetivos de la investigación se definen para cada experto del sector

\subsubsection{Contenido}

Mediante el presente instrumento, se intenta conocer a través de las respuestas a las preguntas planteadas a los cuatro entrevistados el funcionamiento del sector de salud y belleza de lujo en el Perú. Específicamente se busca identificar los factores críticos de éxito del formato del negocio, identificar el hábito de compra de las clientes potenciales, el pronóstico del mercado potencial, el tipo de competencia en el sector así como la tendencia del mismo en el presente y a futuro determinando la viabilidad del negocio.

\subsubsection{Perfil del Participante}

Entrevistas realizadas en profundidad a los siguientes expertos

- Administrador de Servicios exclusivos

— Administrador de centro de salud exclusivo

- Cliente potencial Nivel socioeconómico A

— Proveedor de distribuidora de productos de lujo 


\subsubsection{Cuestionario}

Cada uno de los expertos cuenta con su propia guía de Pautas y estas se pueden apreciar en el anexo 7

\subsubsection{Resultados}

En las cuatro entrevistas desarrolladas en la semana del 21 al 27 de octubre de 2019 las conclusiones fueron las siguientes:

— El público objetivo de América Deluxe Health es muy exigente tanto en la atención como en los requerimientos de pedido. No solo busca el producto sino la atención y orientación personalizada sin importar el costo o precio a pagar.

— Dicho público está concentrado en el cuidado de la piel y las limpiezas faciales. Para ello requiere que el local cuente con todos los productos que busca; eso incluye la variedad, el surtido y la calidad requerida ya que en Lima no existe un único local que expenda productos de lujo.

— Se valora la atención, el trato y la ayuda requerida por la cliente

- Se considera el servicio como una de las variables a medir ya que es considerada vital para los entrevistados por lo que expresaron que el local debería contar con sala de espera, estacionamiento y por lo menos dos personas para atención.

— En el verano es donde se solicitan más cremas y tratamientos dermatológicos antiage además de jabones, lociones y otros productos.

— Todos coinciden que la tendencia para la comercialización de productos dermatológicos es creciente en el Perú sobre todo para el uso de cremas antiarrugas y bloqueadores solares. 
— También coinciden que la competencia en el mercado es fuerte ya que no solo las cadenas farmacéuticas ofrecen productos de lujo sino cadenas retail como Saga, Ripley y Paris.

- De acuerdo al experto de farmacología la facturación de dichos locales es de aproximadamente 20 dólares lo que para el sector es insuficiente. Ello puede deberse a que los expertos no se han enfocado en el sector de lujo. En lo que si coinciden es que el sector es mucho más dinámico los fines de semana.

— En el Perú existen tres distribuidores mayoristas que concentran el $85 \%$ de la importación: Alfaro, DEKO y Alvis lo que puede significar un pequeño oligopolio en el sector. Dichos distribuidores ofrecen promociones, ofertas y precios por volumen.

\subsubsection{Ficha técnica investigación cualitativa: focus}

\subsubsection{Objetivo de la Investigación}

Los objetivos de la investigación cualitativa del focus group son validar la propuesta de valor y conocer las expectativas del público potencial respecto a las características del servicio que se quiere ofrecer. En el focus se debe determinar las características generales del negocio, establecer la comprensión y valoración de la idea del mismo, validar la propuesta de valor del negocio, mesurar los servicios ofrecidos y definir los Factores Críticos de Éxito

\subsubsection{Perfil del Participante}

Dirigido a mujeres/hombres del nivel socioeconómico A entre 20 y 70 años que residan en Lima Metropolitana.

\subsubsection{Determinación de número de focus group que se realizarán}


El reclutamiento de los participantes se realizó a través de una ficha filtro para asegurarse que se cumplan los requisitos respectivos. El focus Group se desarrolla en función a la guía de pautas establecida.

En la Tabla 37 se aprecia la formación de grupos y sus características para el focus

\section{Tabla 37}

Formación de Grupos para Focus

\begin{tabular}{llllll}
\hline Focus & Cantidad & & & & \\
& personas & Sexo & Edad & NSE & Condición \\
\hline & & & $20-70$ & & Residan en Lima Metropolitana, e \\
& 8 & Mixto & años & A & ingresos mayores de 13105 soles
\end{tabular}

Fuente: Estudio de mercado (2019)

\subsubsection{Guía de Pautas}

La Guía de Pautas del focus se muestra en el anexo 8.

\subsubsection{Resultados del Focus}

Los cuatro focus fueron desarrollados desde el 23 al 30 de octubre y los resultados fueron los siguientes:

\section{- Características del Servicio.}

Los usuarios utilizan una gran variedad de productos dermatológicos adquiridos en el Perú y el extranjero como Cetaphil, Estee lauder, Lancome, Clinique, Biocare, Mac y Eucerin utilizando para ellos retails como Saga y Ripley en los que deben visitar varias tiendas para encontrar lo que buscan, la atención no es personalizada, los vendedores ofrecen su marca y hay mucha público en las tiendas. La compra la realizan generalmente 
cada mes y/o cuando lo requieren. A pesar de ello valoran que los retails cuentan con cierto grado de variedad y vendedores que, aunque no ofrezcan servicio personalizado, atienden sus necesidades como clientes.

\section{- Comprensión de la Idea del negocio}

El público objetivo relacionó la idea del negocio con exclusividad y poder encontrar variedad de productos en un solo lugar. Sugirieron que la tienda cuente con personal propio para atención y que cuenten con lugares de espera donde puedan ser atendidos por personal de negocio y por personal de servicio. Apreciaron además que exista un lugar exclusivo para pruebas y el delivery, el cual fue comparado al servicio de Herbalife. Además el local debe ser amplio y bonito para hacer una diferencia con las tiendas retails. En cuanto a que la tienda sea únicamente dermatológica no fue resaltado en ninguno de los focus. Resaltaron adicionalmente que el personal esté preparado y capacitado para una buena atención con amabilidad y paciencia tomando en cuenta las personas que están en espera los que deben contar con algún entretenimiento.

El nombre fue aceptado por todos los participantes ya que indicaron que representaba lo que significaba el negocio pero en el logo si hubo discrepancias en el color y en la relevancia del mismo respecto al producto ofrecido tanto en el diseño como en el posicionamiento.

\section{- Mesurar idea del negocio}

El factor más importante nombrado por los participantes para representar el servicio del negocio es que el servicio sea personalizado, tenga una salita de espera con entretenimientos, brinden servicios como limpiezas faciales y testers además de contar con los gustos de cliente codificados para que a su segunda visita ya los asistentes que laboran en la farmacia identifiquen sus gustos y preferencias. 
En cuanto al producto les gustaría encontrar toda la gama de productos dermatológicos, maquillajes y perfumes ofrecidos además de contar con gamas de productos que no se encuentren en el país.

En cuanto al precio la inversión podría ser superior a $\$ 300$ el ticket promedio si los productos lo ameritan.

Todos los participantes pagarían con tarjeta de crédito y la mayoría estaría dispuesta a participar en las activaciones para lo cual preferirían ser invitados por correo electrónico y/o redes sociales. En cuanto a la ubicación del local prefieren San Isidro.

\section{- Validación de las propuesta de Marketing}

En cuanto a la propuesta de negocio opinan que es innovadora, interesante y llamativa y que el diferenciador principal es que el negocio este enfocado en el cliente mediante un servicio personalizado. Algunos sugirieron que cuente con un dermatólogo que ofrezca realizar un buen servicio de limpieza contando con todos los productos, se cuente con valet parking y que el local sea pet friendly

\subsection{Método de investigación Cuantitativo}

\subsubsection{Objetivos de la Investigación}

Los objetivos de la investigación son

a) Cuantificar la propuesta de valor del Plan de Marketing,

b) Confirmar la demanda del público objetivo para asumir el servicio

c) Cuantificar las características del Mix de Marketing.

\section{Contenido}

Se sondea a través de las respuestas a las preguntas planteadas a los entrevistados, características específicas de las expectativas del producto como variedad de servicios, 
precios, calidad y la aceptación o no de la propuesta de valor del Plan de Marketing como también sistemas de pago preferidos por las usuarias, tipos de promoción preferidas, forma de contacto con el cliente, ubicación de local, inversión aproximada de la muestra

\subsubsection{Proceso de Muestreo}

El universo está compuesto por mujeres y hombres pertenecientes al nivel socio económico A de Lima y suman 261,144. Para la encuesta la representatividad es del $100 \%$ ya que se están considerando en la muestra todos los clientes potenciales que residen en la zona y utilizan servicios de salud/ belleza de lujo.

\section{Cálculo del Tamaño de Muestra}

Debido a que el mercado potencial supera los 100,000 clientes para calcular el tamaño de muestra, se utiliza la fórmula de población infinita

$$
n=\frac{z^{2} p q}{e^{2}}
$$

Donde:

$\mathrm{n}=$ tamaño de muestra

$\mathrm{z}=$ nivel de confianza elegido (valor elegido al $95 \%$ que equivale a 1.96 )

$\mathrm{p}=$ porcentaje de éxito $(0.5)$ 
$q=$ porcentaje de fracaso $(p-q=0.5)$

e = error máximo permitido $(5 \%)$

Reemplazando los datos en la fórmula se estima que el tamaño mínimo de la muestra para que ésta tenga validez estadística es de 385 personas en Lima Metropolitana.

La investigación es del tipo aplicada de diseño cuantitativa, ya que examina los perfiles de las personas que puedan estar interesadas en el producto ofrecido Los resultados a partir de este tipo de investigación podrán ser utilizados de manera inmediata en la implementación del proyecto o plan de negocios

\subsubsection{Diseño de Instrumento}

Se utilizará un cuestionario de preguntas cerradas para desarrollar una encuesta la cual será entregada al público objetivo de acuerdo a la siguiente metodología:

- Se elabora un cuestionario con las preguntas pertinentes fruto de la investigación primaria y del resultado de las entrevistas de profundidad.

- Se realiza una prueba piloto, para verificar si existe facilidad de responder a las preguntas y si ellas desencadenan las respuestas necesarias para el análisis.

- Se realiza el trabajo de encuesta.

- Obtenida la cantidad de respuestas necesarias, se procederá a tabular en una matriz, la cual servirá de insumo para proponer conclusiones y recomendaciones.

\subsubsection{Propuesta del Instrumento}

El cuestionario de la encuesta se aprecia en el anexo 10. 


\subsubsection{Resultados}

Los resultados de la encuesta realizada del 1 al 11 de noviembre de 2019 se aprecian en el anexo 16.

\subsection{Análisis del producto}

De acuerdo a la Investigación de mercado los productos preferidos por el público objetivo son las cremas dermatológicas (62\%) mientras que los maquillajes y las colonias y perfumes cuentan con el 18\% de aceptación. Ello puede deberse a la tendencia mundial por la cual las cremas naturales humectantes son la moda del momento ya que contribuyen a fortalecer y mantener la tersura de manos, piel y cara del público usuario siendo de uso diario mientras que los demás productos son de uso ocasional. Debido a ello ADH debe enfocarse en promover la venta de cremas dermatológicas que han sido las preferidas por el público objetivo sin descuidar los maquillajes y las colonias que gozan de la preferencia del público objetivo. Es de resaltar, por informaciones de la investigación cualitativa, que este tipo de cliente prefiere encontrar todos los productos en un solo lugar ya que es más cómodo para ellos encontrarlos en un solo lugar. La propuesta de valor en la investigación cuantitativa sostiene que 7 de cada 10 personas del target comprarían en $\mathrm{ADH}$

\subsection{Tendencias del producto.}

Debido a que la tendencia del producto va en aumento se propone un mix de productos encabezados por cremas dermatológicas acompañadas de maquillajes y colonias.

En la Tabla 38 se muestra el mix de productos para America Deluxe Health 


\section{Tabla 38}

Mix de Productos América Deluxe Health

\begin{tabular}{lll}
\hline Cremas & Maquillajes & Colonias /Perfumes \\
\hline Clinique & Clinique & Carolina Herrera \\
Estee Lauder & MAC & Chanel \\
Dior & Dior & Dolce Gabanna \\
Bioderma & Estee Lauder & Imperial Majesty \\
Chanel & Chanel & Eau d Hadrien \\
Isdn & Lositam & Bulgary \\
Cetaphil & Anastasia & Ninna Ricci \\
La Roche Posay & & Calvin Kline \\
Guerbin & & \\
\hline Fuente: Investigación de Mercado (2019) &
\end{tabular}

Fuente: Investigación de Mercado (2019)

Dicha distribución, precios de costo, venta y márgenes se muestran en el anexo 11.

\subsection{Análisis de ventas.}

De acuerdo a la investigación de mercado de acuerdo a la intención de compra del público objetivo, este asciende a que el $62 \%$ adquiriría definitivamente el producto mientras que el 30\% podría adquirirlo. Ello puede deberse a que en el Perú no existe un lugar que ofrezca cremas, maquillaje y perfumes de lujo en una sola ubicación, además de garantizar detalles de exclusividad, servicio personalizado y calidad que hagan sentir al usuario como cliente especial en un lugar en el cual los especialistas lo conozcan por su nombre y sus gustos. 
En el estudio de mercado que está detallado en el anexo 17 se aprecia que que se espera atender el $2 \%$ del mercado objetivo por lo que se espera atender 845 clientes el primer año que regresaran por lo menos seis veces a adquirir sus cremas y sus lociones haciendo un total de 5070 operaciones.

\subsection{Tendencias del comportamiento del consumidor}

De acuerdo a los resultados de la encuesta se puede determinar el comportamiento del público objetivo el que se esquematiza en la Tabla 39

\section{Tabla 39}

Comportamiento del Consumidor

\begin{tabular}{ll}
\hline Consumidor Objetivo & Hombres y mujeres de nivel socio \\
& económico A con edades comprendidas \\
& entre 20 y 70 años
\end{tabular}

\begin{tabular}{llllll}
\hline Tipo de compra & Cremas & $(62 \%)$ & Maquillaje & $(18 \%)$ & y
\end{tabular}

colonias $(18 \%)$

\begin{tabular}{ll}
\hline Frecuencia de Compra & Cada dos meses (68\%) \\
\hline Preferencia de Atención & Entre una (19\%) o dos personas (45\%) \\
\hline Lugar de Residencia & San Isidro (49\%) y Miraflores (21\%)
\end{tabular}

Fuente: Investigación de Mercado (2019)

Al existir cremas, maquillajes y colonias de alta gama para todas las edades sin importar el sexo y contar ADH con servicio para dicho público se considera lo definido por Arellano (2017) que precisa seis estilos de vida para el peruano promedio. Estos son: progresistas, sofisticados, austeros, formalistas, modernas y conservadoras 
De acuerdo al target seleccionado ADH se orienta únicamente a los Sofisticados cuyas características se aprecian en la Tabla 40

Tabla 40

Características de los Sofisticados

\begin{tabular}{ll}
\hline \multicolumn{1}{c}{ Característica } & \multicolumn{1}{c}{ Definición } \\
\hline Ingresos & $\begin{array}{l}\text { Top. Son los más altos de todos los estilos de } \\
\text { vida }\end{array}$ \\
Educación & Superior a la de los otros estilos de vida \\
Estilos de Vida & Modernos, educados, liberales, cosmopolitas \\
Tendencias de Consumo & y valoran mucho la imagen personal \\
Importancia Social & Innovadores y cazadores de tendencia \\
& Les importa mucho su estatus, siguen la moda \\
& y son asiduos consumidores de productos \\
& light
\end{tabular}

Fuente: Adaptado de Arellano, R (2017) Mucho más que tener: LATIR

\subsection{Tendencias de medios, distribución, precio.}

\section{Medios}

De acuerdo a la investigación de mercado el público objetivo tiene una misma forma de informarse y participar en un mercado determinado. Para informarse prefiere utilizar el Internet (61\%) y el contacto boca oreja (19\%) mientras que para participar prefiere ser invitado (58\%) y mediante contacto con personas de su mismo nivel social (19\%)

\section{Distribución}

El público objetivo prefiere que el local quede ubicado en San Isidro (78\%) debido a que el público objetivo reside y/o labora en dicho distrito por lo que la cercanía es uno de los factores que incide para la elección, mientras que un $16 \%$ preferiría que quedara en Miraflores. La distribución es personalizada para que los clientes puedan conocer el local. 
En la figura 6 se aprecia la ubicación del local en San Isidro

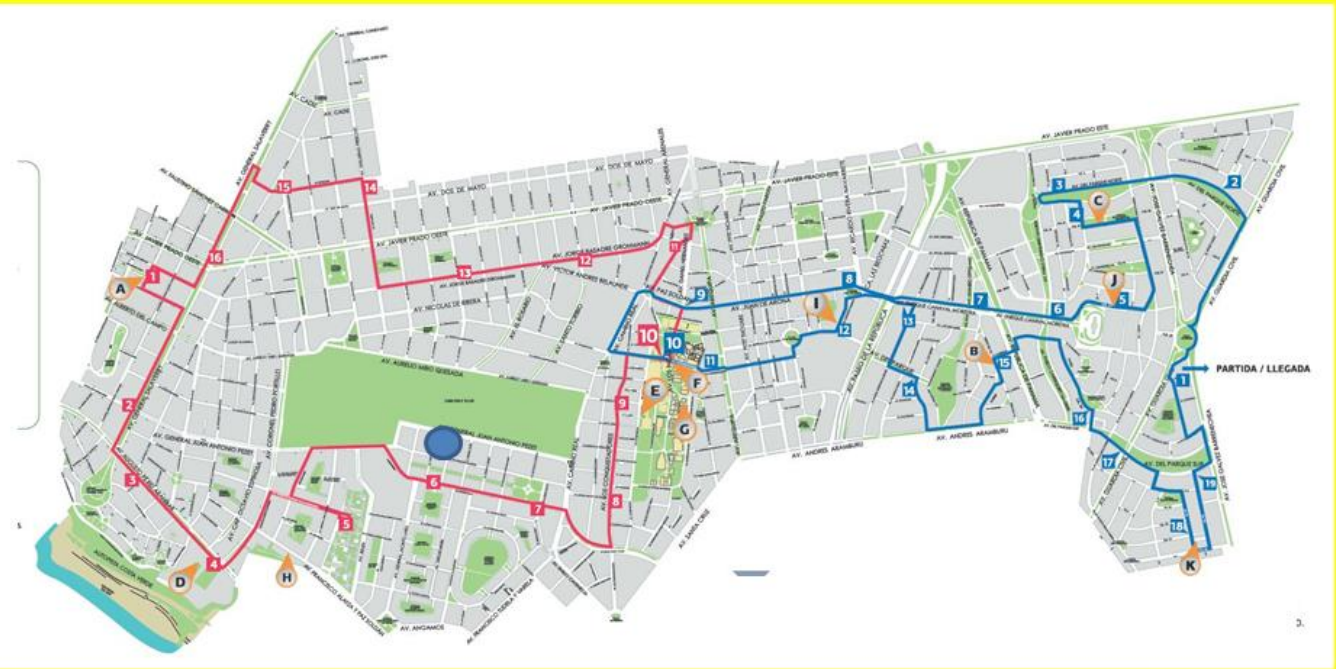

Figura 6

Ubicación ADH San Isidro

Adaptado Mapa San Isidro (2019)

Precio

El precio de los productos es un factor menor ya que según el estudio de mercado este tipo de público no lo valora como a la calidad (4.59), a la variedad y novedad del servicio (4.33) y a la exclusividad (4.08). El ticket promedio de venta fluctúa entre 300 y 600 dólares por visita $(53 \%)$ y prácticamente todas las compras se realizan por tarjeta de crédito.

\subsection{Segmentos del mercado que compran el producto}

El segmento de mercado que adquiere los productos dermatológicos y colonias de lujo son hombres y mujeres que pertenecen al nivel socio económico A y se preocupan por cuidados en la piel ya sea con cremas y maquillajes además de comprar perfumes de marca. El negocio no está pensado en ventas masivas por lo que la diferenciación es uno de los factores de éxito para este mercado. 


\subsection{Foda Cruzado}

Kotler \& Keller (2012) definen el análisis FODA como un método para evaluar de una manera general las fortalezas, oportunidades, debilidades y amenazas de una empresa, además es una forma de evaluar el entorno interno y externo de marketing.

En la Tabla 41 se muestra la matriz FODA cruzada con las estrategias derivadas del análisis externo e interno. 
Tabla 41 Matriz, FODA

\begin{tabular}{ll}
\hline \multicolumn{1}{c}{ FORTALEZA } & \multicolumn{1}{c}{ DEBILIDAD } \\
\hline F1 Conocimiento del Negocio & D1 Nuevo en el Mercado de Belleza de Lujo \\
F2 Experiencia en el Mercado & D2 Nula Diversificación en el mercado Perú \\
F3 Locales Propios & D3 Requiere Fuerte Inversión en Infraestructura \\
F4 Integración Vertical como Negocio & D4 Requiere relaciones exclusivas \\
F5 Ubicación & D5 No se cuenta con un portafolio completo de \\
F6 Personal dermatologico especializado & maquillajes y cremas \\
& D6 No se cuenta con valet parking \\
F7 Servicio Exclusivo & D7 Local no es pet friendly \\
& D8 Local no cuenta con lugar de espera VIP \\
& D9 Todos los productos no son orgánicos
\end{tabular}

OPORTUNIDAD

O1 Crecimiento del mercado peruano de belleza

O2 Globalización del mercado de belleza

03 Crecimiento de mercado objetivo

O4 Pago justo por el servicio ofrecido

O5 Desarrollo de la tecnología

$$
\text { AMENAZA }
$$

A1 Alta Oferta Mundial de belleza de lujo

A2 Escasas posibilidades de diferenciación

A3 Fuerte demanda por personal especializado

A4 Selectividad del Mercado Objetivo

A5 Inestabilidad Política disolución congreso
Desarrollo de un panel especializado de prueba de

articulos de belleza en el local de ventas (F3,F6,01) Activaciones exclusivas en eventos especiales(D1,03)

Contar con un producto de lujo del mes para testeo Espacio para clientes VIP con productos exclusivos (F2,F7, 02) (D2, D8, 02)

Desarrollo de la base de clientes y actualización del Lanzamiento ADH con auspicio de marca exclusiva mismo (F1,03) (D3,01)

Campaña "Customer Day Off" (F4,F5,04) Venta a Domicilio para productos exclusivos(D6,05)

Ventas virtuales con promociones especiales Campaña exclusiva incluyendo productos para

$(\mathrm{F} 2,05) \quad$ mascotas $(\mathrm{D} 7,03)$

Implementación DermaTruck en clubes privados

Implementación DermaTruck en clubes privados Cartera de Productos Exclusivos ADH (A1,D5)
por invitación (A2,F3)

Eersonal en convenio con centros

mundiales de belleza (A3, F4)

Auspicio de eventos exclusivos fuera de Lima con

productos especiales (A2,F1,F7)

Eventos controlados de acuerdo a tensión política Inversión selectiva de Marketing para publico objetivo

$(\mathrm{A} 5, \mathrm{~F} 4)$

(D1,A2,A4)

Reconvertir la cartera de productos a productos orgánicos (D9,A2,A1) 


\section{Fortaleza-Oportunidad}

$\checkmark$ Gracias a contar con un local propio y aprovechando el crecimiento del mercado peruano de belleza se brindará un panel especializado de prueba de artículos de belleza en el local de ventas (F3,F6, 01)

$\checkmark$ Debido a la experiencia en el mercado con el que cuenta la corporación y a la globalización del mercado de belleza se contará con un producto de lujo del mes para testeo aplicado a las clientes de $A D H(\mathrm{~F} 2, \mathrm{~F} 7,02)$

$\checkmark$ El conocimiento del negocio y el crecimiento del mercado objetivo deben permitir desarrollar la base de clientes y la actualización periódica del mismo (F1,03)

$\checkmark$ Estar integrados verticalmente permite contar con una ventaja diferencial para aprovechar que el cliente puede pagar el precio justo. Para ello se ejecutará la Campaña "Customer Day Off" (F4,F5, 04)

$\checkmark$ La experiencia en el mercado peruano y el desarrollo de la tecnología permite a ADH Ventas virtuales con promociones especiales $(\mathrm{F} 2,05)$

\section{Debilidad- Oportunidad}

$\checkmark$ Para hacerse conocido en el mercado y conociendo la tendencia creciente del mismo se realizarán activaciones exclusivas en eventos especiales (D1,03)

$\checkmark$ Al no estar diversificados en el mercado local para aprovechar la oportunidad de un mercado globalizado se requiere contar con un espacio dentro del local para clientes VIP con productos exclusivos (D2,D8, 02)

$\checkmark$ A fin de contrarrestar la fuerte inversión requerida y aprovechando el crecimiento del mercado de belleza peruano el lanzamiento de $\mathrm{ADH}$ se puede efectuar con el auspicio de marcas exclusivas (D3,01) 
Implementar las ventas a domicilio para productos exclusivos a fin de evitar que las clientes tengan que movilizarse a la tienda y aprovechando el desarrollo tecnológico donde los clientes podrán elegir sus productos $(\mathrm{D} 6,05)$

\section{Amenaza-Fortaleza}

Frente a las escasas oportunidades de diferenciación aprovechando que la corporación cuenta con infraestructura se implementará DermaTrucks $A D H$ en clubes privados por invitación $(\mathrm{A} 2, \mathrm{~F} 3)$

$\checkmark$ Al requerir personal capacitado y que se encuentre identificado con la marca aprovechando que la corporación se encuentra integrada verticalmente el entrenamiento del personal de $\mathrm{ADH}$ se realizará en convenio con centros mundiales de belleza (A3, F4)

$\checkmark$ Para diferenciar la marca y gracias al conocimiento del negocio se auspiciarán eventos exclusivos fuera de Lima con productos especiales (A2,F1)

\section{Debilidad Amenaza}

$\checkmark$ Para reducir el riesgo de que existe una alta oferta mundial de productos de lujo y ante la novedad de $\mathrm{ADH}$ en el mercado peruano es necesario contar con una cartera de Productos Exclusivos ADH a fin que el público objetivo conozca la marca(A1,D1)

$\checkmark$ Ante las escasas oportunidades de diferenciación y la nula diversificación en el Perú se hace necesario contar con un local altamente diferenciado para lo que se realizará un Bench Marking con Centros Mundiales de belleza para la decoración del local $(\mathrm{A} 2, \mathrm{D} 2)$

$\checkmark$ Para disminuir el riesgo de la selectividad del público objetivo y garantizar la presencia de ese público se organizará eventos exclusivos con Gurús del Sector $(\mathrm{A} 4, \mathrm{D} 4)$ 
$\checkmark$ Se requiere una Inversión selectiva de Marketing para público objetivo ya que es necesario potenciar la marca a fin de que el target conozca la propuesta de valor que brinda ADH.(D1,A2,A4)

$\checkmark$ Reconvertir progresivamente la cartera de cremas a productos orgánicos (D9,A2,A1) 


\section{CAPITULO III: PLAN DE MARKETING}

ADH está dirigida a un público comprendido entre los 20 y los 70 años, que recibe ingresos superiores a $\$ 3,800$, residen en los distritos de Miraflores, San isidro, San Borja, La Molina y Santiago de Surco.

ADH desarrollará su posicionamiento ofreciendo cremas, maquillajes y colonias de lujos como una alternativa natural orientada a aquellos consumidores que cuidan su salud sin importarle el precio a cancelar en un ambiente exclusivo, personalizado y de calidad.

Las seis macro estrategias establecen que, en la estrategia de cartera a través de la matriz de Ansoff se define que, inicialmente, $A D H$ se encuentra en una etapa de Diversificación ya que se trata de un mercado y un producto nuevo mientras que la Matriz BCG indica que se trata de productos interrogantes con una alta tasa de crecimiento de mercado y una baja tasa de market share. En cuanto a la estrategia de segmentación esta define un único segmento el cual prefiere la calidad, exclusividad y variedad de productos dirigida a un $1.8 \%$ de mercado. La estrategia de posicionamiento señala que ADH busca posicionarse como líder del mercado frente a la competencia siendo el primero en la mente del consumidor. Por otra parte, la estrategia genérica indica que ADH empleará la estrategia de diferenciación pues se concentrará en ofrecer un producto natural mediante un servicio de atención personalizado con información clara y precisa a través de la atención de asesores capacitados y empáticos. La estrategia competitiva $A D H$ califica como empresa especializada debido a que ofrecerá productos orientados a un nicho de mercado determinado. Finalmente la macro estrategia de fidelización está orientada a la fidelización de los heavy users mediante una comunicación activa con los clientes brindándoles toda la información sobre los productos, los servicios y las novedades que 
ADH planea brindar en el mercado y personal especializado para el Soporte y apoyo constante para impulsar la venta en las activaciones y local exclusivo.

Las estrategias funcionales están orientadas a lograr los objetivos del plan de marketing y se dividen en cuatro estrategias de producto, una estrategia de precio, seis estrategias de plaza y ventas y seis estrategias de promoción y comunicación de marca.

Finalizado el análisis externo donde se analiza el sector, industria y competencia y el análisis interno donde se precisas las fortalezas y debilidades de América salud y la investigación de mercado que permite demostrar que los objetivos de Marketing de ADH son viables y son los siguientes:

Incrementar las ventas en $\$ 171,423$

Incrementar la rentabilidad en $8 \%$

Obtener el posicionamiento de ADH como "líder" en el primer año de operación

Reconvertir la cartera de cremas a productos orgánicos consiguiendo que el $25 \%$ de la venta de cremas sea orgánica

\subsection{Relación entre el Plan Estratégico y el Plan de marketing (objetivos estratégicos y objetivos de marketing)}

El presente plan de Marketing está alineado con el plan estratégico de la empresa y ayudará al cumplimiento de los objetivos de América Deluxe Health y tiene por objetivo articular diversas estrategias para promover y garantizar el éxito de la comercialización de sus productos. Dichos objetivos están enlazados a los objetivos específicos del plan estratégico de la Corporación y se visualizan en la tabla 42. 


\section{Tabla 42}

Relación Objetivos Plan de Marketing versus

\begin{tabular}{lllll}
\hline Objetivos del Plan de Marketing de la & Objetivo Plan Estratégico de la \\
Corporación 2020 & Corporación 2022 & \\
\hline Incrementar ventas ascendentes & a & Incrementar ventas ascendientes por \\
$\$ 6,702,067$ & $\$ 8,630,000$ al 2022. & \\
\hline Mejorar la rentabilidad al 18\% & Mejorar la rentabilidad a 20\% para el \\
& 2022 & \\
\end{tabular}

Elaboración Grupo de Tesis (2019)

\subsection{Formulación de objetivos: venta, margen, comerciales, de producto,} comunicación.

En la Tabla 43 se muestra la participación de mercado de América Salud en el mercado de cremas, maquillajes y perfumes de lujo

Tabla 43

Participación de Mercado América Salud

\begin{tabular}{lllll}
\hline Empresa & $\mathbf{2 0 1 9}$ & \% & $\mathbf{2 0 2 0}$ & \% \\
& & & & \\
\hline América Salud & $\$ 384,594$ & $3.16 \%$ & $\$ 556,017$ & $4 \%$ \\
& & & & \\
\hline Competencia & $\$ 11,756,495$ & $96.84 \%$ & $\$ 13,344,408$ & $96 \%$ \\
\hline Total & $\$ 12,141,089$ & $100 \%$ & $\$ 13,900,425$ & $100 \%$ \\
\hline Elaboración Propia (2019) & & & & \\
\hline
\end{tabular}

Kotler \& Keller (2012) sostienen que los objetivos de marketing proporcionan puntos de referencia específicos y cuantitativos que se pueden usar para medir el progreso 
hacia el logro de las metas de marketing. Las metas sin objetivos en esencia no tienen sentido porque es imposible medir su progreso

En la tabla 44 se aprecian los objetivos de marketing de ADH

Tabla 44 Objetivos de marketing ADH

\begin{tabular}{|c|c|c|c|c|}
\hline Objetivo & Unidad de Medición & Cómo & 2019 & 2020 \\
\hline Incrementar las ventas en $\$ 171,423$ & $\begin{array}{c}\text { Ventas expresadas en } \\
\text { dólares }\end{array}$ & Plan de Marketing & $\$ 384,594$ & $\$ 556,017$ \\
\hline Incrementar la rentabilidad en $8 \%$ & $\%$ de Margen operativo & Flujo de caja & $18 \%$ & $26 \%$ \\
\hline $\begin{array}{l}\text { Obtener el posicionamiento de } \\
\text { ADH como "líder" en el primer } \\
\text { año de operación. }\end{array}$ & $\begin{array}{l}\text { \% de personas del target } \\
\text { que lo reconocen como } \\
\text { tal. }\end{array}$ & $\begin{array}{l}\text { Investigación de } \\
\text { mercado }\end{array}$ & $3 \%$ & $15 \%$ \\
\hline $\begin{array}{c}\text { Reconvertir la cartera de cremas a } \\
\text { productos orgánicos }\end{array}$ & $\begin{array}{c}\% \text { de cremas orgánicas } \\
\text { en portafolio }\end{array}$ & Portafolio ADH & $10 \%$ & $25 \%$ \\
\hline
\end{tabular}

Fuente: Elaboración propia (2019)

\subsection{Seleccionar mercado objetivo}

De acuerdo al estudio de mercado el público objetivo se caracteriza y clasifica en cuatro criterios y seis variables de segmentación.

Ello se aprecia en la Tabla 45 


\section{Tabla 45}

Mercado Objetivo

Criterio de Variable Segmento Descripción
segmentación

\begin{tabular}{llll}
\hline Geográfica & $\begin{array}{l}\text { Distritos de Zona } 7 \\
\text { Lima } \\
\text { Metropolitana }\end{array}$ & $\begin{array}{l}\text { Personas de nivel socio económico } \\
\text { A que habiten en La Molina, San } \\
\text { Borja, Miraflores, San Isidro y } \\
\text { Santiago de Surco. }\end{array}$ \\
\hline Demográficos & NSE & A & $\begin{array}{l}\text { Estas personas cuentan con dinero } \\
\text { disponible y se interesan en su salud } \\
\text { con cremas, maquillajes y perfumes } \\
\text { de lujo. }\end{array}$ \\
& Género & $\begin{array}{l}\text { Hombres } \\
\text { mujeres }\end{array}$ & $\begin{array}{l}\text { Tanto hombres y mujeres que } \\
\text { consumen cremas dermatológicas, } \\
\text { colonias y maquillajes de lujo. }\end{array}$
\end{tabular}

Rango de edad $20-70$ años Edad en la que se preocupan por el cuidado del cuerpo y la piel y está en su poder decidir en qué gastar su dinero ya que son sofisticados.

\begin{tabular}{|c|c|c|}
\hline Psicográfico & $\begin{array}{l}\text { Estilos de Sofisticados } \\
\text { Vida }\end{array}$ & $\begin{array}{l}\text { Los sofisticados constituyen el } \\
\text { segmento de género mixto con } \\
\text { mayores ingresos que el promedio. } \\
\text { Modernos, educados liberales, } \\
\text { cosmopolitas que valoran mucho la } \\
\text { imagen personal. Les importa } \\
\text { mucho su estatus valorando el } \\
\text { servicio y la calidad. }\end{array}$ \\
\hline Conductual & $\begin{array}{lll}\text { Consumo de } & \text { Constante } \\
\text { artículos de } & \\
\text { belleza de lujo } & \end{array}$ & $\begin{array}{l}\text { Personas que compran productos } \\
\text { dermatológicos de } \\
\text { bimensualmente. }\end{array}$ \\
\hline
\end{tabular}

Elaboración propia (2019)

Se llegará al mercado objetivo a través de la tienda principal ubicada en el distrito de San Isidro de Lima Metropolitana. La presentación se realizará en la tienda y utilizará activaciones a través de desfiles y eventos exclusivos. Además, se alcanzará al target señalado mediante la página web, información virtual y redes sociales, ya que es 
normalmente el medio utilizado por el consumidor objetivo para informarse. Los objetivos principales de estas herramientas serán el branding, el brand equity y la comunicación de iniciativas como: introducción de nuevas marcas, promociones exclusivas, activaciones, entre otros.

\subsection{Desarrollar el posicionamiento del producto.}

La propuesta de valor de ADH es:

"Somos un centro exclusivo de salud y belleza personalizada que brinda una alternativa para la generación de bienestar del cuerpo y la mente de las usuarias mediante productos dermatológicos y de belleza exclusivos en un solo lugar de Lima Metropolitana”

En consecuencia el posicionamiento de la empresa es el siguiente:

"ADH ofrece cremas, maquillajes y colonias de lujos como una alternativa natural orientada a aquellos consumidores que cuidan su salud sin importarle el precio a cancelar en un ambiente exclusivo, personalizado y de calidad".

\subsection{Macro estrategias}

\subsubsection{Estrategia de cartera}

Santesmases (2012) propone la siguiente clasificación de los objetivos de expansión y crecimiento utilizando la matriz de Igor Ansoff y la matriz de Boston Consulting Group (BCG).

Esta se aprecia en la figura 7 


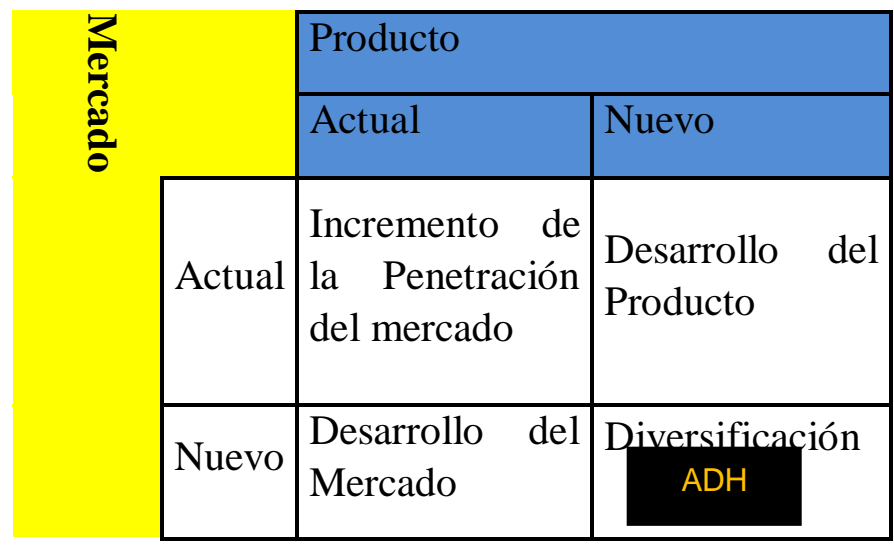

\section{Figura 7}

Matriz de expansión Producto/Mercado

Adaptado de: Santesmases (2012) "Fundamentos del Marketing Sexta Edición”

De ello se deduce que inicialmente $A D H$ se encuentra en una etapa de Diversificación ya que se trata de un mercado y un producto nuevo.

En la figura 8 se desarrolla la Matriz BCG en la cual se aprecia la posición relativa de los productos $\mathrm{ADH}$ 


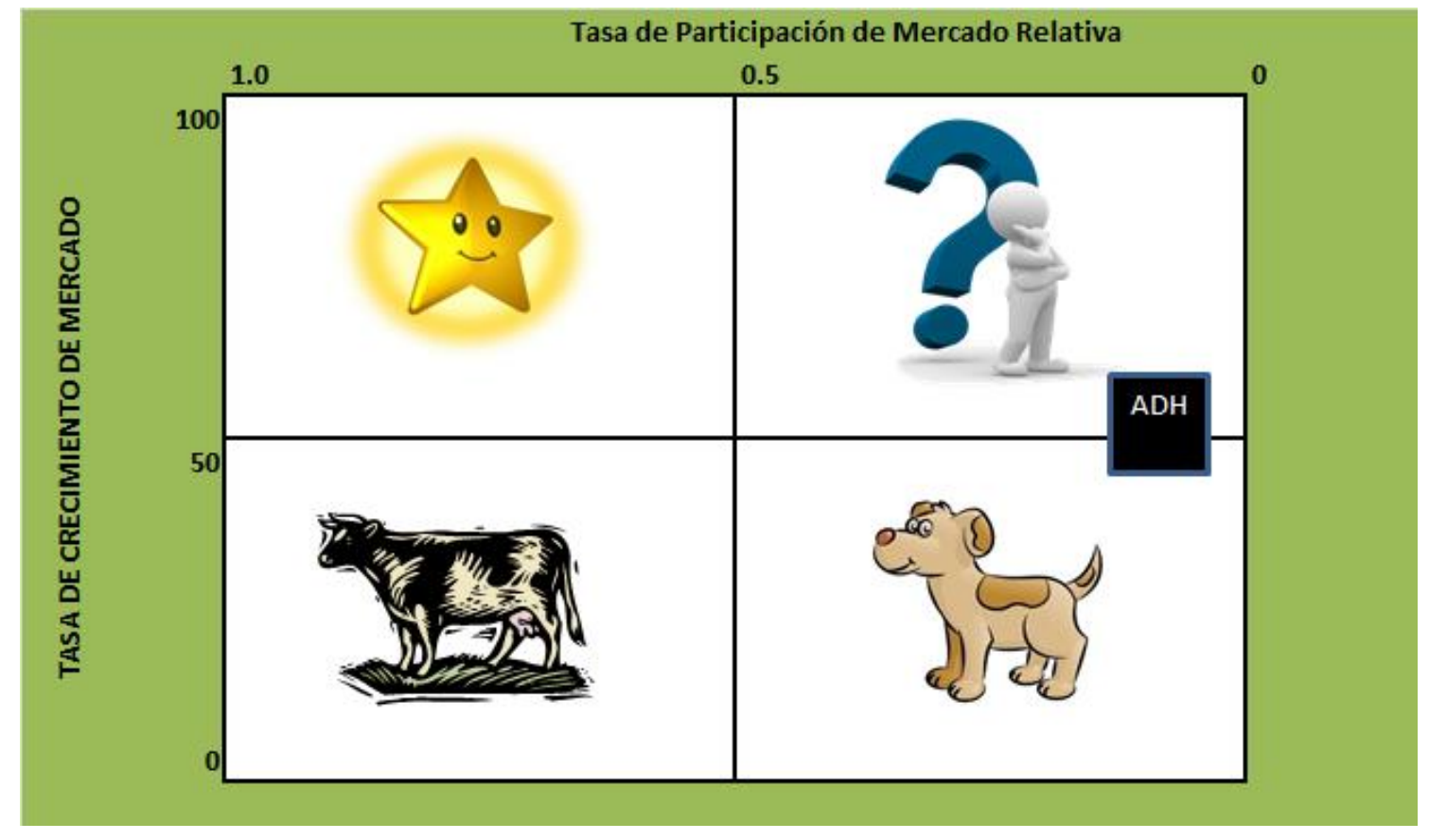

\section{Figura 8}

\section{Matriz BCG}

Adaptado de Santesmases (2012) "Fundamentos del Marketing Sexta Edición"

En esta matriz se observa que la participación de mercado es baja ya que ADH es una nueva unidad de negocio sin embargo el crecimiento del mercado es importante por lo que se encuentra inicialmente el signo interrogativo.

En la tabla 46 se aprecia las estrategias de crecimiento en el corto, mediano y largo plazo de America Deluxe Health

A futuro, consolidada la demanda, la empresa será líder en el sector por lo que se invertirá para el crecimiento de la corporación. 


\section{Tabla 46}

Estrategias de Crecimiento en el tiempo

\begin{tabular}{|c|c|}
\hline Plazos de Tiempo & Estrategias de Crecimiento \\
\hline Corto Plazo (uno a tres años) & $\begin{array}{ll}\checkmark & \text { Cremas Dermatológicas (60\%), } \\
& \text { colonias (20\%) y maquillajes (20\%). } \\
\checkmark & \text { Un local de Venta } \\
\checkmark & \text { Dos Activaciones } \\
\checkmark & \text { Un evento exclusivo }\end{array}$ \\
\hline Mediano Plazo (tres a cinco años) & $\begin{array}{ll}\checkmark & \text { Cremas Dermatológicas }(50 \%), \\
& \text { colonias (20\%) y maquillajes (30\%). } \\
\checkmark & \text { Un local de Venta } \\
\checkmark & \text { Cuatro Activaciones } \\
\checkmark & \text { Dos eventos exclusivos }\end{array}$ \\
\hline Largo Plazo (Mas de cinco años & $\begin{aligned} \checkmark & \text { Cremas Dermatológicas }(40 \%), \\
& \text { colonias }(20 \%) \text { y maquillajes }(20 \%) \\
& \text { y Otros }(20 \%) . \\
\checkmark & \text { Un local de Ventas } \\
\checkmark & \text { Seis Activaciones } \\
\checkmark & \text { Tres eventos Exclusivos }\end{aligned}$ \\
\hline
\end{tabular}

Elaboración Propia (2019)

\subsubsection{Estrategia de Segmentación}

De acuerdo a la investigación de mercado solo existe un segmento de mercado al cual va orientado $\mathrm{ADH}$ por lo que la estrategia de segmentación se aprecia en la Tabla 47 


\section{Tabla 47}

Estrategia de Segmentación

\begin{tabular}{llllr}
\hline Segmento & $\begin{array}{l}\text { Aspectos que valora el } \\
\text { segmento }\end{array}$ & $\begin{array}{l}\text { Estrategia } \\
\text { Segmentación }\end{array}$ & de \\
& & & \\
\hline Personas que ganan más de & $\bullet$ & Calidad del producto & Local exclusivo y servicio \\
$\$ 3,854$ de nivel socio & $\bullet$ & Exclusividad & personalizado & para \\
económico A y residen en & $\bullet$ & Variedad & de la población de Lima \\
los distritos de Miraflores, & & \\
San Isidro, San Borja, & & \\
Surco y La Molina & & \\
\hline Elaboración Propia (2019)
\end{tabular}

Asimismo se propone una segmentación por edades de acuerdo al tipo de clientes esperados en la Tabla 48 en base a los resultados de la investigación cuantitativa.

Tabla 48

Segmentación Esperada por tipo de clientes

\begin{tabular}{ccc}
\hline Edades & Sexo & $\begin{array}{c}\text { Porcentaje Atención } \\
\text { esperada }\end{array}$ \\
\hline $18-30$ & Ambos & $20 \%$ \\
$30-45$ & Hombres & $10 \%$ \\
$30-45$ & Mujeres & $25 \%$ \\
$45-60$ & Mujeres & $25 \%$ \\
$45-60$ & Hombres & $10 \%$ \\
$60-70$ & Ambos & $10 \%$ \\
\hline
\end{tabular}

Fuente: Elaboración Grupo (2020)

\subsubsection{Estrategia de Posicionamiento}

Ferrell \& Hartline (2012) definen el posicionamiento como 
"Crear una imagen mental de la oferta de productos y sus características de diferenciación en la mente de los clientes en el mercado meta. Esta imagen mental puede basarse en diferencias reales o percibidas entre las ofertas en competencia".

En la tabla 49 se define la respuesta a las preguntas de posicionamiento:

\section{Tabla 49}

Respuesta al Posicionamiento

\begin{tabular}{ll}
\hline PREGUNTAS & DEFINICIONES \\
\hline ¿Quién es? & ADH es una marca orientada al servicio \\
& personalizado de productos de belleza de lujo de la \\
& corporación América Salud \\
& Ofrece la venta de cremas, maquillajes y perfumes \\
¿Qué es? & de lujo. \\
¿Para quién? & Público sofisticado de nivel socio económico A que \\
¿Qué Ofrece? & no considera el precio un factor de compra. \\
& Servicio de calidad, personalizado y exclusivo en \\
& su local de San Isidro \\
& Productos de lujo de marcas exclusivas. Ventas \\
& virtuales
\end{tabular}

Fuente: Adaptado de Ferrel \& Hartline (2012) “Estrategia de Marketing” Sexta edición

ADH busca posicionarse como líder del mercado frente a la competencia siendo el primero en la mente del consumidor. 


\subsubsection{Estrategia Genérica}

Porter (2010) sostiene que las tres estrategias genéricas son: liderazgo en costes, diferenciación y enfoque. Cada una de ellas requiere una forma especial de alcanzar la ventaja competitiva lograda a través de un desempeño superior al promedio del sector.

$\checkmark$ El liderazgo en costes se define como como aquella organización que quiere convertirse en el "fabricante de coste bajo de la industria". Las fuentes de esa ventaja son diversas y están subordinadas a la estructura de la industria. Estas pueden ser: economías de escala, obtención de una patente, acceso preferencial a materias primas, entre otros factores.

La estrategia de diferenciación se define cuando una organización intenta distinguirse dentro de su sector industrial en ciertos aspectos que son apreciados por los compradores. Esta compañía escogerá uno o más atributos que considere importantes y adoptará un posicionamiento especial para atender esas necesidades. Al final, verá premiada si singularidad con un precio más alto.

$\checkmark$ Por último, la estrategia de enfoque es aquella en donde la empresa basa su elección en un estrecho ámbito competitivo («enfoque») dentro de un sector industrial. Además, selecciona un segmento o grupo de segmentos de él y adapta su estrategia para atenderlos y excluir a los restantes.

En consecuencia se afirma que $A D H$ empleará la estrategia de diferenciación pues se concentrará en brindar un servicio exclusivo y único con productos premium para el cuidado de la piel y la belleza a través de la atención de asesores capacitados y empáticos en un local exclusivo en el distrito de San Isidro. 


\subsubsection{Estrategia competitiva}

Kotler \& Singh (2010) clasifican a las empresas como líderes, retadoras, seguidoras y especializadas. En este caso, $A D H$ califica como empresa especializada debido a que ofrecerá productos orientados a un nicho de mercado determinado.

Kotler \& Keller (2012) sostienen que “Las empresas cuya participación es pequeña en relación con el mercado total pueden ser muy rentables si implementan una buena estrategia de especialización en nichos. Estas organizaciones tienden a ofrecer un alto valor, cobrar precios elevados, lograr bajos costos de producción y desarrollar una cultura y una visión corporativa bastante sólidas”.

En tal sentido, $A D H$ se concentrará en la atención de un mercado limitado ya que el público objetivo es un segmento por tanto debe centrar su atención inicialmente en su rentabilidad, concentrándose en la calidad del producto y la atención del servicio.

\subsubsection{Estrategia de Fidelización}

Para fidelizar al público objetivo se utilizará la siguiente estrategia:

- Comunicación activa con los clientes brindándoles toda la información sobre los productos, los servicios y las novedades que ADH planea brindar en el mercado.

- Personal especializado para el Soporte y apoyo constante para impulsar la venta en las activaciones y local exclusivo.

- Constantes promociones como herramienta para fidelizar a los heavy users.

- Implementación del programa de fidelización ADH.

\subsection{Estrategias Funcionales}

Las estrategias funcionales se derivan de las estrategias emanadas del FODA cruzado y son las siguientes; 


\subsubsection{Estrategia de Producto}

$\checkmark$ Ep1 Contar con una Cartera de Productos Exclusivos ADH

$\checkmark$ Ep2 El entrenamiento del personal ADH en convenio con centros mundiales de belleza

$\checkmark$ Ep3 Contar con un producto de lujo del mes para testeo

$\checkmark$ Ep4 Reconvertir la cartera de cremas dermatológicas a productos orgánicos

\subsubsection{Estrategia de Precio}

Epx1 Iniciar las Ventas virtuales con promociones especiales

\subsubsection{Estrategia de Distribución y ventas}

$\checkmark$ ED1 Benchmarking con Centro Mundial de belleza para decoración del local

$\checkmark$ ED2 Implementación de los DermaTruck en clubes privados por invitación

$\checkmark$ ED3 Desarrollo de un panel especializado de prueba de artículos de belleza en el local de ventas (Test de Productos)

$\checkmark$ ED4 Desarrollo de la base de clientes y actualización del mismo

$\checkmark \quad$ ED5 Espacio para clientes VIP con productos exclusivos

$\checkmark$ ED6 Venta a Domicilio para productos exclusivos

\subsubsection{Estrategia de Promoción y Comunicación de Marca}

$\checkmark$ EC1 Organización de Evento con gurús del Sector

$\checkmark$ EC2 Inversión selectiva de Marketing para el público objetivo

$\checkmark$ EC3 Auspicio de eventos exclusivos fuera de Lima con productos especiales

$\checkmark$ EC4 Campaña "Customer Day Off"

$\checkmark$ EC5 Activaciones exclusivas en eventos especiales 
$\checkmark$ EC6 Lanzamiento ADH con auspicio de marca exclusiva

\subsection{Planes de acción}

El plan de acción de ADH contempla el desarrollo de doce actividades divididas en cuatro estrategias de precio, tres actividades en una estrategia de precios, quince actividades en seis estrategias de plaza y ventas y trece actividades para seis estrategias de promoción y comunicaciones. Dichas actividades serán realizadas durante todo el año 2020 significando un presupuesto de $\$ 140,700$ que representa el $25 \%$ de las ventas totales esperadas por $\mathrm{ADH}$.

Los planes de acción se desarrollan a través de la Mezcla de marketing y contemplan acciones, responsables, plazos, costos y control que se desarrollaran dentro de cada estrategia para obtener los objetivos

\subsubsection{Mezcla de Marketing: producto y precio}

Los planes de acción para producto y precio se presentan en el orden en el que surgieron en el FODA cruzado

\begin{tabular}{|c|c|c|c|c|c|c|}
\hline $\begin{array}{l}\text { Estrategia } \\
\text { P1 }\end{array}$ & $\begin{array}{l}\text { Códig } \\
\text { o }\end{array}$ & Acción & $\begin{array}{l}\text { Responsab } \\
\text { le }\end{array}$ & Plazo & $\begin{array}{l}\text { Cost } \\
\text { o }\end{array}$ & Kpi \\
\hline \multirow[t]{3}{*}{$\begin{array}{l}\text { Contar con } \\
\text { una Cartera } \\
\text { de Productos } \\
\text { Exclusivos } \\
\text { ADH. }\end{array}$} & P1.1 & $\begin{array}{lr}\text { Desarrollar } & \text { un } \\
\text { catálogo } & \text { de } \\
\text { productos. } & \text { Dicha } \\
\text { cartera cuenta } & \text { con } \\
\text { doce productos } & \text { que } \\
\text { han } & \text { sido } \\
\text { seleccionados de la } \\
\text { investigación } \\
\text { mercado. }\end{array}$ & $\begin{array}{l}\text { Gerente } \\
\text { Marketing }\end{array}$ & Febrero & $\begin{array}{l}\$ 100 \\
0\end{array}$ & $\begin{array}{l}\% \\
\text { Variedad } \\
\text { de } \\
\text { productos }\end{array}$ \\
\hline & P1.2 & $\begin{array}{l}\text { Seleccionar } \\
\text { Realizar el pedido }\end{array}$ & $\begin{array}{l}\text { Gerente de } \\
\text { tienda }\end{array}$ & Marzo & & \\
\hline & P1.3 & $\begin{array}{l}\text { Desarrollar el trade } \\
\text { marketing }\end{array}$ & $\begin{array}{l}\text { Gerente } \\
\text { Marketing }\end{array}$ & Marzo & & \\
\hline
\end{tabular}




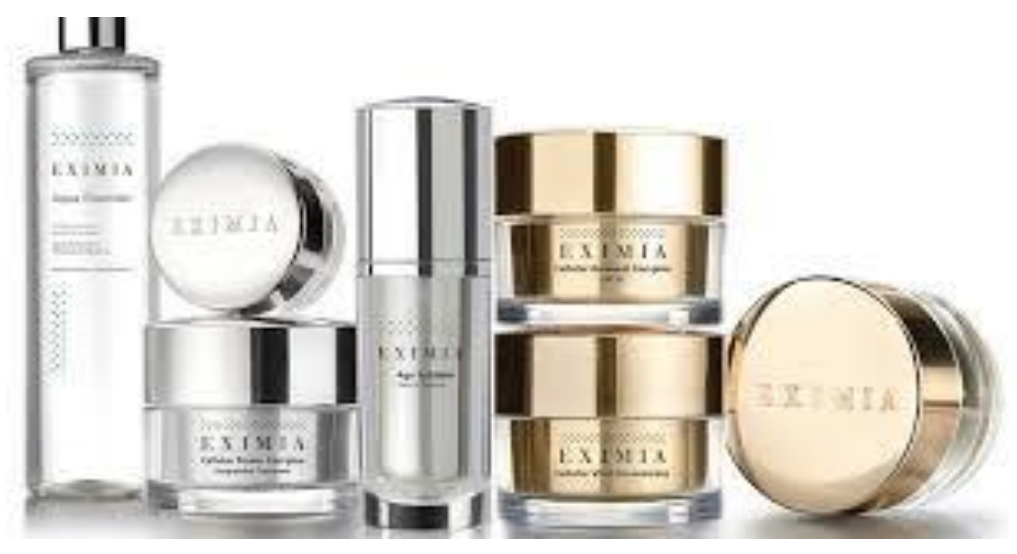

Figura 9

Cartera de Productos

Fuente: Tomado de Eximia diario Clarín (2019)

\begin{tabular}{|c|c|c|c|c|c|c|}
\hline Estrategia P2 & Código & Acción & Responsable & Plazo & Costo & Kpi \\
\hline $\begin{array}{l}\text { Entrenamiento } \\
\text { del personal } \\
\text { ADH en } \\
\text { convenio con } \\
\text { centros } \\
\text { mundiales de } \\
\text { belleza }\end{array}$ & P2.1 & \begin{tabular}{l}
\multicolumn{2}{l}{ Capacitaciones } \\
mensuales en \\
ADH en \\
convenio con \\
los laboratorios \\
dermatológicos.
\end{tabular} & $\begin{array}{l}\text { Gerente } \\
\text { Personal }\end{array}$ & Enero & 12,500 & $\begin{array}{l}\text { \%cantidad } \\
\text { personal } \\
\text { capacitado }\end{array}$ \\
\hline
\end{tabular}

\begin{tabular}{llll}
\hline P2.2 & $\begin{array}{l}\text { Firma convenio } \\
\text { con centro }\end{array}$ & $\begin{array}{l}\text { Gerente } \\
\text { General }\end{array}$ & Febrero \\
& $\begin{array}{l}\text { Entrenamiento } \\
\text { de personal }\end{array}$ & $\begin{array}{l}\text { Gerente } \\
\text { General }\end{array}$ & $\begin{array}{l}\text { Marzo- } \\
\text { Diciembre }\end{array}$
\end{tabular}

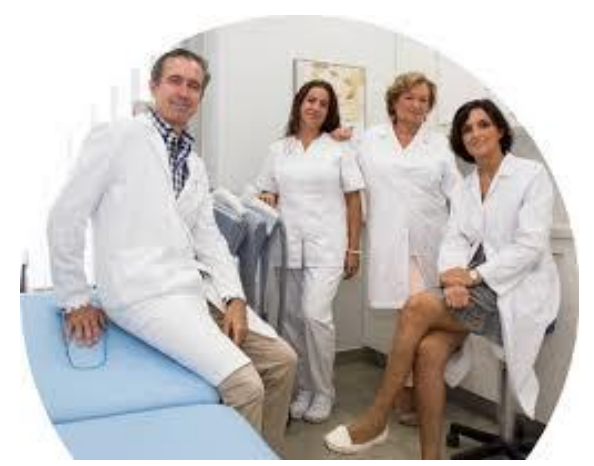

Figura 10

Personal ADH

Fuente: Tomado de Clínica Dermatológica Novaderma (2019) 


\begin{tabular}{|c|c|c|c|c|c|c|}
\hline Estrategia P3 & Código & Acción & Responsable & $\begin{array}{l}\text { Plaz } \\
\text { o }\end{array}$ & Costo & Kpi \\
\hline \multirow[t]{3}{*}{$\begin{array}{l}\text { Contar con un } \\
\text { producto de } \\
\text { lujo del mes } \\
\text { para testeo. }\end{array}$} & P3.1 & $\begin{array}{lr}\text { Selección } & \text { de } \\
\text { Producto. } & \\
\text { Mensualmente } & \text { un } \\
\text { auspiciador } & \text { se } \\
\text { encargará } & \text { de } \\
\text { habilitar } & \text { el } \\
\text { ambiente contando } \\
\text { con promociones y } \\
\text { activaciones } \\
\text { especiales. }\end{array}$ & $\begin{array}{l}\text { Gerente } \\
\text { Marketing }\end{array}$ & $\begin{array}{l}\text { Ener } \\
\text { o }\end{array}$ & $\$ 2,000$ & \multirow[t]{3}{*}{$\begin{array}{l}\text { \%Ventas } \\
\text { /ventas } \\
\text { totales }\end{array}$} \\
\hline & P3.2 & $\begin{array}{l}\text { Promoción del } \\
\text { producto }\end{array}$ & $\begin{array}{l}\text { Gerente } \\
\text { Marketing }\end{array}$ & $\begin{array}{l}\text { Feb- } \\
\text { dic. }\end{array}$ & & \\
\hline & P3.3 & $\begin{array}{l}\text { Selección del } \\
\text { Trade Marketing }\end{array}$ & & $\begin{array}{l}\text { Ener } \\
\text { o- } \\
\text { Abril }\end{array}$ & & \\
\hline
\end{tabular}

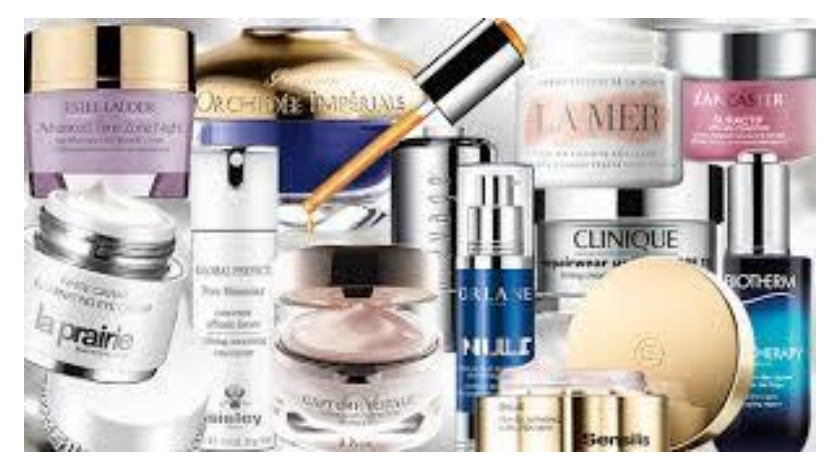

Figura 11

Producto de lujo mensual

Fuente: Tomado de blog Antena 3 Tv (2019) 


\begin{tabular}{|c|c|c|c|c|c|c|}
\hline Estrategia P4 & Código & Acción & Responsable & Plazo & Costo & Kpi \\
\hline \multirow[t]{3}{*}{$\begin{array}{l}\text { Reconvertir la } \\
\text { cartera de } \\
\text { cremas } \\
\text { dermatológicas } \\
\text { a productos } \\
\text { orgánicos. }\end{array}$} & P4.1 & $\begin{array}{l}\text { Selección } \\
\text { Cartera de } \\
\text { productos. Se } \\
\text { inicia la } \\
\text { campaña } \\
\text { utilizando los } \\
\text { productos } \\
\text { más } \\
\text { conocidos de } \\
\text { la cartera. }\end{array}$ & $\begin{array}{l}\text { Gerente de } \\
\text { Marketing/Tienda }\end{array}$ & Abril & $\$ 2000$ & $\begin{array}{l}\text { \%productos } \\
\text { /orgánicos/producto } \\
\text { totales }\end{array}$ \\
\hline & $\mathrm{P} 4.2$ & $\begin{array}{l}\text { Identificación } \\
\text { de productos } \\
\text { para } \\
\text { reconversión }\end{array}$ & Gerente de tienda & Junio & & \\
\hline & P4.3 & $\begin{array}{l}\text { Venta de } \\
\text { productos } \\
\text { orgánicos }\end{array}$ & Gerente de tienda & $\begin{array}{l}\text { Julio- } \\
\text { Diciembre }\end{array}$ & & \\
\hline
\end{tabular}

En cuanto a la estrategia de precio el plan de acción se muestra a continuación

\begin{tabular}{|c|c|c|c|c|c|c|}
\hline $\begin{array}{l}\text { Estrategia } \\
\text { Px1 }\end{array}$ & Código & Acción & Responsable & Plazo & Costo & Kpi \\
\hline \multirow[t]{3}{*}{$\begin{array}{l}\text { Ventas } \\
\text { virtuales con } \\
\text { promociones } \\
\text { especiales. }\end{array}$} & Px1.1 & $\begin{array}{l}\text { Desarrollo de } \\
\text { plataforma } \\
\text { virtual. Se } \\
\text { inician } \\
\text { campañas } \\
\text { para cyber } \\
\text { ventas y } \\
\text { promociones. }\end{array}$ & $\begin{array}{l}\text { Gerente } \\
\text { Marketing }\end{array}$ & En-Marzo & $\$ 10,000$ & $\begin{array}{l}\text { \% Ventas } \\
\text { Virtuales/Venta } \\
\text { totales }\end{array}$ \\
\hline & Px1.2 & $\begin{array}{l}\text { Desarrollo } \\
\text { Operaciones } \\
\text { Venta }\end{array}$ & $\begin{array}{l}\text { Gerente } \\
\text { tienda }\end{array}$ & $\begin{array}{l}\text { Abril- } \\
\text { Diciembre }\end{array}$ & & \\
\hline & Px1.3 & Promociones & $\begin{array}{l}\text { Gerente } \\
\text { Marketing }\end{array}$ & $\begin{array}{l}\text { Abril- } \\
\text { Diciembre }\end{array}$ & $\$ 5,000$ & \\
\hline
\end{tabular}




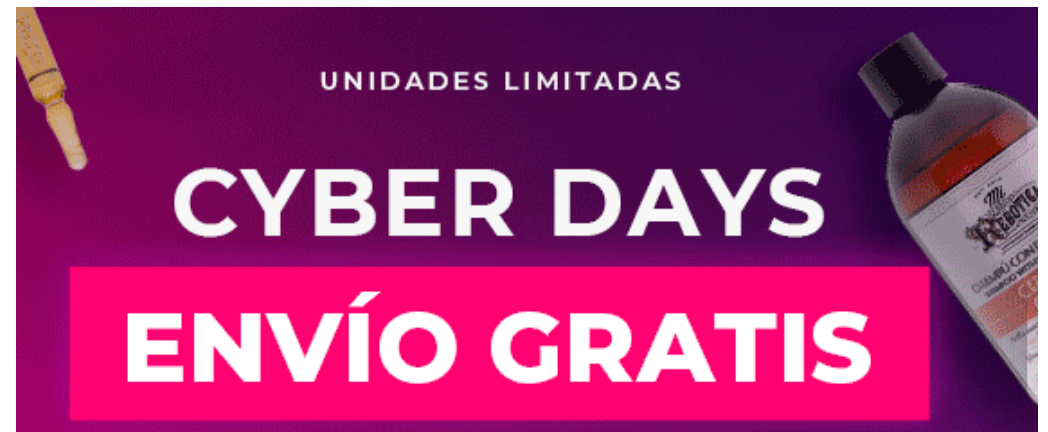

Figura 12

Modelo Campaña Ventas Virtuales

Fuente: Tomado de Cyberdays.com (2019)

\section{Mezcla de Marketing: Distribución, y promoción.}

Los planes de acción para distribución y promoción se presentan en el orden en el que surgieron en el FODA cruzado

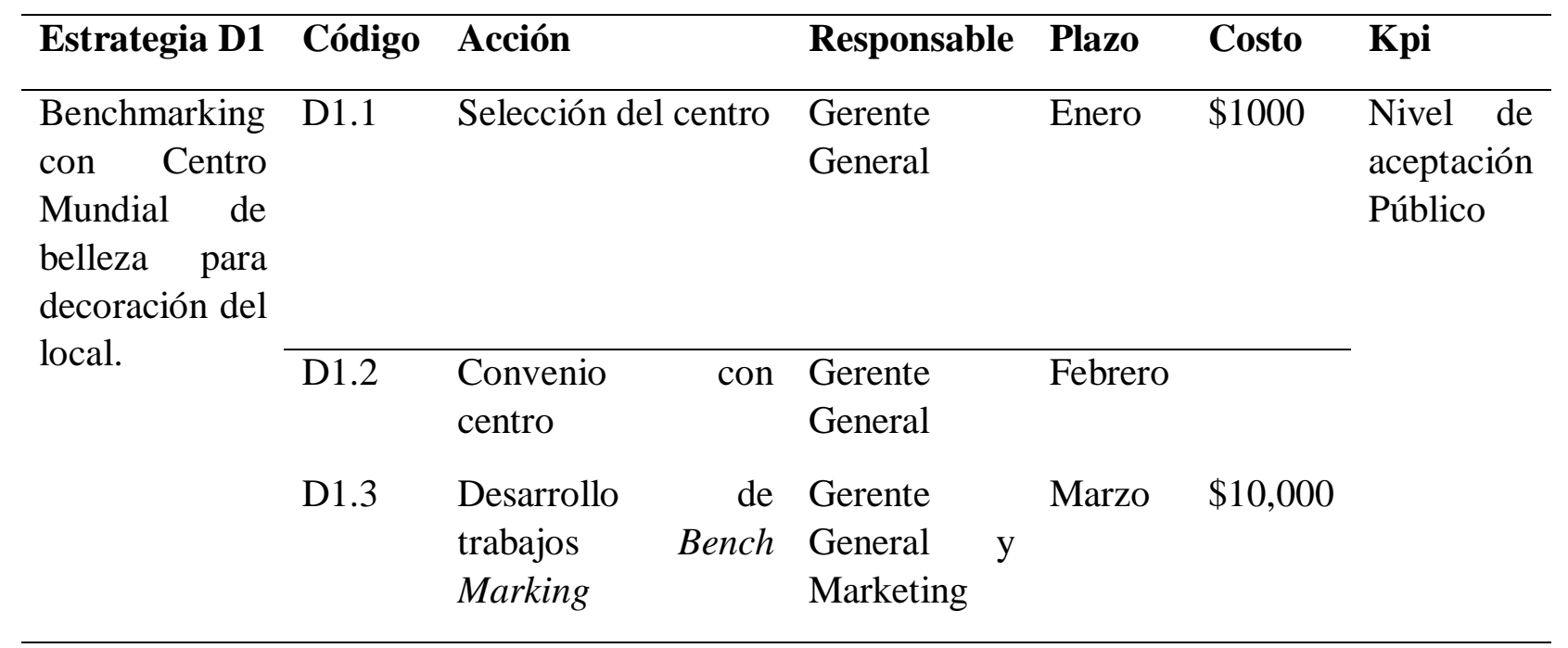




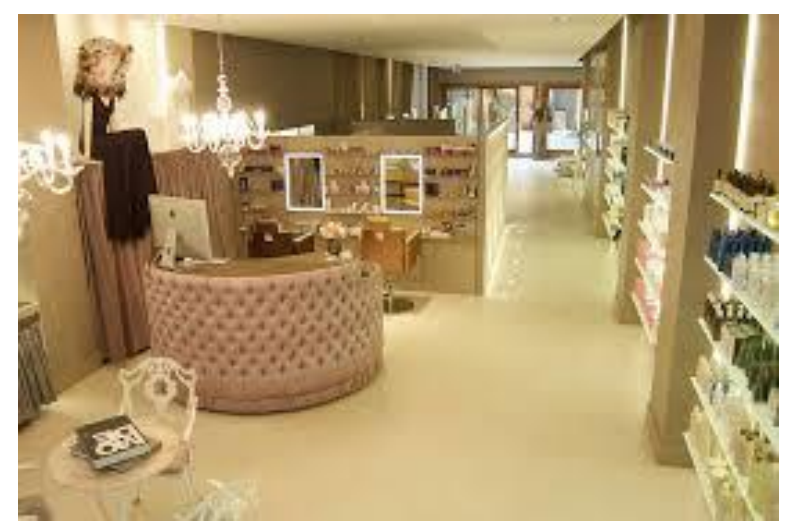

Figura 13

Modelo de Local ADH

Fuente: Tomado de revistaad.es(2019)

En la figura 14 se muestra el lay out de ADH

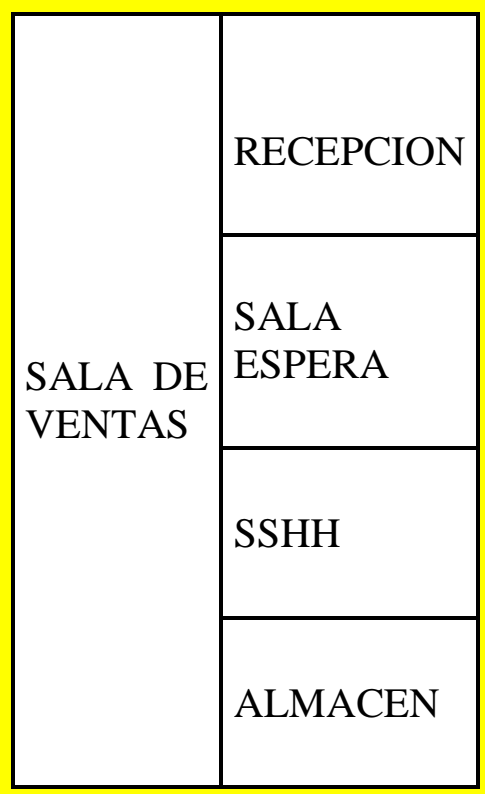

Figura 14

\section{Lay Out ADH}

Elaboración Grupo (2019)

Dicho local cuenta con un espacio de recepción orientado para el público objetivo, los acabados serán de mármol manteniendo los estándares de salones de belleza de lujo y moda en el mundo. La recepción estará aislada de la sala de ventas manteniendo cada área su propia independencia. En la sala de espera los clientes gozarán de privacidad atendidos 
por personal entrenado y educado en lugares sibaritas. Cuando llegue el turno un asistente de servicio atenderá al cliente para lo cual contará con una base de datos completa sobre el mismo.

\begin{tabular}{|c|c|c|c|c|c|c|}
\hline Estrategia D2 & Código & Acción & Responsable & Plazo & Costo & Kpi \\
\hline \multirow{11}{*}{$\begin{array}{l}\text { Implementación } \\
\text { de los } \\
\text { DermaTruck en } \\
\text { clubes privados } \\
\text { por invitación. }\end{array}$} & \multirow[t]{9}{*}{$\mathrm{D} 2.1$} & Diseño $\quad \mathrm{de}$ & Gerente & \multirow[t]{9}{*}{ Febrero } & \multirow[t]{9}{*}{$\$ 2,500$} & \multirow{11}{*}{$\begin{array}{l}\text { \%Nivel } \\
\text { de } \\
\text { ventas } \\
\text { de } \\
\text { Derma } \\
\text { truck }\end{array}$} \\
\hline & & DermaTruck. Estos & Marketing & & & \\
\hline & & han sido testeados & & & & \\
\hline & & y llevan la cartera & & & & \\
\hline & & de productos & & & & \\
\hline & & seleccionada para & & & & \\
\hline & & el mes además de & & & & \\
\hline & & $\begin{array}{lr}\text { contar } & \text { con } \\
\text { activaciones } & \text { parta }\end{array}$ & & & & \\
\hline & & el público objetivo. & & & & \\
\hline & \multirow[t]{2}{*}{$\mathrm{D} 2.2$} & Implementación & Gerente & \multirow[t]{2}{*}{ Marzo } & \multirow[t]{2}{*}{$\$ 6,000$} & \\
\hline & & Dermatruck & Marketing & & & \\
\hline
\end{tabular}

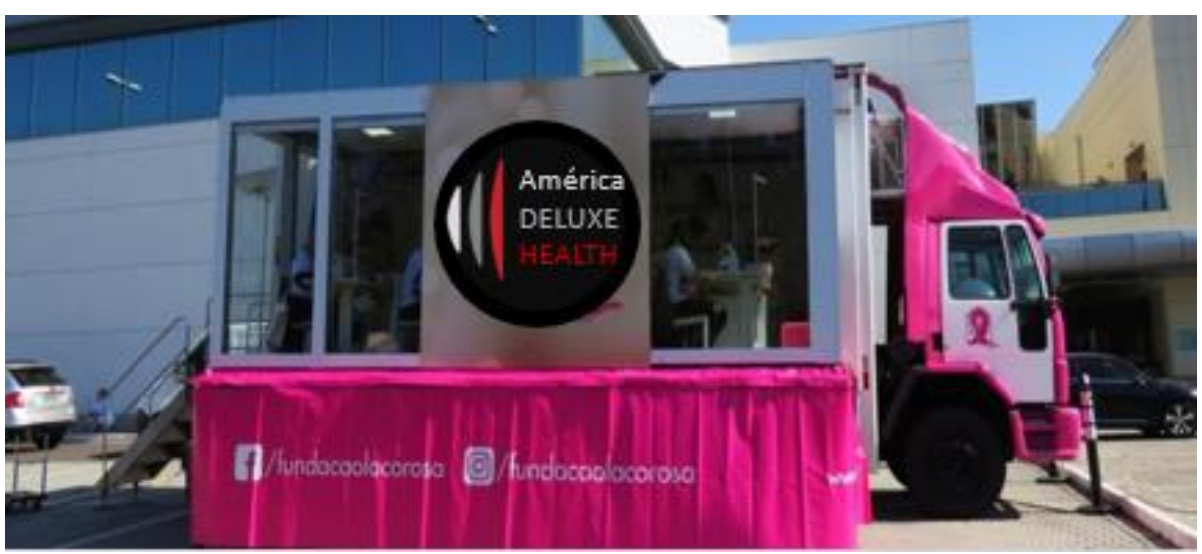

Figura 15

Ejemplo de Dermatruck ADH

Fuente: Investigación Grupo (2019) 


\begin{tabular}{|c|c|c|c|c|c|c|}
\hline $\begin{array}{l}\text { Estrategia } \\
\text { D3 }\end{array}$ & Código & Acción & Responsable & Plazo & Costo & Kpi \\
\hline \multirow[t]{3}{*}{$\begin{array}{l}\text { Panel } \\
\text { especializado } \\
\text { de prueba de } \\
\text { artículos de } \\
\text { belleza en el } \\
\text { local de } \\
\text { ventas. }\end{array}$} & D3.1 & $\begin{array}{lr}\text { Selección } & \text { del } \\
\text { panel. } & \text { Se } \\
\text { desarrolla } & \\
\text { mensualmente } \\
\text { un fin } & \text { de } \\
\text { semana para } & \text { proceder a la } \\
\text { invitación } & \text { al } \\
\text { público } & \\
\text { objetivo }\end{array}$ & $\begin{array}{l}\text { Gerente de } \\
\text { Marketing }\end{array}$ & Enero & $\$ 500$ & \multirow[t]{3}{*}{$\begin{array}{l}\text { Nivel de } \\
\text { satisfacción } \\
\text { del cliente }\end{array}$} \\
\hline & D3.2 & $\begin{array}{l}\text { Capacitación } \\
\text { del panel }\end{array}$ & $\begin{array}{l}\text { Gerente } \\
\text { personal }\end{array}$ & Febrero & $\$ 1200$ & \\
\hline & D3.3 & $\begin{array}{l}\text { Desarrollo plan } \\
\text { de operaciones }\end{array}$ & $\begin{array}{l}\text { Gerente de } \\
\text { tienda }\end{array}$ & Marzo & $\$ 500$ & \\
\hline
\end{tabular}

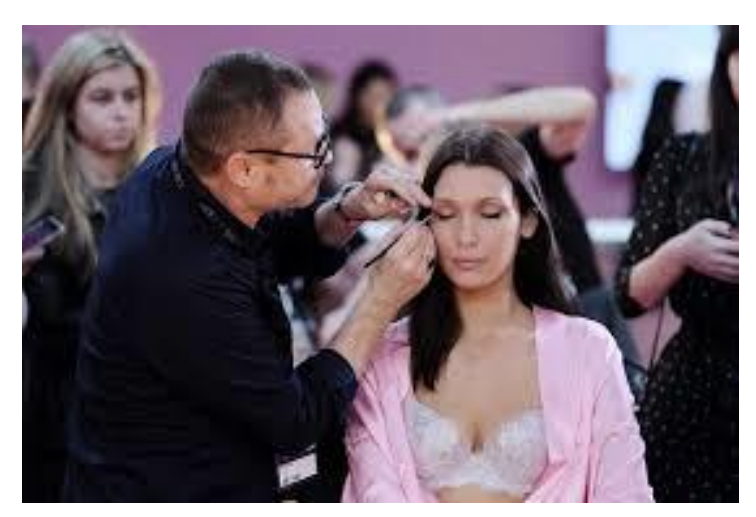

Figura 16

Modelo Panel ADH

Fuente: Tomado de nupcias magazine. com (2019) 


\begin{tabular}{lllllll}
\hline $\begin{array}{l}\text { Estrategia } \\
\text { D4 }\end{array}$ & Código & Acción & Responsable & Plazo & Costo & Kpi \\
\hline $\begin{array}{l}\text { Desarrollo } \\
\text { de la base de } \\
\text { clientes y }\end{array}$ & D4.1 & $\begin{array}{l}\text { Implementación } \\
\text { base de clientes. }\end{array}$ & $\begin{array}{l}\text { Gerente } \\
\text { Marketing }\end{array}$ & Enero & $\$ 1000$ & $\%$ \\
$\begin{array}{l}\text { actualización } \\
\text { del mismo }\end{array}$ & D4.2 & $\begin{array}{l}\text { Confirmación } \\
\text { base clientes }\end{array}$ & & $\begin{array}{l}\text { clientes/Base } \\
\text { de clientes }\end{array}$ \\
& D4.3 & $\begin{array}{l}\text { Actualización } \\
\text { base }\end{array}$ & Feb- & & \\
& & & May & \\
& & & Junio- & \\
& & & Dic & \\
\hline
\end{tabular}

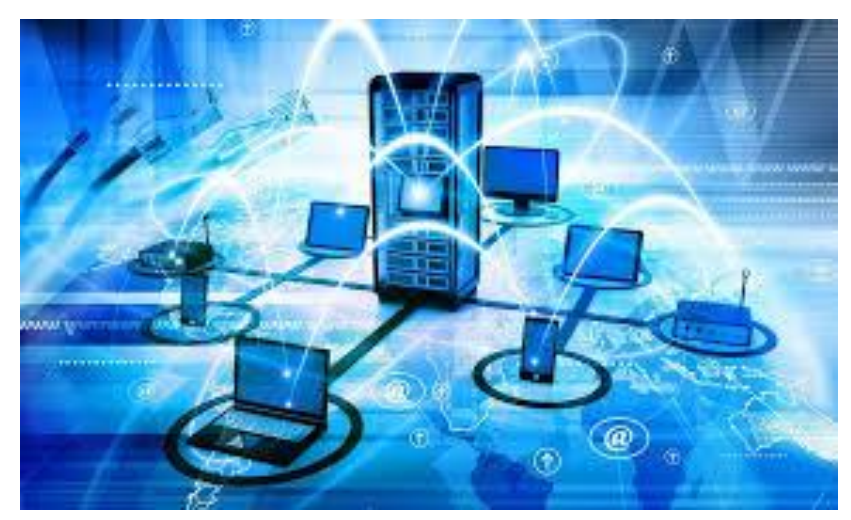

Figura 17

Desarrollo Base de Datos ADH

Fuente: Tomado de revistabyte.es (2019)

\begin{tabular}{|c|c|c|c|c|c|c|}
\hline $\begin{array}{l}\text { Estrategi } \\
\text { a D5 }\end{array}$ & $\begin{array}{l}\text { Códig } \\
\text { o }\end{array}$ & Acción & $\begin{array}{l}\text { Responsabl } \\
\text { e }\end{array}$ & Plazo & Costo & Kpi \\
\hline $\begin{array}{l}\text { Espacio } \\
\text { para } \\
\text { clientes }\end{array}$ & D5.1 & $\begin{array}{l}\text { Implementació } \\
\mathrm{n} \text { del espacio }\end{array}$ & $\begin{array}{l}\text { Gerente } \\
\text { Marketing }\end{array}$ & $\begin{array}{l}\text { Febrer } \\
\text { o }\end{array}$ & $\begin{array}{l}\$ 1,20 \\
0\end{array}$ & $\begin{array}{l}\text { Nivel } \\
\text { satisfacció } \\
\text { n clientes }\end{array}$ \\
\hline $\begin{array}{l}\text { VIP con } \\
\text { productos } \\
\text { exclusivos }\end{array}$ & D5.2 & $\begin{array}{l}\text { Desarrollo de } \\
\text { programa VIP }\end{array}$ & $\begin{array}{l}\text { Gerente } \\
\text { Marketing }\end{array}$ & Marzo & $\begin{array}{l}\$ 4,00 \\
0\end{array}$ & \\
\hline
\end{tabular}




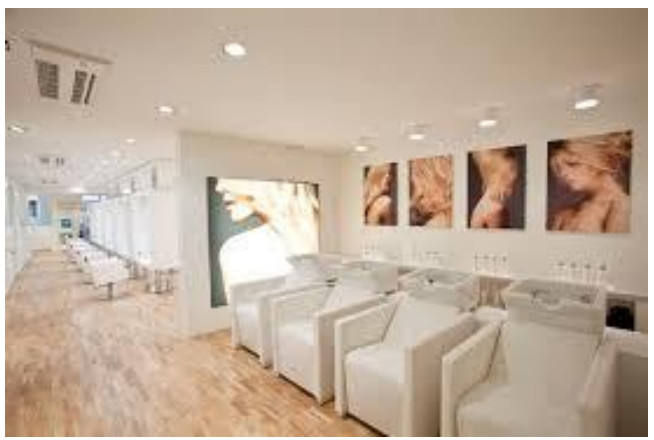

Figura 18

Ejemplo de Espacio VIP ADH

Fuente : Tomado de pinterest.com (2019)

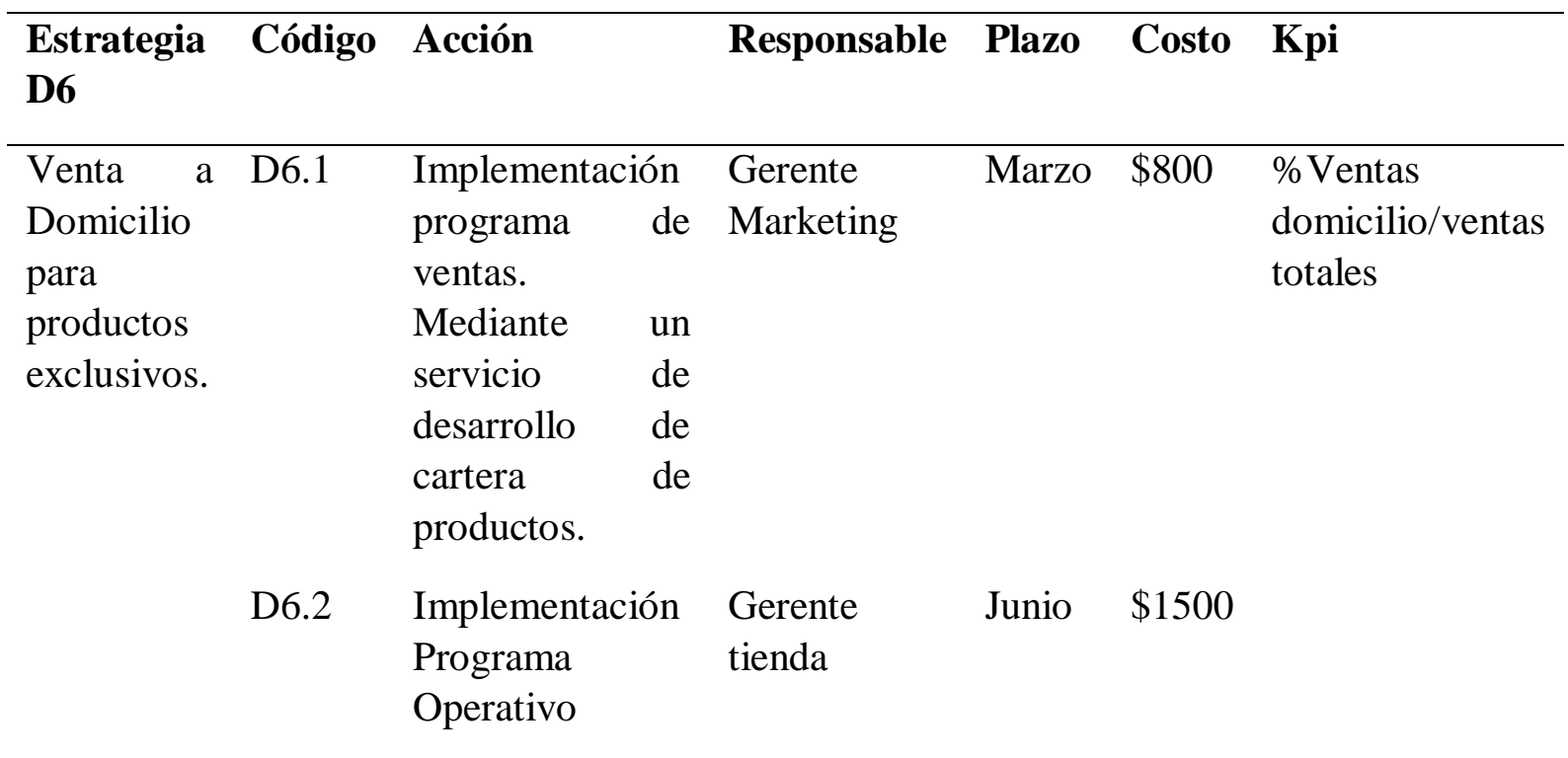

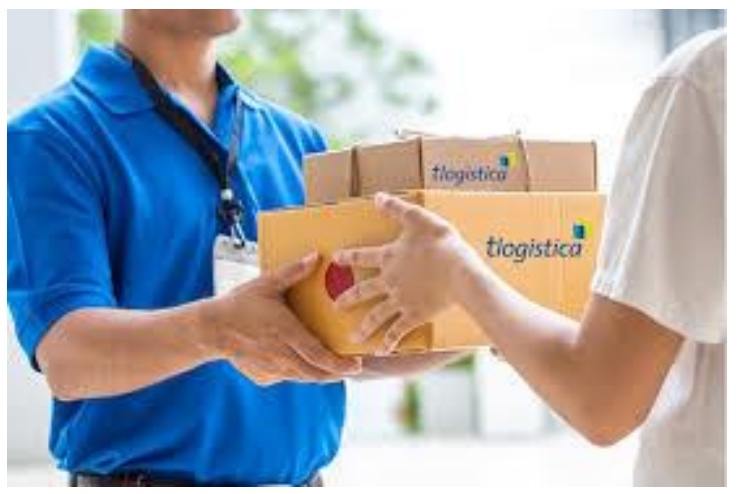

Figura 19

Servicio de venta a Domicilio

Fuente: Tomado de tlogistica.pe(2019) 
Para las estrategias de promoción y comunicación

\begin{tabular}{|c|c|c|c|c|c|c|}
\hline $\begin{array}{l}\text { Estrategia } \\
\text { PC1 }\end{array}$ & Código & Acción & Responsable & Plazo & Costo & Kpi \\
\hline \multirow[t]{2}{*}{$\begin{array}{l}\text { Organización } \\
\text { de Evento con } \\
\text { gurús del } \\
\text { Sector. }\end{array}$} & PC1.1 & $\begin{array}{l}\text { Selección } \\
\text { Programa } \\
\text { de Gurús. } \\
\text { Se } \\
\text { programa } \\
\text { eventos con } \\
\text { referentes } \\
\text { de la } \\
\text { belleza y se } \\
\text { invitará al } \\
\text { público } \\
\text { objetivo a } \\
\text { participar. }\end{array}$ & $\begin{array}{l}\text { Gerente } \\
\text { Marketing }\end{array}$ & Febrero & $\$ 15,000$ & $\begin{array}{l}\text { Nivel } \\
\text { satisfacción } \\
\text { participantes }\end{array}$ \\
\hline & PC1.2 & $\begin{array}{l}\text { Desarrollo } \\
\text { del } \\
\text { programa }\end{array}$ & $\begin{array}{l}\text { Gerente } \\
\text { Marketing }\end{array}$ & Abril & & \\
\hline
\end{tabular}

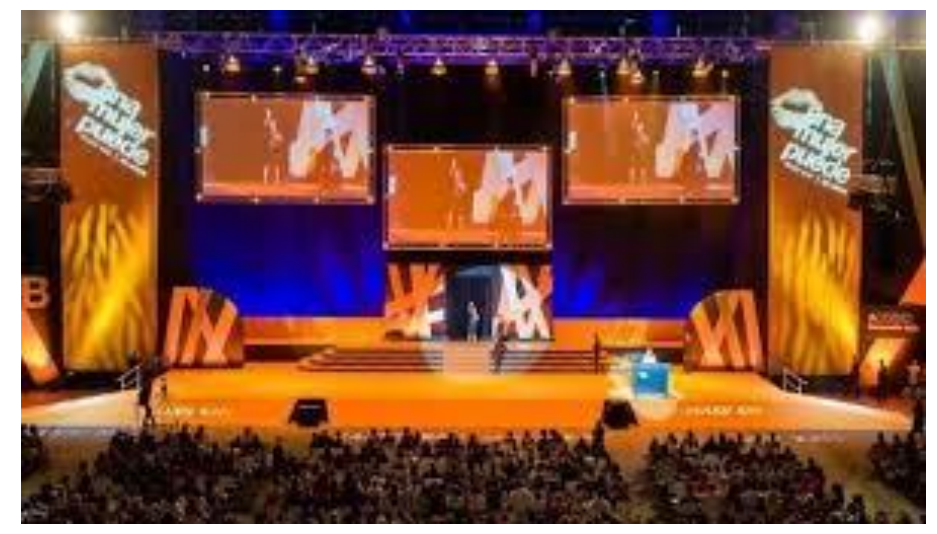

Figura 20

Organización Conferencias ADH

Fuente: Tomado de multinivelzgz.com (2019) 


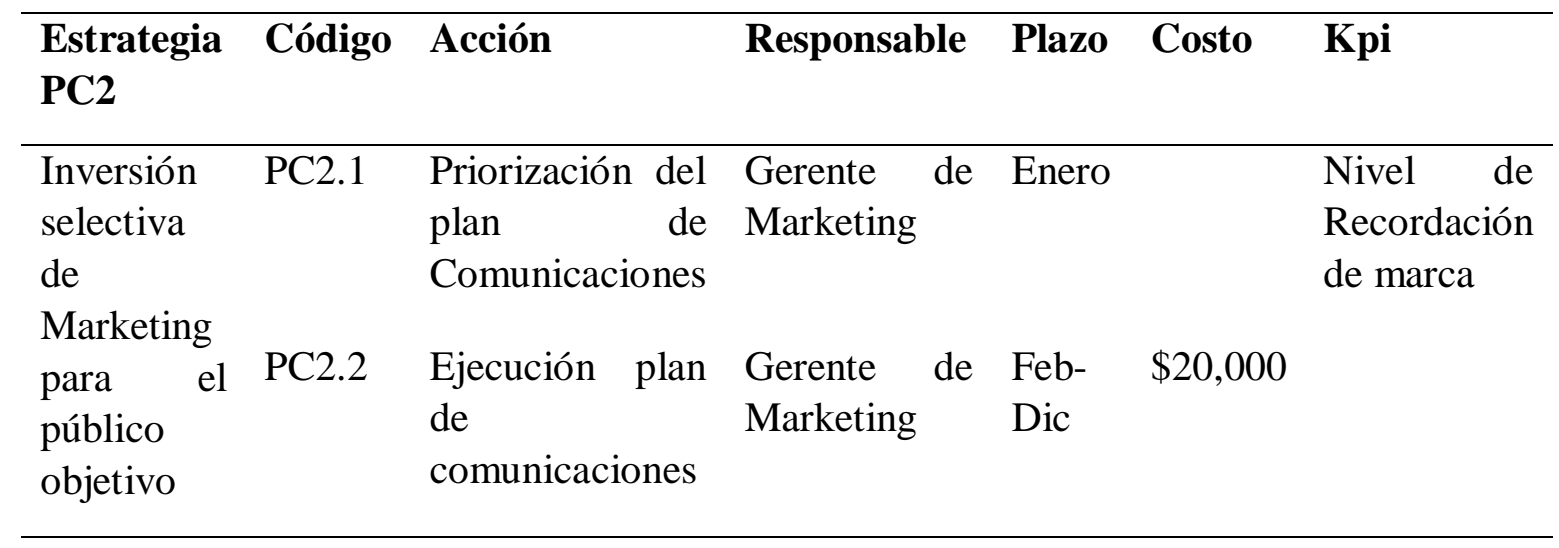

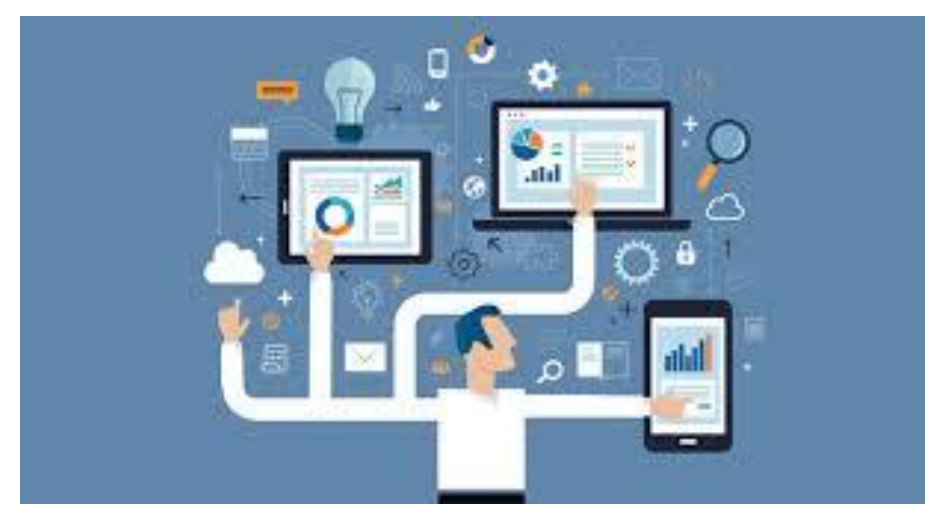

Figura 21

Selección Inversión Selectiva de Marketing

Fuente: Tomado de blog mailrelay.com (2019)

\begin{tabular}{|c|c|c|c|c|c|c|}
\hline $\begin{array}{l}\text { Estrategia } \\
\text { PC3 }\end{array}$ & Código & Acción & Responsable & Plazo & Costo & Kpi \\
\hline \multirow[t]{2}{*}{$\begin{array}{l}\text { Auspicio } \\
\text { de eventos } \\
\text { exclusivos } \\
\text { fuera de } \\
\text { Lima con } \\
\text { productos } \\
\text { especiales. }\end{array}$} & PC3.1 & $\begin{array}{l}\text { Desarrollo Plan } \\
\text { de auspicios. } \\
\text { Estos eventos se } \\
\text { desarrollarán de } \\
\text { acuerdo al plan } \\
\text { de marketing y a } \\
\text { las necesidades } \\
\text { de los clientes. }\end{array}$ & $\begin{array}{l}\text { Gerente de } \\
\text { Marketing }\end{array}$ & Enero & & \multirow[t]{2}{*}{$\begin{array}{l}\text { Nivel de } \\
\text { participación } \\
\text { público } \\
\text { objetivo }\end{array}$} \\
\hline & PC3.2 & $\begin{array}{l}\text { Implementación } \\
\text { plan de auspicios }\end{array}$ & $\begin{array}{l}\text { Gerente de } \\
\text { Marketing }\end{array}$ & Marzo & $\$ 20,000$ & \\
\hline
\end{tabular}




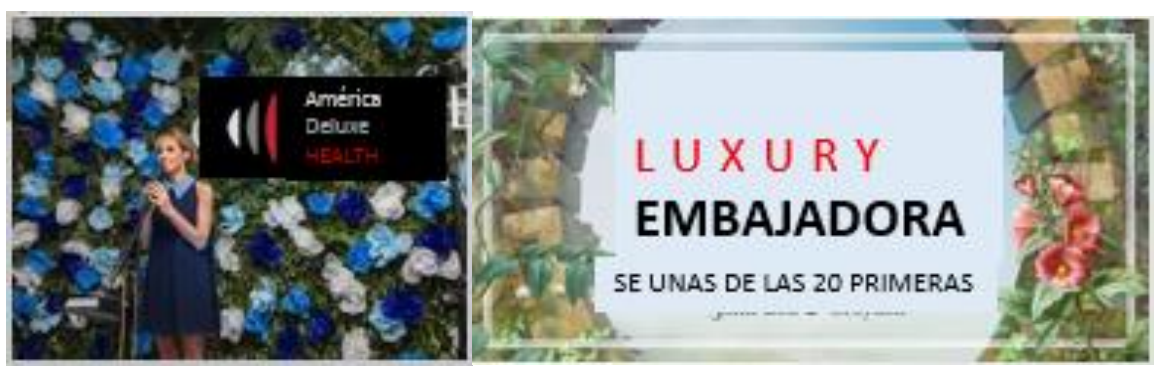

Figura 22

Auspicio Eventos Selectivos

Fuente: Elaborado Grupo de Tesis (2019)

\begin{tabular}{|c|c|c|c|c|c|c|}
\hline $\begin{array}{l}\text { Estrategia } \\
\text { PC4 }\end{array}$ & Código & Acción & Responsable & Plazo & Costo & Kpi \\
\hline \multirow[t]{2}{*}{$\begin{array}{l}\text { Campaña } \\
\text { "Customer } \\
\text { Day Off". }\end{array}$} & PC4.1 & 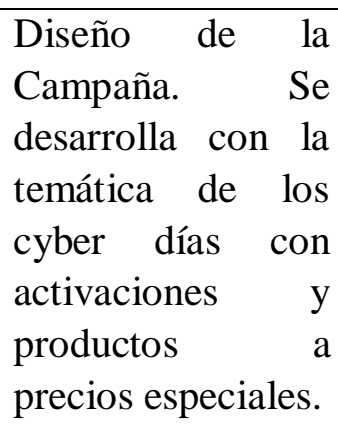 & $\begin{array}{l}\text { Gerente } \\
\text { Marketing }\end{array}$ & Febrero & & \multirow[t]{2}{*}{$\begin{array}{l}\text { Nivel de } \\
\text { participación } \\
\text { público } \\
\text { objetivo }\end{array}$} \\
\hline & PC4.2 & $\begin{array}{l}\text { Implementación } \\
\text { de dos campañas } \\
\text { "customer off" }\end{array}$ & $\begin{array}{l}\text { Gerente } \\
\text { Marketing }\end{array}$ & Junio & 2,500 & \\
\hline
\end{tabular}

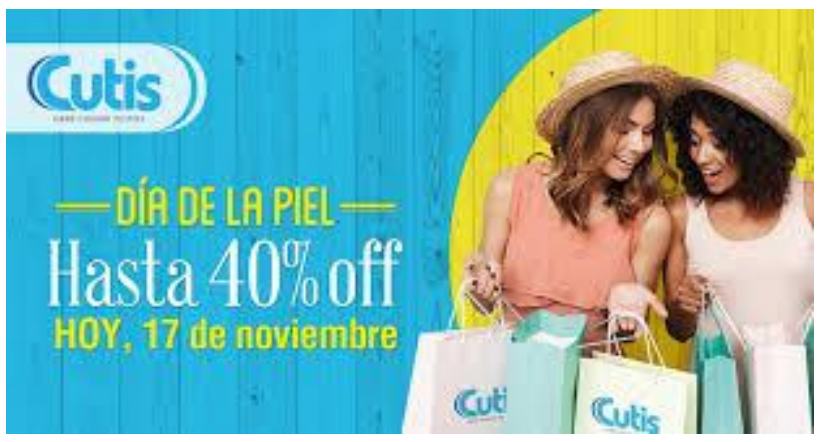

Figura 23

Ejemplo Modelo Campaña "Customer Day Off"

Fuente: Adaptado de Campaña Cutis (2018) 


\begin{tabular}{|c|c|c|c|c|c|c|}
\hline $\begin{array}{l}\text { Estrategia } \\
\text { PC5 }\end{array}$ & Código & Acción & Responsable & Plazo & Costo & Kpi \\
\hline $\begin{array}{l}\text { Activaciones } \\
\text { exclusivas en } \\
\text { eventos } \\
\text { especiales }\end{array}$ & PC5.2 & $\begin{array}{l}\text { Diseño } \\
\text { Implementaciones } \\
\text { Implementación } \\
\text { dos Activaciones }\end{array}$ & $\begin{array}{l}\text { Gerente } \\
\text { Marketing } \\
\text { Gerente } \\
\text { Marketing }\end{array}$ & Febrero & $\$ 10,000$ & $\begin{array}{l}\text { Nivel de } \\
\text { satisfacción } \\
\text { público } \\
\text { objetivo }\end{array}$ \\
\hline
\end{tabular}

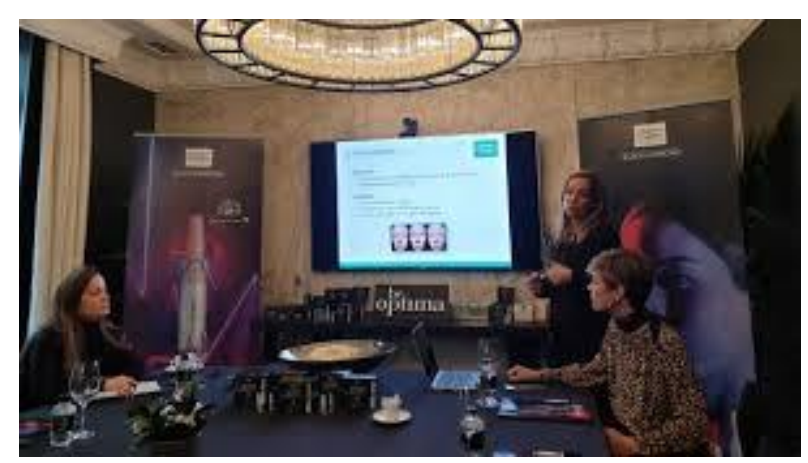

Figura 24

Ejemplo Activaciones Eventos Especiales

Fuente: Tomado de correofarmaceutico.com (2019)

\begin{tabular}{|c|c|c|c|c|c|c|}
\hline $\begin{array}{l}\text { Estrategia } \\
\text { PC6 }\end{array}$ & Código & Acción & Responsable & Plazo & Costo & Kpi \\
\hline \multirow{3}{*}{\begin{tabular}{l}
\multicolumn{2}{l}{ Lanzamiento } \\
ADH con \\
auspicio de \\
marca \\
exclusiva
\end{tabular}} & PC6.1 & $\begin{array}{l}\text { Selección } \\
\text { marca líder }\end{array}$ & $\begin{array}{l}\text { Gerente } \\
\text { General/Marketing }\end{array}$ & Enero & $\$ 500$ & $\begin{array}{l}\text { Nivel de } \\
\text { Recordación } \\
\text { de marca }\end{array}$ \\
\hline & PC6.2 & Convenio & Gerente General & Marzo & & \\
\hline & PC6.3 & Inauguración & Gerente Marketing & Abril & $\$ 10,000$ & \\
\hline
\end{tabular}

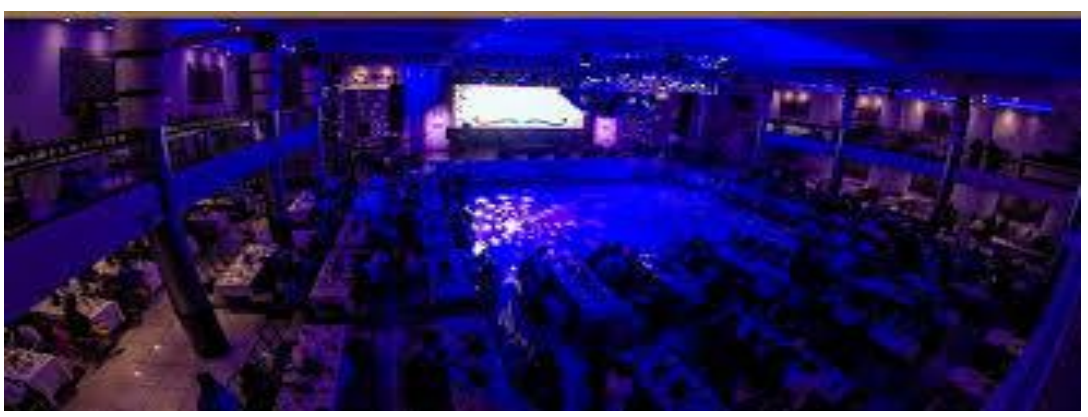

Figura 25 Ejemplo Lanzamiento de Marca ADH

Fuente: Tomado de scencia.com.pe (2019) 


\section{CAPITULO IV: PROYECCIONES FINANCIERAS}

\subsection{Presupuesto de marketing}

El Presupuesto de Marketing presenta una participación de 11\% para la inversión en estrategia de producto, $12 \%$ para la inversión en estrategia de precios, $21 \%$ para la inversión en plaza y ventas y 56\% para la estrategia en promociones y comunicación que es aceptable al tratarse de un producto nuevo y exclusivo en el mercado. Ello significa que la utilidad operativa del año 2020 es similar a la del año 2019.

El presupuesto de Marketing se aprecia en la Tabla 50.

\section{Tabla 50}

Presupuesto de Marketing ADH

\begin{tabular}{lrrrrr}
\hline & & & & \multicolumn{3}{c}{ PROMOCION } \\
MESES & PRODUCTO & PRECIO & PLAZA Y VENTAS & COMUNICACION & TOTAL \\
\hline FEBRERO & $\$ 2,000$ & $\$ 5,000$ & $\$ 2,500$ & $\$ 500$ & $\$ 10,000$ \\
MARZO & $\$ 1,000$ & $\$ 5,000$ & $\$ 4,900$ & $\$ 15,000$ & $\$ 25,900$ \\
ABRIL & $\$ 1,250$ & $\$ 500$ & $\$ 11,700$ & $\$ 2,000$ & $\$ 15,450$ \\
MAYO & $\$ 3,250$ & $\$ 500$ & $\$ 6,400$ & $\$ 17,000$ & $\$ 27,150$ \\
JUNIO & $\$ 1,250$ & $\$ 500$ & $\$ 400$ & $\$ 7,000$ & $\$ 9,150$ \\
JULIO & $\$ 1,250$ & $\$ 500$ & $\$ 1,900$ & $\$ 4,500$ & $\$ 8,150$ \\
AGOSTO & $\$ 1,250$ & $\$ 500$ & $\$ 400$ & $\$ 7,000$ & $\$ 9,150$ \\
SETIEMBRE & $\$ 1,250$ & $\$ 500$ & $\$ 400$ & $\$ 2,000$ & $\$ 4,150$ \\
OCTUBRE & $\$ 1,250$ & $\$ 500$ & $\$ 400$ & $\$ 7,000$ & $\$ 9,150$ \\
NOVIEMBRE & $\$ 1,250$ & $\$ 500$ & $\$ 400$ & $\$ 7,000$ & $\$ 9,150$ \\
DICIEMBRE & $\$ 1,250$ & $\$ 500$ & $\$ 400$ & $\$ 2,000$ & $\$ 4,150$ \\
Ene-21 & $\$ 1,250$ & $\$ 500$ & $\$ 400$ & $\$ 7,000$ & $\$ 9,150$ \\
\hline TOTAL & $\$ 17,500$ & $\$ 15,000$ & $\$ 30,200$ & $\$ 78,000$ & $\$ 140,700$
\end{tabular}

Elaboración Propia (2019)

En la Tabla 51 se muestra el porcentaje de participación del mix de marketing 


\section{Tabla 51}

Porcentaje de participación del Mix de Marketing primer año

\begin{tabular}{lll}
\hline Mix & Inversión & Porcentaje \\
\hline Producto & $\$ 17,500$ & $12 \%$ \\
Precio & $\$ 15,000$ & $11 \%$ \\
Distribución y Ventas & $\$ 30,200$ & $21 \%$ \\
Promoción y Comunicación & $\$ 78,000$ & $56 \%$ \\
\hline Total & $\$ 140,700$ & 100
\end{tabular}

Elaboración Propia (2019)

\subsection{Estado de resultados}

La proyección de ventas de los tres primeros Años para ADH se detalla en el anexo 12

El estado de resultados se muestra en la Tabla 52

Tabla 52

Estado de resultados

\begin{tabular}{|c|c|c|c|c|c|c|c|c|}
\hline CONCEPTO & 2019 & & 2020 & & 2021 & & 2022 & \\
\hline Ventas & $\$ 384,594$ & & $\$ 556,017$ & & $\$ 611,619$ & & $\$ 672,781$ & \\
\hline Costos & $\$ 315,368$ & $82 \%$ & $\$ 389,211$ & $70 \%$ & $\$ 408,672$ & $67 \%$ & $\$ 425,018$ & $63 \%$ \\
\hline Utilidad Bruta & $\$ 69,226$ & $18 \%$ & $\$ 166,806$ & $30 \%$ & $\$ 202,947$ & $33 \%$ & $\$ 247,762$ & $37 \%$ \\
\hline Gastos de Marketing & $\$ 43,277$ & & $\$ 140,700$ & & $\$ 147,735$ & & $\$ 155,122$ & \\
\hline Utilidad Operativa & $\$ 25,249$ & & $\$ 26,106$ & & $\$ 55,212$ & & $\$ 92,640$ & \\
\hline
\end{tabular}

Elaboración Propia (2019)

*Los costos incluyen los gastos de personal y administración.

En el anexo 13 se muestra la inversión inicial y en el anexo 14 se muestran los gastos administrativos 


\subsection{Evaluación Financiera del Plan}

La evaluación financiera del Plan de Marketing de ADH considera las ventas proyectadas al cierre del 2020. La tasa interna de retorno obtenida (TIR) es de $29 \%$ y el VAN obtenido fue \$42,286 considerando un 15\% como tasa referencial. Para el retorno de la inversión se obtuvo un ROI de 1.97

En la Tabla 53 se aprecia la proyección de ventas del primer año

Tabla 53

Resultados del Primer año ADH

\begin{tabular}{|c|c|c|c|c|c|c|c|c|c|c|c|c|c|}
\hline & & FEBRER & MARZ & & & & & AGOST & & OCTUBR & NOVIEMB & DICIEMB & \\
\hline & ENERO & O & $\mathbf{O}$ & ABRIL & MAYO & JUNIO & JULIO & $\mathbf{O}$ & SET & & & & TOTAL \\
\hline CREMAS & $\$ 13,344$ & $\$ 13,344$ & $\$ 16,681$ & $\$ 16,681$ & $\$ 26,689$ & $\$ 20,017$ & $\$ 40,033$ & $\$ 40,033$ & $\$ 36,697$ & $\$ 33,361$ & $\$ 30,025$ & $\$ 46,705$ & $\begin{array}{l}\$ 333,61 \\
0\end{array}$ \\
\hline MAQUILLAJES & $\$ 4,448$ & $\$ 4,448$ & $\$ 5,560$ & $\$ 5,560$ & $\$ 8,896$ & $\$ 6,672$ & $\$ 13,344$ & $\$ 13,344$ & $\$ 12,232$ & $\$ 11,120$ & $\$ 10,008$ & $\$ 15,568$ & $\begin{array}{r}3 \\
\$ 111,20\end{array}$ \\
\hline PERFUMES & $\$ 4,448$ & $\$ 4,448$ & $\$ 5,560$ & $\$ 5,560$ & $\$ 8,896$ & $\$ 6,672$ & $\$ 13,344$ & $\$ 13,344$ & $\$ 12,232$ & $\$ 11,120$ & $\$ 10,008$ & $\$ 15,568$ & 3 \\
\hline VENTAS & 2,241 & $\$ 22,241$ & $\$ 27,801$ & $\$ 27,801$ & $\$ 44,481$ & $\$ 33,361$ & $\$ 66,722$ & $\$ 66,722$ & $\$ 61,162$ & $\$ 55,602$ & $\$ 50,042$ & $\$ 77,842$ & $\begin{array}{r}\$ 556,01 \\
7 \\
\end{array}$ \\
\hline Costos & $\$ 15,568$ & $\$ 15,568$ & $\$ 19,461$ & $\$ 19,461$ & $\$ 31,137$ & $\$ 23,353$ & $\$ 46,705$ & $\$ 46,705$ & $\$ 42,813$ & $\$ 38,921$ & $\$ 35,029$ & $\$ 54,490$ & $\begin{array}{r}\$ 389,21 \\
1 \\
\end{array}$ \\
\hline lad & $\$ 6,672$ & $\$ 6,672$ & $\$ 8,340$ & $\$ 8,340$ & $\$ 13,344$ & $\$ 10,008$ & $\$ 20,017$ & $\$ 20,017$ & $\$ 18,349$ &, 681 & 5,013 & 3,353 & $\begin{array}{r}\$ 166,80 \\
6 \\
\end{array}$ \\
\hline $\begin{array}{l}\text { gastos } \\
\text { marketing }\end{array}$ & $\$ 10,000$ & $\$ 25,900$ & $\$ 15,450$ & $\$ 27,150$ & $\$ 9,150$ & $\$ 8,150$ & $\$ 9,150$ & $\$ 4,150$ & $\$ 9,150$ & $\$ 9,150$ & $\$ 9,150$ & $\$ 4,150$ & $\begin{array}{r}\$ 140,70 \\
0\end{array}$ \\
\hline & $-\$ 3,328$ & $\$ 19,228$ & $-\$ 7,110$ & $-\$ 18,810$ & $\$ 4,194$ & $\$ 1,858$ & $\$ 10,867$ & $\$ 15,867$ & $\$ 9,199$ & $\$ 7,531$ & $\$ 5,863$ & $\$ 19,203$ & $\$ 26,106$ \\
\hline
\end{tabular}




\section{CAPÍTULO V IMPLEMENTACION Y CONTROL}

Los objetivos de marketing que para el caso de ADH son cuatro y deben ser analizados de acuerdo a las estrategias planteadas. En caso no se esté alcanzando dichos objetivos, de acuerdo los indicadores, se cuenta con un plan de contingencia que para el caso de ADH está presupuestado en $\$ 8700$ que representa el 6\% del presupuesto de Marketing. Los resultados económicos arrojan un TIR de 29\% y un VAN de \$42,286 lo que conlleva un ROI de 1.97

\subsection{Sistema de Información y Control}

El sistema de control debe manifestarse según los objetivos trazados, analizando las desviaciones y realizando las correcciones mediante acciones de control. En consecuencia es importante establecer los indicadores de la gestión para los objetivos y las estrategias que más aportarán a cumplir el objetivo. En la Tabla 54 se aprecian los objetivos y sus indicadores de gestión.

Tabla 54

Control de indicadores de gestión

\begin{tabular}{|c|c|c|}
\hline Objetivo1 & Indicador & $\begin{array}{l}\text { Unidad de } \\
\text { Medida }\end{array}$ \\
\hline Incrementar las ventas en $\$ 171,423$ & Nivel de Ventas & Dólares \\
\hline \multicolumn{3}{|l|}{ Estrategias Aportantes } \\
\hline +Ejecutar la Campaña "Customer Day Off". & Nivel de ventas & Dólares \\
\hline +Contar con un espacio dentro del local para & Satisfacción & Porcentaje \\
\hline $\begin{array}{l}\text { clientes VIP con productos exclusivos } \\
\text { +Inversión selectiva de Marketing para } \\
\text { público objetivo }\end{array}$ & Top Mind & Recordación \\
\hline +Activaciones exclusivas en eventos & Satisfacción & Porcentaje \\
\hline $\begin{array}{l}\text { especiales. } \\
\text { +Auspicio eventos exclusivos con fuera de }\end{array}$ & Participación & Porcentaje \\
\hline Lima con productos especiales & & \\
\hline $\begin{array}{l}\text { +Organizar eventos exclusivos con gurus del } \\
\text { sector }\end{array}$ & Satisfacción & Porcentaje \\
\hline
\end{tabular}




\section{Objetivo 2}

Incrementar la rentabilidad en $8 \%$

Estrategias Aportantes

+Contar con un producto de lujo del mes

Nivel de rentabilidad Porcentaje

para testeo aplicado a las clientes de $A D H$

+ Contar con cartera de productos exclusivos

$\mathrm{ADH}$

Numero de Productos Porcentaje

+Implementar las ventas a domicilio

Ventas

Dolares

\section{Objetivo 3}

Obtener el posicionamiento de ADH como Top Mind

Recordación

"líder" en el primer año de operación

Estrategias Aportantes

+Brindar un panel especializado de prueba

Satisfacción Cliente

Porcentaje

de artículos de belleza en el local de ventas

+Desarrollar la base de clientes y la

Clientes

Porcentaje

actualización periódica del mismo.

+Firmar convenios con centros mundiales de

Personal entrenado

Porcentaje

belleza para el entrenamiento del personal

de ADH

+Bench Marking con Centros Mundiales de

belleza para la decoración del local.

\section{Top mind Recordación}

\section{Objetivo 4}

Reconvertir la cartera de cremas a productos

Cartera de Productos

Porcentaje

orgánicos consiguiendo que el $25 \%$ de la venta de cremas sea orgánica 
Estrategias Aportantes

+Lanzamiento de ADH mediante el auspicio

Recordación

Porcentaje

de marcas exclusivas

+Implementar DermaTrucks ADH en clubes

privados por invitación

Ventas Porcentaje

+Reconvertir progresivamente la cartera de

Cartera de Productos Porcentaje

cremas dermatológicos a productos

orgánicos

+Ventas virtuales con promociones

exclusivas

Ventas Porcentaje

De acuerdo a la segmentación del público objetivo se aprecia en la Tabla 55 las

actividades orientadas por tipo de cliente

Tabla 55

Segmentación de actividades por tipo de clientes

\begin{tabular}{|c|c|c|c|c|c|c|}
\hline ACTIVIDAD & $\begin{array}{l}\text { Ambos } \\
20-30\end{array}$ & $\begin{array}{l}\mathrm{M} \\
30-45\end{array}$ & $\begin{array}{l}\mathrm{H} \\
30-45\end{array}$ & $\begin{array}{l}M \\
45-60\end{array}$ & $\begin{array}{l}H \\
45-60\end{array}$ & $\begin{array}{l}\text { Ambos } \\
60-70 \\
\end{array}$ \\
\hline +Ejecutar la Campaña "Customer Day Off". & $x$ & $x$ & $x$ & $\mathrm{x}$ & $\mathrm{x}$ & $\mathrm{x}$ \\
\hline \multicolumn{7}{|l|}{ +Contar con un espacio dentro del local para clientes } \\
\hline VIP con productos exclusivos & & $\mathrm{x}$ & & $\mathrm{x}$ & & $x$ \\
\hline +Inversión selectiva de Marketing para público objeti & $x$ & $\mathrm{x}$ & $\mathrm{x}$ & $\mathrm{x}$ & $\mathrm{x}$ & $\mathrm{x}$ \\
\hline +Activaciones exclusivas en eventos especiales. & $\mathrm{x}$ & $\mathrm{x}$ & & $\mathrm{x}$ & & \\
\hline $\begin{array}{l}\text { +Auspicio eventos exclusivos con fuera de Lima c } \\
\text { productos especiales }\end{array}$ & $x$ & $\mathrm{x}$ & & $\mathrm{x}$ & & \\
\hline +Organizar eventos exclusivos con gurus del sector & & $\mathrm{x}$ & $x$ & $\mathrm{x}$ & $x$ & $x$ \\
\hline \multicolumn{7}{|l|}{ +Contar con un producto de lujo del mes para testeo } \\
\hline aplicado a las clientes de $A D H$ & $\mathrm{x}$ & $\mathrm{x}$ & $\mathrm{x}$ & $\mathrm{x}$ & $\mathrm{x}$ & $\mathrm{x}$ \\
\hline +Contar con cartera de productos exclusivos $\mathrm{ADH}$ & $\mathrm{x}$ & $\mathrm{x}$ & $\mathrm{x}$ & $\mathrm{x}$ & $\mathrm{x}$ & $\mathrm{x}$ \\
\hline +Implementar las ventas a domicilio & & & & & & $\mathrm{x}$ \\
\hline \multicolumn{7}{|l|}{ +Brindar un panel especializado de prueba de articulos } \\
\hline de belleza en el local de ventas & $\mathrm{x}$ & $\mathrm{x}$ & & $\mathrm{x}$ & & $\mathrm{x}$ \\
\hline \multicolumn{7}{|l|}{ +Desarrollar la base de clientes y la actualización } \\
\hline periódica del mismo. & $\mathrm{x}$ & $\mathrm{x}$ & $\mathrm{x}$ & $\mathrm{x}$ & $\mathrm{x}$ & $\mathrm{x}$ \\
\hline \multicolumn{7}{|l|}{$\begin{array}{l}\text { +Firmar convenios con centros mundiales de belleza } \\
\text { para el entrenamiento del personal de ADH }\end{array}$} \\
\hline \multicolumn{7}{|l|}{$\begin{array}{l}\text { + Bench Marking con Centros Mundiales de belleza } \\
\text { para la decoración del local. }\end{array}$} \\
\hline \multicolumn{7}{|l|}{ +Lanzamiento de $\mathrm{ADH}$ mediante el auspicio de marcas } \\
\hline exclusivas & $\mathrm{x}$ & $\mathrm{x}$ & $\mathrm{x}$ & $\mathrm{x}$ & $\mathrm{x}$ & $\mathrm{x}$ \\
\hline \multicolumn{7}{|l|}{ +Implementar DermaTrucks $A D H$ en clubes privados } \\
\hline por invitación & $x$ & $\mathrm{x}$ & & $\mathrm{x}$ & & $\mathrm{x}$ \\
\hline \multicolumn{7}{|l|}{ +Reconvertir progresivamente la cartera de cremas } \\
\hline dermatológicos a productos orgánicos & $x$ & & & & & $\mathrm{x}$ \\
\hline +Ventas virtuales con promociones exclusivas & $x$ & & & & & $x$ \\
\hline
\end{tabular}




\subsection{Plan de Contingencia}

Los planes de contingencia son aquellos planes que permiten establecer medidas para corregir resultados que no están funcionando de acuerdo a los objetivos trazados

\section{Tabla 56}

Planes de contingencia ADH

\begin{tabular}{|c|c|c|c|}
\hline Objetivos & Medidas Contingencia & Presupuesto & Responsable \\
\hline $\begin{array}{l}\text { Incrementar las ventas en } \\
\$ 171,423\end{array}$ & $\begin{array}{l}\text { En el mes de agosto el objetivo de } \\
\text { ventas debe estar en } 75 \% \text { : sino } \\
\text { debe analizarse el plan de acción. }\end{array}$ & $\$ 3500$ & Gerente de Tienda \\
\hline $\begin{array}{l}\text { Incrementar } \\
\text { rentabilidad en } 8 \%\end{array}$ & $\begin{array}{l}\text { En el mes de julio debe } \\
\text { proyectarse la rentabilidad a los } \\
\text { niveles esperados de } 26 \% \text {. En } \\
\text { caso contrario debe analizarse el } \\
\text { margen de los productos de ADH }\end{array}$ & $\$ 1700$ & Gerente de Marketing \\
\hline $\begin{array}{l}\text { Obtener el } \\
\text { posicionamiento de ADH } \\
\text { como "líder" en el primer } \\
\text { año de operación }\end{array}$ & $\begin{array}{l}\text { En el mes de octubre debe } \\
\text { realizarse un análisis de mercado } \\
\text { para determinar el estado del } \\
\text { mismo. Si los resultados no son } \\
\text { los esperados revisar el plan de } \\
\text { acción }\end{array}$ & $\$ 2000$ & Gerente de Marketing \\
\hline $\begin{array}{l}\text { Reconvertir la cartera de } \\
\text { cremas a productos } \\
\text { orgánicos en } 25 \%\end{array}$ & $\begin{array}{l}\text { En el mes de agosto revisar la } \\
\text { distribución de ventas. En caso no } \\
\text { se encuentren los resultados } \\
\text { esperados proyectar acciones de } \\
\text { Marketing hacia ese producto }\end{array}$ & $\$ 1500$ & Gerente de Marketing \\
\hline
\end{tabular}

Fuente: Elaboración Propia (2019

\subsection{Calendario de ejecución del plan}

En la Tabla 57 se muestra el calendario para las estrategias de producto para el primer año. 


\section{Tabla 57}

Calendario Ejecución Mix Producto Plan de Marketing primer año

\begin{tabular}{|c|c|c|c|c|c|c|c|c|c|c|c|c|}
\hline & feb & marzo & abril & mayo & junio & julio & agosto & set & oct & nov & dic & Ene-21 \\
\hline P1.1 & & $x$ & & & & & & & & & & \\
\hline P1.2 & & & $x$ & & & & & & & & & \\
\hline P1.3 & & & $x$ & & & & & & & & & \\
\hline P2.1 & $x$ & & & & & & & & & & & \\
\hline P2.2 & & $x$ & & & & & & & & & & \\
\hline P2.3 & & & $x$ & $x$ & $x$ & $x$ & $x$ & $x$ & $x$ & $x$ & $\mathrm{x}$ & $x$ \\
\hline P3.1 & $x$ & & & & & & & & & & & \\
\hline P3.2 & & $x$ & $x$ & $x$ & $x$ & $x$ & $x$ & $x$ & $x$ & $x$ & $x$ & $x$ \\
\hline P3.3 & $x$ & $\mathrm{x}$ & $x$ & $\mathrm{x}$ & & & & & & & & \\
\hline P4.1 & & & & $x$ & & & & & & & & \\
\hline P4.2 & & & & & & $x$ & & & & & & \\
\hline P4.3 & & & & & & & $\mathrm{x}$ & $\mathrm{x}$ & $\mathrm{x}$ & $x$ & $\mathrm{x}$ & $x$ \\
\hline
\end{tabular}

Elaboración Propia (2019)

En la Tabla 58 se muestra el calendario para las estrategias de precio para el primer año.

\section{Tabla 58}

Calendario Ejecución Mix Precio Plan de Marketing primer año

\begin{tabular}{lrrrrrrrrrrrrr}
\hline & feb & marzo & abril & mayo & junio & julio & agosto & set & oct & nov & dic & Ene-21 \\
\hline PX1.1 & $\mathrm{X}$ & $\mathrm{X}$ & $\mathrm{X}$ & & & & & & & & & & \\
PX1.2 & & & & $\mathrm{X}$ & $\mathrm{X}$ & $\mathrm{X}$ & $\mathrm{X}$ & $\mathrm{X}$ & $\mathrm{X}$ & $\mathrm{X}$ & $\mathrm{X}$ & $\mathrm{X}$ \\
PX1.3 & & & $\mathrm{X}$ & $\mathrm{X}$ & $\mathrm{X}$ & $\mathrm{X}$ & $\mathrm{X}$ & $\mathrm{X}$ & $\mathrm{X}$ & $\mathrm{X}$ & $\mathrm{X}$ \\
\hline
\end{tabular}

Elaboración Propia (2019)

En la Tabla 59 se muestra el calendario para las estrategias de plaza en el 2020 


\section{Tabla 59}

Calendario Ejecución Mix Plaza Plan de Marketing primer año

\begin{tabular}{|c|c|c|c|c|c|c|c|c|c|c|c|c|}
\hline & feb & marzo & abril & mayo & junio & julio & agosto & set & oct & nov & dic & Ene-21 \\
\hline D1.1 & $x$ & & & & & & & & & & & \\
\hline D1.2 & & $x$ & & & & & & & & & & \\
\hline D1.3 & & & $x$ & & & & & & & & & \\
\hline D2.1 & & $x$ & & & & & & & & & & \\
\hline D2.2 & & & $x$ & & & & & & & & & \\
\hline D3.1 & $x$ & & & & & & & & & & & \\
\hline D3.2 & & $x$ & & & & & & & & & & \\
\hline D3.3 & & & $x$ & $x$ & $x$ & $x$ & $x$ & $x$ & $\mathrm{x}$ & $x$ & $x$ & $x$ \\
\hline D4.1 & $\mathrm{x}$ & & & & & & & & & & & \\
\hline D4.2 & & $x$ & $x$ & $x$ & $x$ & & & & & & & \\
\hline D4.3 & & & & & & $x$ & $\mathrm{x}$ & $\mathrm{x}$ & $x$ & $\mathrm{x}$ & $x$ & $\mathrm{x}$ \\
\hline D5.1 & & $x$ & & & & & & & & & & \\
\hline D5.2 & & & $\mathrm{x}$ & $x$ & $x$ & $x$ & $x$ & $x$ & $\mathrm{x}$ & $x$ & $x$ & $x$ \\
\hline D6.1 & & & $x$ & & & & & & & & & \\
\hline D6.2 & & & & & & $x$ & & & & & & \\
\hline
\end{tabular}

Elaboración Propia (2019)

En la Tabla 60 se muestra el calendario para las estrategias de promoción para el primer año.

\section{Tabla 60}

Calendario Ejecución Mix Promoción y Comunicación Plan de Marketing primer año

\begin{tabular}{|c|c|c|c|c|c|c|c|c|c|c|c|c|}
\hline & feb & marzo & abril & mayo & junio & julio & agosto & & oct & nov & dic & Ene-21 \\
\hline PC1.1 & & $x$ & & & & & & & & & & \\
\hline PC1.2 & & & & $\mathrm{x}$ & & & & & & & & \\
\hline PC2.1 & $x$ & & & & & & & & & & & \\
\hline PC2.2 & & $x$ & $x$ & $x$ & $x$ & $x$ & $x$ & $\mathrm{x}$ & $\mathrm{x}$ & $x$ & $\mathrm{x}$ & $x$ \\
\hline PC3.1 & $x$ & & & & & & & & & & & \\
\hline PC3.2 & & & $x$ & & & & & & & & & \\
\hline PC4.1 & & $x$ & & & & & & & & & & \\
\hline PC4.2 & & & & & & $\mathrm{x}$ & & & & & & \\
\hline PC5.1 & & $x$ & & & & & & & & & & \\
\hline PC5.2 & & & & & $\mathrm{x}$ & & & & & & & \\
\hline PC6.1 & $x$ & & & & & & & & & & & \\
\hline PC6.2 & & & $x$ & & & & & & & & & \\
\hline PC6.3 & & & & $x$ & & & & & & & & \\
\hline
\end{tabular}

Elaboración Propia (2019) 
Tabla 61 Consolidado Calendario Anualizado de Actividades

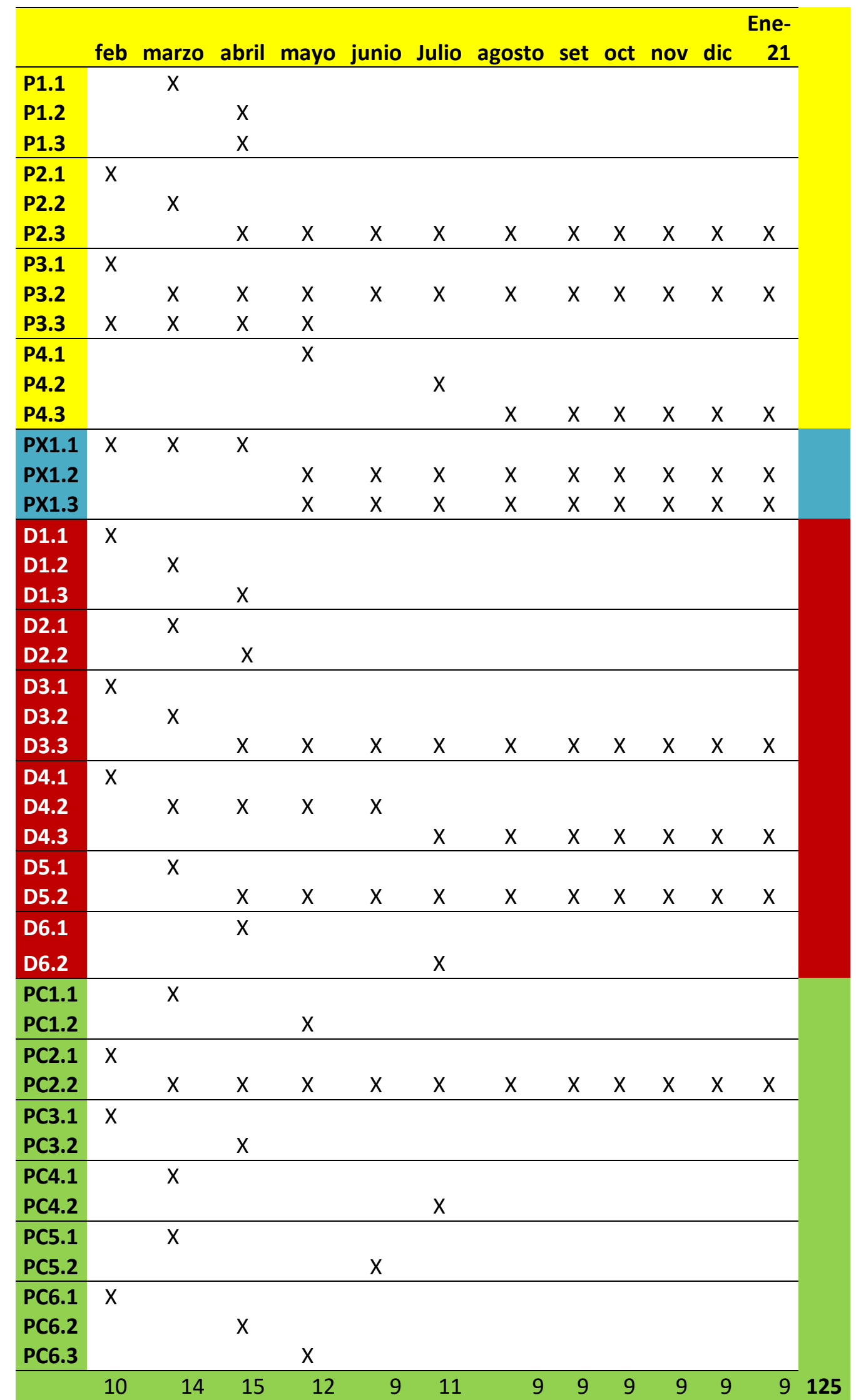




\section{CONCLUSIONES}

1. Para alcanzar el primer objetivo de incrementar las ventas en $\$ 171,423$ se considera que el plan de Marketing de $\mathrm{ADH}$ está dirigido a un público objetivo de nivel socioeconómico A que representa el $3.46 \%$ de la población de los distritos considerados de mayor ingresos en Lima, el cual está orientado a la compra de cremas, maquillaje y perfumes de lujo en un ambiente exclusivo, selecto y de roce social por lo que se debe desarrollar las estrategias de Campaña "Customer Day Off", contar con un espacio dentro del local para clientes VIP con productos exclusivos y planificar una Inversión selectiva de Marketing para el público objetivo.

2. Para alcanzar el segundo objetivo que es incrementar la rentabilidad en $8 \%$ se conoce gracias a la investigación de mercado, que el público objetivo no repara en gastos para satisfacer sus necesidades por lo que se debe desarrrollar la estrategia de contar con un producto de lujo del mes para testeo aplicado a las clientes de $A D H$ que permita mejorar la rentabilidad de la empresa.

3. Para conseguir el tercer objetivo de obtener el posicionamiento de ADH como "líder" en el primer año de operación, se considera que en el mercado peruano no existe una empresa que brinde el servicio personalizado que $\mathrm{ADH}$ ofrece, siendo esa información confirmada en la investigación de mercado desarrollada durante el 2019 por lo que las estrategias son brindar un panel especializado de prueba de artículos de belleza en el local de ventas, desarrollar la base de clientes y la actualización periódica del mismo, firmar convenios con centros mundiales de belleza para el entrenamiento del personal de ADH y desarrollar un Bench Marking con Centros Mundiales de belleza para la implementación del local.

4. Para alcanzar el cuarto objetivo de reconvertir la cartera de cremas a productos orgánicos consiguiendo que el $25 \%$ de la venta de cremas sea orgánica se considera 
que la tendencia en el mercado de belleza es regresar a lo natural por lo que las estrategias son el lanzamiento de $\mathrm{ADH}$ mediante el auspicio de marcas exclusivas, la Implementación del DermaTrucks $A D H$ en clubes privados por invitación y la Reconversión progresiva de la cartera de cremas dermatológicos a productos orgánicos 


\section{RECOMENDACIONES}

1. Implementar un plan de marketing que permita alcanzar un TIR de $29 \%$ un VAN de \$42,286 dólares y un ROI de 1.97 con una venta de \$556,017 el primer año.

2. Planificar un estudio de mercado que permita evaluar los resultados del primer año considerando la segmentación del mercado por edades planteada en este trabajo.

3. Realizar el seguimiento y control de los indicadores los primeros seis meses a fin de determinar el cumplimiento de los objetivos. 


\section{Referencias Bibliográficas}

America Salud (2018) Plan de Marketing Curso de Marketing Universidad

San Ignacio de Loyola.

América Salud (2019) Manual de Organización y Funciones

APEIM (2018) Niveles Socio Económicos 2018

Aramburu, C.,Dávila, J,Morales, P.\& Rodriguez, K (2017) Salón de belleza

móvil para mujeres de Lima Metropolitana Tesis para obtener el grado

de Maestro en Ciencias Empresariales Universidad San Ignacio de Loyola.

Arellano, R (2017) Mucho más que tener LATIR Editorial Arellano Lima.

Banco Central de Reserva del Perú( 2019) Estadísticas anuales

Caballero, J (2019) Así el millonario futuro de la cosmética Eco

Diario el País Recuperado de

https://smoda.elpais.com/belleza/asi-es-el-millonario-futuro-de-lacosmetica-eco/

Ccanahuire, D. \& Fuentes, J (2017) Innovación estratégica comercial en una empresa de cuidados de belleza y salud, 2016 tesis para obtener el título profesional de licenciado en Administración de la Universidad Santa María de Arequipa.

Chacón, C (2015) Propuesta de un plan de mercadeo para la expansión de la cadena de farmacias Santiago en la gran área metropolitana tesis para optar el grado y título de Maestría Profesional en Ventas y Mercadeo de la Universidad de Costa Rica

David, F (2013) Conceptos de Administración Estratégica 14ava Edición

ESAN (18 de junio 2019) ¿Cómo se comporta el consumidor online en Perú? Conexión Esan Recuperado https://www.esan.edu.pe/apuntes-empresariales/2019/06/como-se-comporta-elconsumidor-online-en-peru/

Fashion Network (2018) El mercado de la belleza en el Perú crecerá por 
encima de las proyecciones del año

Recuperado de https://pe.fashionnetwork.com/news/El-mercado-de-la-

belleza-en-Peru-crecera-por-encima-de-las-proyecciones-este

ano,1014232.html\#.XQpiEvmG9VE

Ferrel, O \& Hartline,M (2012) Marketing Strategy $6^{\text {th }}$ edition

Forbes (2017) Tiendas de lujo ¿Cómo son diferente?

Recuperado de https://www.forbes.com.mx/tiendas-de-lujo-como-son-diferentes/

Instituto Nacional de Estadística e Informática (2013) Censo poblacional de Hogares

Lima

Infovaticana(2019) De antibióticos a perfumes de marca de lujo

Recuperado de https://infovaticana.com/2019/03/21/de-antibioticos-aperfumes-de-marcas-de-lujo-la-nueva-farmacia-vaticana/

Kotler, P. \& Keller, K (2012) Dirección de Marketing Décimo cuarta edición Pearson Educación. Mexico.

Kotler \& Singh (2010) Strategic Marketing

Mendez, J (2017) Análisis estratégico del plan de marketing de la Botica GC Farma, en el distrito de Independencia, año 2016 tesis para optar el grado de Maestra en Administración de Negocios de la Universidad Cesar Vallejo.

Ministerio de Economía y Finanzas (2019) Plan Multianual 2019-2022

Olarte, M \& Ramirez, M (2018) Comportamiento del Consumidor del Segmento de Mujeres Benefit Seeker aplicado a la empresa Lam Cosmeticos Trabajo de grado para obtener el titulo de Ingenieras Administradoras Universidad EIA Antioquia Colombia.

Peru Retail (2017) Sector Farmacéutico crece pero a tasa más bajas en el Perú Recuperado de https://www.peru-retail.com/sector-farmaceutico-crecepero-a-tasas-mas-bajas-peru/

Pope, J (2002) Investigación de Mercado” Editorial Norma 
Porter M (2009) Estrategias Competitivas: Técnicas para el Análisis de la empresa y sus competidores. 
PromPeru (2018) Tendencias Mundiales de la Línea Cosmética y Cuidado Personal Informe Especializado Departamento de Inteligencia de Mercados PROMPERU.

Rallón (2016) Plan de Negocios Oasis SPA Campestre trabajo de investigación para optar el título de administrador en la Universidad Cooperativa de Colombia.

Santesmases, M (2012) Marketing: Conceptos y Estrategias Editorial Piramide $14^{\circ}$ Edición

SUNAT (2019) Clasificación Industrial Internacional Uniforme Recuperado de http://orientacion.sunat.gob.pe/index.php/personas menu/ruc-personas/inscripcion-al-ruc-personas/6745-03-tablas-anexas ruc-personas

Vargas, J (2014) El exclusivo club de los millonarios peruanos Recuperado de https://www.managementsociety.net/2014/06/16/el-exclusivo-club-de-losmillonarios-peruanos/ 


\section{Anexos}

\section{Anexo 1 FODA PARA OBJETIVOS}

En la Tabla 1 se muestra la ponderación de las Fortalezas, Oportunidades Debilidades y Amenazas expresadas en porcentaje de acuerdo a la evaluación interna y externa del negocio.

\section{Tabla 1}

Ponderación FODA expresadas en porcentaje para América Deluxe Health

\begin{tabular}{|c|c|c|}
\hline Fortalezas & VALOR & porcentaje \\
\hline Conocimiento del Negocio & 3 & $6 \%$ \\
\hline Experiencia en el Mercado & 2 & $4 \%$ \\
\hline Locales Propios & 2 & $4 \%$ \\
\hline Integración Vertical como Negocio & 3 & $\begin{array}{r}6 \% \\
20 \% \\
\end{array}$ \\
\hline \multicolumn{3}{|l|}{ Debilidades } \\
\hline $\begin{array}{l}\text { Ingresante en Mercado de Belleza de } \\
\text { Lujo }\end{array}$ & 2 & $4 \%$ \\
\hline $\begin{array}{l}\text { Nula Diversificación en el mercado } \\
\text { Perú }\end{array}$ & 2 & $4 \%$ \\
\hline $\begin{array}{l}\text { Requiere Fuerte Inversión en } \\
\text { Infraestructura }\end{array}$ & 3 & $6 \%$ \\
\hline $\begin{array}{l}\text { Requiere relaciones exclusivas para } \\
\text { Mkt }\end{array}$ & 2 & $4 \%$ \\
\hline & & $18 \%$ \\
\hline
\end{tabular}

\begin{tabular}{|c|c|c|}
\hline OPORTUNIDADES & VALOR & porcentaje \\
\hline $\begin{array}{l}\text { Crecimiento del mercado peruano de } \\
\text { belleza }\end{array}$ & 3 & $6 \%$ \\
\hline Globalización del mercado de belleza & 4 & $8 \%$ \\
\hline Crecimiento de mercado objetivo & 4 & $8 \%$ \\
\hline Pago justo por el servicio ofrecido & 3 & $6 \%$ \\
\hline Desarrollo de la tecnología & 3 & $\begin{array}{c}6 \% \\
34 \%\end{array}$ \\
\hline \multicolumn{3}{|l|}{ Amenazas } \\
\hline Alta Oferta Mundial de belleza de lujo & 2 & $4 \%$ \\
\hline \multirow{2}{*}{$\begin{array}{l}\text { Escasas posibilidades } \quad \text { de } \\
\text { diferenciación } \\
\text { Fuerte demanda por personal } \\
\text { especializado }\end{array}$} & 2 & $4 \%$ \\
\hline & 2 & $4 \%$ \\
\hline Selectividad del Mercado Objetivo & 3 & $6 \%$ \\
\hline \multirow[t]{2}{*}{$\begin{array}{l}\text { Inestabilidad } \\
\text { congreso }\end{array}$} & 5 & $10 \%$ \\
\hline & & $28 \%$ \\
\hline
\end{tabular}

Se observa que las fortalezas superan a las debilidades en $2 \%$ mientras que las oportunidades a las amenazas en $6 \%$ por lo que se puede concluir que existe viabilidad para el negocio.

En la Tabla 2 se aprecia la matriz FODA Cruzada por objetivos para América Deluxe Health 
Tabla 2

\section{Evaluación de la Matriz FODA Cruzada}

\begin{tabular}{|c|c|}
\hline FORTALEZA (22\%) & DEBILIDAD (20\%) \\
\hline Conocimiento del Negocio & Nuevo en el Mercado de Belleza de Lujo \\
\hline Experiencia en el Mercado & Nula Diversificación en el mercado Perú \\
\hline Locales Propios & Requiere Fuerte Imversión en infraestructura \\
\hline Integración Vertical como Negocio & Requiere relaciones exclusivas para Mut \\
\hline $\begin{array}{l}\text { Incrementar en un } 15 \% \text { anual el ingreso de las } \\
\text { ventas anuales de la Corporadion con la apertura } \\
\text { de América Deluxe Health (F1,F2.04) }\end{array}$ & $\begin{array}{l}\text { Mejorar los margenes del } 15 \% \text { al } 18 \% \text { de la } \\
\text { Corporación con el funcionamiento de America } \\
\text { Deluxe Health (D3,03) }\end{array}$ \\
\hline $\begin{array}{l}\text { Incrementar la demanda de dientes en } 1 \% \\
\text { atendiendo el nuevo segmento de dientes objetivos } \\
\text { (F3.03) }\end{array}$ & \\
\hline
\end{tabular}

Pago justo por el senvicio ofrecido

Desarrollo de la tecnologia

AMENAZA (28\%)

Alta Oferta Mundial de belleza de lujo

Incrementar el scket promedio de ventas en un

Mejorar los indices de recordación de la marca

$50 \%$ anual ( $F 4, A 1, A 4)$

en un $100 \%$ al 2022 en el mercado objetivo

(D1,A2,A4)

Escasas posibilidades de diferenciación

Fuerte demanda por personal especializado

Selectividad del Mercado Objetwo

Inestabilidad Politica disolución congreso 


\section{Anexo 2 Desarrollo de Demanda Potencial}

En la Tabla 1 se aprecia el mercado objetivo para América Deluxe Healh en Lima metropolitana

Tabla 1

Mercado Objetivo América Deluxe Health

\begin{tabular}{llll}
\hline Distrito & $\begin{array}{l}\text { Población } \\
\text { Total }\end{array}$ & nivel A & TOTAL \\
\hline MIRAFLORES & 82805 & 0.346 & \\
LAMOLINA & 166912 & & \\
SAN BORJA & 111808 & & \\
SAN ISIDRO & 55006 & & \\
SANTIAGO & DE & & \\
SURCO & 338509 & & \\
\hline TOTAL & 755040 & & 261,244
\end{tabular}

Fuente: INEI (2018) y APEIM (2019)

De dicho análisis se establece que existe una demanda potencial de 261,244 mujeres y hombre de nivel socio económico A que residen en los distritos de Miraflores, San Isidro, San Borja, Santiago de Surco y La Molina.

Para el nivel socio económico A el tipo de gasto promedio se aprecia en la Tabla 2.

Tabla 2

Tipo de Gasto Promedio Nivel Socio Económico A

\begin{tabular}{llll}
\hline Tipo de Gasto & Inversión & & Porcentaje \\
\hline Alimento & $\$$ & 449.71 & $19 \%$ \\
Vestido y Calzado & $\$$ & 110.88 & $5 \%$ \\
Vivienda electricidad & $\$$ & 346.18 & $15 \%$ \\
Muebles y enseres & $\$$ & 260.29 & $11 \%$ \\
Cuidado y conservación de la salud & & & $8 \%$ \\
& $\$$ & 197.35 & \\
Transportes y comunicaciones & & & $17 \%$ \\
Esparcimiento & $\$$ & 399.41 & \\
Otros bienes y servicios & $\$$ & 419.71 & $18 \%$ \\
\hline Total Gastos & $\$$ & 142.35 & $6 \%$ \\
\hline
\end{tabular}

Fuente: APEIM (2018) 
Anexo 3 Justificación Objetivo 1

\begin{tabular}{lllll}
\hline Objetivo 1 Corporación & Objetivo 1 American Deluxe Health \\
\hline En el 2020 obtener ventas por 6,720,067 & Obtener ventas por & 556,017 & dólares \\
dólares americanos & americanos & & & \\
& & & & \\
& & & &
\end{tabular}

En la Tabla 1 se aprecia la evolución de ventas de la corporación

Tabla 1

Evolución de ventas de la Corporación

\begin{tabular}{|c|c|c|}
\hline AÑNO & VENTAS (\$) & INCREMENTO \\
\hline 2014 & $\$ \quad 5,342,682$ & \\
\hline 2015 & $5,863,539$ & 1.097489777 \\
\hline 2016 & $6,323,866$ & 1.078506563 \\
\hline 2017 & $4,742,803$ & 0.7499848 \\
\hline 2018 & $3,706,782$ & 0.781559312 \\
\hline 2019 & $5,585,056$ & 1.573718 \\
\hline 2020 & $6,720,067$ & 1.200000 \\
\hline
\end{tabular}

Para determinar el nivel de ventas de American Deluxe Health (ADH) se muestra los resultados esperados en la Tabla 1

Tabla 1 Resultados Esperados Corporación 2020

\begin{tabular}{llll}
\hline Negocio & Margen & Nuevos Clientes & Nuevos Productos \\
\hline Corporación & $18 \%$ & 0 & 0 \\
\hline ADH & $26 \%$ & 5041 & 556,017 \\
\hline
\end{tabular}

La estrategia desarrollada para la consecución de los objetivos de venta es de diferenciación apelando al espíritu nacional innovador del producto, la calidad de atención de los consultores internacionales y los productos importados exclusivos para el negocio que ,junto a la cercanía de los locales permitirán crear la diferencia. 
* Se espera que los clientes de la corporación y la venta de productos sea la misma para el 2020 por lo que el margen incremental lo determina ADH.

En la Tabla 2 se muestra como el FODA apoya para que los objetivos de marketing se cumplan para el 2020 tal como se muestra en el anexo 1

Tabla 2 Objetivos de Marketing Alineados al FODA

\begin{tabular}{|c|c|c|}
\hline & FORTALEZA $(24 \%)$ & DEBILIDAD $(21 \%)$ \\
\hline & Conocimiento del Negocio & Nuevo en el Mercado de Belleza de Lujo \\
\hline & Experiencia en el Mercado & Nula Diversificación en el mercado Perú \\
\hline & Locales Propios & Requiere Fuerte Inversión en Infraestructura \\
\hline & Integración Vertical como Negocio & Requiere relaciones exclusivas para Mkt \\
\hline \multicolumn{3}{|l|}{ OPORTUNIDAD (29\%) } \\
\hline Crecimiento del mercado peruano de belleza & $\begin{array}{l}\text { Incrementar en un } 20 \% \text { anual el ingreso de las } \\
\text { ventas anuales de la Corporación con la apertura } \\
\text { de América Deluxe Health ( } \mathrm{F} 1, \mathrm{~F} 2,04)\end{array}$ & $\begin{array}{l}\text { Mejorar las utilidades de la Corporación al } 20 \% \\
\text { con el funcionamiento de America Deluxe Health } \\
\text { (D3,03) }\end{array}$ \\
\hline Globalización del mercado de belleza & $\begin{array}{l}\text { Incrementar la demanda de clientes en } 1 \% \\
\text { atendiendo el nuevo segmento de clientes objetivos } \\
\text { (F3.03) }\end{array}$ & \\
\hline \multicolumn{3}{|l|}{ Crecimiento de mercado objetivo } \\
\hline \multicolumn{3}{|l|}{ Pago justo por el servicio ofrecido } \\
\hline \multicolumn{3}{|l|}{ AMENAZA $(26 \%)$} \\
\hline Alta Oferta Mundial de belleza de lujo & $\begin{array}{l}\text { Incrementar el ticket promedio de ventas en un } \\
50 \% \text { anual ( } \mathrm{F} 4, \mathrm{~A} 1, \mathrm{~A} 4)\end{array}$ & $\begin{array}{l}\text { Mejorar los indices de recordación de la marca } \\
\text { en un } 100 \% \text { al } 2022 \text { en el mercado objetivo } \\
\text { (D1,A2,A4) }\end{array}$ \\
\hline \multicolumn{3}{|l|}{ Escasas posibilidades de diferenciación } \\
\hline \multicolumn{3}{|l|}{ Fuerte demanda por personal especializado } \\
\hline \multicolumn{3}{|l|}{ Selectividad del Mercado Objetivo } \\
\hline Inestabilidad Política disolución congreso & & \\
\hline
\end{tabular}

Por tanto las ventas de $\mathrm{ADH}$ se calculan de la siguiente manera:

VENTAS ADH = Ventas Corporacion2020-Ventas corporación2019

Ventas ADH: $\$ \mathbf{5 5 6 , 0 1 7}$ 


\section{Anexo 4 Justificación Objetivo 2}

\section{Objetivo 2 Corporación}

Objetivo 2 America Deluxe Healt

Mejorar las utilidades de la Corporación Obtener un margen del 26\% que permita de $15 \%$ al $18 \%$ con el funcionamiento de una utilidad de $18 \%$ a la corporación América Deluxe Health.

En la figura 1 se aprecia el porcentaje de las utilidades de la Corporación

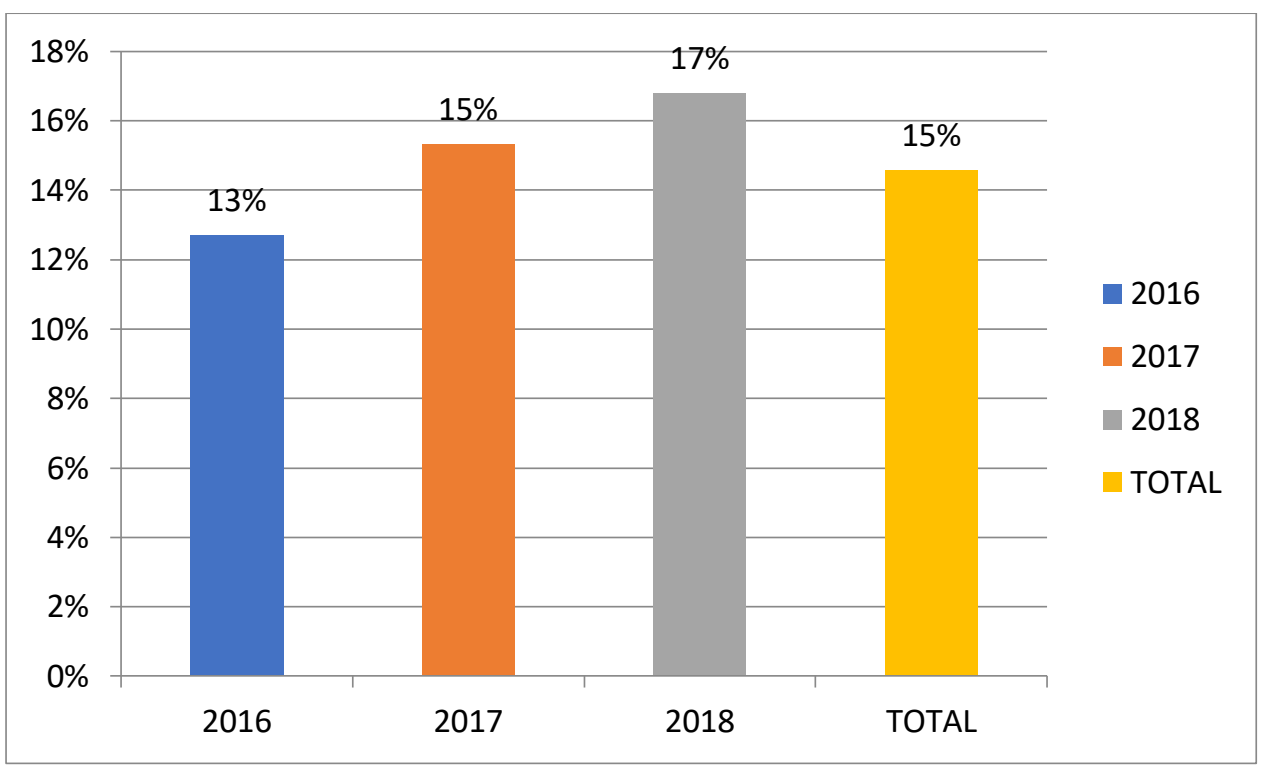

\section{Figura 1}

Porcentaje de las Utilidades de la Corporación

De acuerdo a Santesmases (2012) para obtener el 18\% de utilidades totales en la Corporación para el 2020 se calcula mediante una regla de tres donde:

0.18 es el margen de utilidad esperado

0.15 es el margen de utilidad del 2019

VT son las ventas totales de la corporación para el 2020

VTC son las ventas totales de la Corporación el 2019

VTADH son las ventas esperadas 2020 del American Deluxe Health 
$\% \mathrm{ADH}=\underline{0.18 \mathrm{VT} 2020-(0.15) \mathrm{VTC}}$

(VTADH)

Reemplazando los datos se obtiene el \% de utilidades de America Deluxe Health que es $26 \%$. 
Anexo 5 Sueldos y salarios personal de ADH

\begin{tabular}{|c|c|c|c|c|c|c|c|c|c|}
\hline & Administrador & Dermatologos & Comunity Manager & Asistenterendedores & Recepcionista & Anfitrionas & Vigilante & Deliverys & total \\
\hline $\begin{array}{l}\text { Número de } \\
\text { colaboradores }\end{array}$ & 1 & 2 & 1 & 4 & 1 & 2 & 2 & 2 & 15 \\
\hline Sueldo básico & $\$ 1,500$ & $\$ 900$ & $\$ 600$ & $\$ 500$ & $\$ 400$ & $\$ 350$ & $\$ 280$ & $\$ 280$ & \\
\hline Gratificación & $\$ 250$ & $\$ 150$ & $\$ 100$ & $\$ 83$ & $\$ 67$ & $\$ 58$ & $\$ 47$ & $\$ 47$ & \\
\hline Sueldo promedio & $\$ 1,750$ & $\$ 1,050$ & $\$ 700$ & $\$ 583$ & $\$ 467$ & $\$ 408$ & $\$ 327$ & $\$ 327$ & \\
\hline CTS & $\$ 146$ & $\$ 88$ & $\$ 58$ & $\$ 49$ & $\$ 39$ & $\$ 34$ & $\$ 27$ & $\$ 27$ & \\
\hline ESSALUD & $\$ 158$ & $\$ 95$ & $\$ 63$ & $\$ 53$ & $\$ 42$ & $\$ 37$ & $\$ 29$ & $\$ 29$ & \\
\hline Vacaciones & $\$ 125$ & $\$ 75$ & $\$ 50$ & $\$ 42$ & $\$ 33$ & $\$ 29$ & $\$ 23$ & $\$ 23$ & \\
\hline Seguro & $\$ 18$ & $\$ 11$ & $\$ 7$ & $\$ 6$ & $\$ 5$ & $\$ 4$ & $\$ 3$ & $\$ 3$ & \\
\hline Total mensual & $\$ 2,196$ & $\$ 1,318$ & $\$ 878$ & $\$ 732$ & $\$ 586$ & $\$ 512$ & $\$ 410$ & $\$ 410$ & $\$ 7,041$ \\
\hline Total anual & $\$ 26,350$ & $\$ 31,620$ & $\$ 10,540$ & $\$ 35,133$ & $\$ 7,027$ & $\$ 12,297$ & $\$ 9,837$ & $\$ 9,837$ & $\$ 142,641$ \\
\hline
\end{tabular}




\section{Anexo 6 Mapa de Operaciones Personal ADH por horario de Trabajo}

\begin{tabular}{|c|c|c|c|c|c|c|c|c|c|c|c|c|}
\hline PERSONAL & $10 \mathrm{~A} 11$ & $11 \mathrm{~A} 12$ & $12 \mathrm{~A} 1$ & $1 \mathrm{~A} 2 \mathrm{PM}$ & 2A 3 PM & $3 \mathrm{~A} 4 \mathrm{PM}$ & $4 \mathrm{~A} 5 \mathrm{PM} 5$ & $5 \mathrm{~A} 6 \mathrm{PM}$ & 6A 7 PM & $7 \mathrm{~A} 8 \mathrm{PM}$ & 8A9 PM & $9 \mathrm{~A} 10 \mathrm{PM}$ \\
\hline Administrador & & & 1 & 1 & 1 & 1 & 1 & 1 & 1 & 1 & 1 & 1 \\
\hline Dermatologos & 1 & 1 & 1 & 1 & 1 & 1 & 1 & 1 & 2 & 2 & 2 & 2 \\
\hline Comunity Manager & & 1 & 1 & 1 & 1 & 1 & 1 & 1 & 1 & 1 & & \\
\hline Asistenterendedores & 2 & 2 & 2 & 2 & 2 & 2 & 2 & 2 & 4 & 4 & 4 & 4 \\
\hline Recepcionista & 1 & 1 & 1 & 1 & 1 & 1 & 1 & 1 & 2 & 2 & 2 & 1 \\
\hline Anfitrionas & 1 & 1 & 1 & 1 & 2 & 2 & 2 & 2 & 2 & 2 & 1 & 1 \\
\hline Vigilante & 1 & 1 & 1 & 1 & 1 & 1 & 1 & 1 & 1 & 1 & 1 & 1 \\
\hline Deliverys & 1 & 1 & 1 & 2 & 2 & 2 & 2 & 2 & 2 & 1 & 1 & 1 \\
\hline TOTAL & 7 & 8 & 9 & 10 & 11 & 11 & 11 & 11 & 15 & 14 & 12 & 11 \\
\hline
\end{tabular}


Anexo 7 Guía de Entrevistas en Profundidad

Entrevista en Profundidad a Giovana Perez Cerdeña Químico Farmaceutico de America Salud

\section{FICHA TECNICA}

Técnica

Instrumento

Muestra

Objetivos

Entrevistador

Lugar

Fecha y Hora

Duración
Entrevista en Profundidad

Guía de entrevista

Cualitativa

- Obtener información sobre el público objetivo

- Conocer cuáles son los productos más buscados por el público objetivo

- Obtener información sobre factores críticos de éxito del negocio

- Conocer la competencia y el mercado.

- Averiguar quiénes son los proveedores más importantes en el sector

Natalie Salas

Oficinas del Experto

Miércoles 23 de octubre 2019

30 minutos

\section{FICHA DEL ENTREVISTADO}

Nombre

Edad

Nacionalidad

Ocupación

Profesión
Giovana Pérez Cerdeña

45

Peruana

Química farmacéutica

Administrador 
OBJETIVO

Obtener información sobre el público objetivo

Conocer cuáles son los productos más buscados por el público objetivo

Obtener información sobre factores críticos de éxito del negocio

Conocer la competencia y el mercado.

Averiguar quiénes son los proveedores más importantes en el sector
CUESTIONARIO A PROFUNDIDAD

1. ¿Cuál considera es el público objetivo de los servicios de salud de lujo? Por que ?

2. ¿Cuáles son las características más saltantes de su cliente? Por qué ?

3. ¿Qué servicios orientados a la salud son los que buscan sus clientes en el negocio? Por qué ?

4. ¿Cuáles son los principales productos/servicios con los que atiende a su público selecto? Por qué ?

5. ¿Cómo es el proceso de atención a su público objetivo en salud exclusiva? Por qué ?

6. Qué es lo que más valoran sus clientes? Por qué ?

7. ¿Qué atributos considera importantes para una boutique de salud y lujo exclusiva en Lima? Por qué ?

8. ¿Cuánto personal requiere para atender un cliente Nivel A? Por qué ?

9. ¿Cómo avizora el futuro del negocio de salud de lujo en el mercado limeño? Por qué?

10. ¿Cuáles deberían ser las características del negocio salud de lujo para ser atractivo? Por qué?

11. ¿Considera que tiene competencia? Si la tiene ¿cuál sería?

12. ¿Cuál es el ticket promedio de venta público objetivo en este rubro? Por qué?

13. ¿Quiénes son sus proveedores más importantes? ¿Por qué ?

14. Cuáles son sus principales características? Por qué ?

15. Algún comentario adicional que nos quiera hacer?

\section{Entrevista en Profundidad a la Administradora de Victorias}


Venta de Servicios dermatológicos exclusivos de lujo en Lima

\section{FICHA TECNICA}

Técnica

Instrumento

Muestra

Objetivos

Entrevistador

Lugar

Fecha y Hora

Duración

\section{Entrevista en Profundidad}

Guía de entrevista

Cualitativa

- Obtener información sobre el público objetivo

- Conocer cuáles son los productos más buscados por el público objetivo

- Obtener información sobre factores críticos de éxito del negocio

- Conocer la competencia y el mercado. Averiguar quiénes son los proveedores más importantes en el sector

Natalie Salas

Local del negocio

Lunes 21de octubre $18.00 \mathrm{pm}$

Dos horas

\section{FICHA DEL ENTREVISTADO}

Nombre

Edad

Nacionalidad

Ocupación

Profesión

Reseña Profesional

\section{Catalina Gutierrez}

31

Peruana

Administradora Victorias

Administrador

Administradora con experiencia de diez años en tiendas de lujo 
Obtener información sobre el público objetivo

Conocer cuáles son los productos más buscados por el público objetivo
1. ¿Cuál considera es el público objetivo de sus servicios? Por que?

2. ¿Cuáles son las características más saltantes de sus clientes? Por que?

3. ¿Qué servicios orientados al cuidado de la piel son los que buscan sus clientes en el negocio? Por que ?

4. ¿Cuáles son las principales atenciones con los que atiende a su público selecto? Por que $?$

5. Dónde compran las cremas? Por que?

Obtener información sobre factores críticos de éxito del negocio

6. ¿Cómo es el proceso de atención a su público objetivo en belleza exclusiva? Por que?

7. Qué es lo que más valoran sus clientes? Por que?

8. ¿Qué atributos considera importantes para una boutique de belleza y lujo exclusiva en Lima? Por que?

9. ¿Cuánto personal requiere para atender un cliente Nivel A? Por que ?

10. ¿Cómo avizora el futuro del negocio de belleza/salud de lujo en el mercado limeño? Por que ?

11. ¿Cuáles deberían ser las características del negocio belleza/salud de lujo para ser atractivo? Por que ?

Conocer la competencia y el 12. ¿Considera que tiene competencia? Si la mercado. tiene Cuál sería? Por que?

13. ¿Cuál es el ticket promedio de venta público objetivo en este rubro? Por que?

Averiguar quiénes son los proveedores más importantes en el sector

14. ¿Quiénes son sus proveedores más importantes? Por que?

15. Cuáles son sus principales características? Por que?

16. Algún comentario adicional que nos quiera hacer?

Entrevista a Tania Elsa Flores Morante Empresaria nivel A en Lima 
FICHA TECNICA

Técnica

Instrumento

Muestra

Objetivos

Entrevistador

Lugar

Fecha y Hora

Duración

\section{Entrevista en Profundidad}

Guía de entrevista

Cualitativa

- Obtener información sobre el público objetivo en Lima

- Obtener información sobre factores críticos de éxito del negocio

- Encontrar que servicios son claves para el público objetivo

- Evaluar la propuesta inicial de valor para el negocio

Natalie Salas

Residencia de la entrevistada

Jueves 24 de octubre- 16.00 pm

Dos Horas

\section{FICHA DEL ENTREVISTADO}

Nombre

Edad

Nacionalidad

Ocupación

Profesión

Reseña Profesional
Tania Elsa Flores Morante

52 años

Peruana

Directora en la Marina de Guerra del Perú

Licenciada en Educación

Master y Doctorado

\section{GUIA DE ENTREVISTA}

Obtener información sobre el 1. ¿Qué servicios orientados a la salud/ belleza público objetivo en Lima son los que buscas? Por qué ? 
2. ¿Cuáles son las marcas dermatológicas y de belleza que prefieres? Por qué ?

3. ¿Cuáles son las marcas que utilizas?

4. ¿Dónde compran sus cremas dermatológicas? Por qué?

5. ¿Qué factores valoran de dicho establecimiento para comprar allí? Por qué ?

6. ¿Cuánto inviertes en promedio por visita en el centro de salud para adquirir los productos? Por qué ?

7. ¿Cada cuánto tiempo asistes a un centro de salud? Por qué ?

Obtener información sobre factores críticos de éxito del negocio

Encontrar que servicios son claves para el público objetivo
8. Como ve la tendencia en el cuidado de la piel? Por qué ?

9. ¿Cuáles deberían ser las características del establecimiento de lujo para que sea atractivo? Por qué ?

10. ¿Cuáles son los principales productos/servicios que usted utiliza en un establecimiento de cuidado de la belleza y la piel? Por qué ?

11. ¿Con qué frecuencia asiste a un tratamiento de piel y/o belleza de lujo exclusivo? Por qué ?

12. ¿Qué atributos considera importantes para una boutique de salud de lujo exclusiva en Lima? Por qué ?

13. ¿Cuánto personal le gustaría que la atienda? Por qué ?

14. Qué opina de la siguiente propuesta:

Somos un centro exclusivo de salud $y$ belleza personalizada que brinda una alternativa para la generación de bienestar del cuerpo y la mente de las usuarias mediante productos dermatológicos y de belleza exclusivos en un solo lugar de Lima Metropolitana

15. Algo adicional que quiera aportar 


\section{Entrevista en Profundidad al Gerente de Logística de América Salud}

\section{FICHA TECNICA}

Técnica

Instrumento

Muestra

Objetivos

Entrevistador

Lugar

Fecha y Hora

Duración

\section{Entrevista en Profundidad}

Guía de entrevista

Cualitativa

- Conocer los procesos y tiempos de importación de artículos de belleza y salud de lujo

- Conocer los precios y márgenes de los productos de belleza y salud de lujo.

- Conocer la distribución y logística de los productos de lujo de belleza y salud.

Natalie Salas

Oficina Logística América Salud

Viernes 25 de octubre- 10.00 am

30 minutos

\section{FICHA DEL ENTREVISTADO}

Nombre

Edad

Nacionalidad

Ocupación

Profesión

Reseña Profesional
Juan Gonzales

52

Peruana

Gerente de Logística

Ingeniero

Licenciado en Logistica

\section{GUIA DE ENTREVISTA}


- Conocer los procesos y tiempos de importación de artículos de belleza y salud de lujo

- Conocer los productos, precios y márgenes de los productos de belleza y salud de lujo.

- Conocer la distribución y logística de los productos de lujo de belleza y salud.

Evaluar la factibilidad del negocio
1. ¿Qué servicios orientados a la salud/ belleza son los que provee? ¿Por qué?

2. ¿Cuáles son los procesos que realiza para importar productos de lujo de belleza /salud exclusiva? ¿Por qué?

3. ¿Cuánto personal labora en el rubro?

4. Cuanto tiempo demora importar productos exclusivos?

5. ¿Cuáles son los productos de lujo de belleza y salud que importa con mayor frecuencia?

6. ¿Qué margen de precios son los que maneja en este negocio?

7. ¿Cuál es el margen que se fija para estos productos?

8. ¿Quiénes son sus proveedores más importantes?

9. ¿Cómo elige a sus proveedores de belleza/servicio?

10. ¿Cómo distribuye sus productos en los negocios minoristas?

11. ¿Qué es lo que más valoran sus clientes en el servicio de distribución?

12. ¿Cómo avizora el futuro del negocio de belleza/salud de lujo en el mercado limeño?

13. ¿Qué atributos considera importantes para un centro de salud/ belleza de lujo exclusiva en Lima? 


\section{Anexo 8 Distribución del Focus}

Se realizaron cuatro focus entre los días 23 al 30 de octubre del año 2019 en San Isidro

En la tabla 1 se muestra la distribución de los participantes.

Tabla 1

Distribución de los Focus

\begin{tabular}{llllll}
\hline Focus & Fecha & Cantidad & Hombres & Mujeres & $\begin{array}{l}\text { Promedio } \\
\text { Edad }\end{array}$ \\
\hline 1 & 23 octubre & 8 & 4 & 4 & 30 \\
2 & 25 octubre & 8 & 4 & 4 & 40 \\
3 & 26 octubre & 8 & 4 & 4 & 45 \\
4 & 30 octubre & 8 & 4 & 4 & 35 \\
\hline
\end{tabular}




\section{Filtros Selección del Focus}

\section{FILTRO 1: NIVEL DE INGRESO}

Más de 13.105 soles mensuales ( )

Menos de 13,105 soles mensuales ( )

Si responde menos de 13,105 soles finaliza el focus

\section{FILTRO 2 : COMPORTAMIENTO DE SERVICIOS}

Utiliza Usted servicios exclusivos de:

a) Peluquería /Servicio de belleza

b) Salud

c) Compra de productos exclusivos

d) No utilizo ningún servicio

En caso la respuesta sea (d), no puede ser seleccionada

Datos de los participantes

Nombre

Apellido

Edad

Contacto

Ciudad

Tipo de prospecto

Guía de Pautas para el Focus Group

\section{Presentación}


Buenos gracias por haber aceptado nuestra invitación al focus group,

mi nombre es y soy alumna de USIL, que está preparando su tesis para graduarse.

Este Focus group tiene como objetivo conocer las percepciones en torno a la implementación de una super botica exclusiva y personalizada con el fin de detectar oportunidades de mejora y fortalecer los aspectos necesarios que impulsen a ofrecer un servicio exclusivo y personalizado

La reunión tendrá una duración aproximada de 40 a 60 minutos y será grabada con fines de recopilación de información. Por lo anterior, no se preocupen ya que dicho material sólo será utilizado por el equipo y lo que ustedes opinen dentro de esta sala no será transmitido a terceros. Todo lo que digan es importante. Díganlo cuando quieran, Las opiniones más sencillas, que quizá consideren demasiado simples o poco interesantes, a veces suelen ser las más importantes.

\section{Frase de Presentación}

Buenos gracias por haber aceptado nuestra invitación al focus group, mi nombre es y soy alumna de USIL, que está preparando su tesis para graduarse.

Este Focus group tiene como objetivo conocer las percepciones en torno a la implementación de un retail que ofrezca productos Premium dermatológicos con el fin de detectar oportunidades de mejora y fortalecer los aspectos necesarios que impulsen a ofrecer un servicio exclusivo y personalizado

La reunión tendrá una duración aproximada de 40 minutos y será grabada con fines de recopilación de información. Por lo anterior, no se preocupen ya que dicho material sólo será utilizado por el equipo y lo que ustedes opinen dentro de esta sala no será transmitido a terceros. Todo lo que digan es importante. Díganlo cuando quieran, Las opiniones más sencillas, que quizá consideren demasiado simples o poco interesantes, a veces suelen ser las más importantes.

Siéntanse en la libertad de discutir y defender sus ideas con confianza. No hay respuestas buenas, ni respuestas malas ya que todas permitirán definir las características del negocio.

\section{CALENTAMIENTO}


Tenemos cinco minutos para conocernos. Vamos a presentarnos mi nombre es y soy moderadora de este focus. Inicia por la derecha hasta finalizar con todas. Luego se le pregunta donde ha pasado vacaciones y si fue con la familia y si es posible el lugar de residencia.

\section{CAPITULO 1 EVALUAR LAS CARACTERISTICAS DEL NEGOCIO}

Ahora vamos a conversar sobre las características de negocios

1. ¿Qué productos de belleza/salud exclusiva utiliza?

2. ¿Dónde compra dichos productos en el Perú?

3. ¿Qué productos dermatológicos utiliza?

4. ¿Prefiere alguna marca en especial?

5. ¿Qué perfumes utiliza?

6. ¿Cuál fue su experiencia en dichos locales?

7. ¿Con que frecuencia compra productos de salud /belleza?

8. ¿Por qué prefiere comprar en dicho local?

9. ¿Qué es lo que más valoran del establecimiento donde compran?,

10. ¿Consideras que el servicio que te brindan es personalizado? ¿Porque?

\section{OBJETIVO 2 ESTABLECER LA COMPRENSION DE LA IDEA}

Ahora, les voy a mostrar la foto de la idea para que conversemos sobre ella. (MOSTRAR LA FOTO DE LA IDEA DEL NEGOCIO CON LOS PRODUCTOS, FOTOS DEL LOCAL, EL SERVICIO A ATENDER, EL ESTACIONAMIENTO DEL LOCAL, MENCIONAR EL NOMBRE Y MOSTRAR EL LOGO DEL NEGOCIO)

¿Qué les pareció la idea que les acabamos de mostrar?

MODERADOR: RECOGER PAPELES Y QUE EXPLIQUE LOS MOTIVOS DE SU RESPUESTA

11. ¿Qué es lo que entienden del concepto de la idea

12. ¿Qué tanto le agrada o no esta idea presentada? ¿Por qué?

13. ¿Qué ventajas y/o desventajas dirían que tiene esta idea? ¿Por qué?

14. ¿Qué es lo que más valoran de la idea?

15. ¿Qué es lo que menos valoran de la idea? 
Si no se ha mencionado espontáneamente, indagar porque:

16. En general, ¿cómo imaginan que sería el servicio ideal del lugar?

17. ¿Qué piensan del nombre?

18. ¿Qué piensan del logo?

\section{OBJETIVO 3 MESURAR LA IDEA DE NEGOCIO}

19. ¿Qué servicios /productos exclusivos debería tener este servicio para que usted lo prefiera?

20. ¿Qué productos exclusivos le gustaría encontrar?

21. ¿Cuál es el precio que estaría dispuesto a pagar?

22. ¿Qué medio de pago utilizaría para cancelar los productos premium?

23. ¿Le gustaría participar en activaciones y/o campañas exclusivas?

24. Si la respuesta es si ¿Cómo le gustaría ser invitada?

25. ¿Cree usted que esta propuesta puede tener fines de responsabilidad social? Cómo?

26. ¿Entre Miraflores y San Isidro dónde debe estar ubicado el local para que usted lo utilice?

\section{OBJETIVO 4 VALIDAR LA PROPUESTA DE NEGOCIO}

27. ¿Qué opina de esta propuesta de negocio?

Somos un centro de salud y belleza exclusiva personalizada que brinda una alternativa para la generación de bienestar del cuerpo del usuario mediante cremas, maquillajes y colonias exclusivas en un solo lugar de Lima Metropolitana

28. ¿Cuáles cree usted deben ser los principales diferenciadores de este servicio para que tenga éxito en el mercado?

29. En general, ¿saben si otros lugares tienen estas características?, ¿cuál?, ¿dónde?

30. ¿Qué otra cosa le gustaría encontrar en el local?

Para terminar, ¿habría algo que cambiarían, eliminarían o añadirían?, ¿qué cosa?, ¿por qué?

Muchas gracias por su tiempo. Agradecemos sus respuestas que permitirán la cristalización del proyecto. 


\section{Anexo 10 Encuesta ADH}

\section{Frase de Presentación}

Buenos días/tardes

Agradecemos su apoyo para el desarrollo de un estudio para la implementación de una boutique de venta de artículos de belleza exclusivos y de lujo en la ciudad de Lima orientado a una persona exclusiva, que siempre busca lo mejor para su salud y su cuerpo en un lugar privilegiado

La información que nos brinde, será utilizada para fines académicos, siendo nuestro principal interés conocer su opinión. Agradeceremos su disponibilidad de tiempo.

\section{PREGUNTAS ENCUESTA}

\section{1) Distrito de residencia}
a) Miraflores
b) San Isidro
c) Surco
d) San Borja
e) La Molina
f) Otro

2) ¿Cuáles son sus ingresos aproximados al mes?

a) 13,105 soles a 17,000 soles ( de $\$ 3854$ a $\$ 5000$ )

b) 17,000 a 27,200 soles (desde $\$ 5000$ a $\$ 8000$ )

c) 27,200 a 40,800 soles (desde $\$ 8000$ a $\$ 12000$ )

d) Más de 40,800 soles (Más de \$12,000)

\section{e) PREGUNTAS DE FONDO}

3. ¿Qué productos de lujo son los que adquiere en tiendas exclusivas
a) Dermatológicos
b) Perfumes y colonias
c) Maquillajes
d) Aditivos/Naturales
e) Otros

4.¿Qué marca prefiere de cremas dermatológicas?
a) Clinique
b) Isdn
c) Estee Lauder 

d) Cetaphil
e) Eucerin
f) Chanel
g) Bioderma
h) Guerbin
i) Dior
j) $3 \mathrm{Lab}$
k) Orlane
1) La Roche Posay
m) Otras especificar

5.¿Que marca prefiere de maquillaje dermatológico?
a) Chanel
b) Dior
c) Estee Lauder
d) MAC
e) Clinique
f) Lositam
g) Otras especificar
a) Chanel
b) Carolina Herrera
c) Eau d Hadrien
d) Imperial Majesty
e) Dolce Gabanna
f) Ninna Ricci
g) Bulgary
h) Otros especificar

3 Que marca prefiere de perfumes/colonias?

7.¿Cada cuánto tiempo compra productos dermatológicos/belleza de lujo?
a) Semanalmente
b) Quincenalmente
c) Mensualmente
d) Bimensualmente
e) otros especificar

8.¿Cuánto invierte en una boutique de lujo en productos dermatológicos y de belleza por visita?

a) Menos de 1000 soles (Menos de \$294)

b) Entre 1001 y 2000 soles (Entre \$294 y \$588)

c) Entre 2001 y 3500 soles (Entre $\$ 588$ y $\$ 1030$ )

c) Más de 3500 soles (Mas de \$1030)

9.¿Cuál es el factor más importante por los que adquiere productos dermatológicos de lujo? 

a) Variedad de promociones
b) Profesionalismo del proveedor
c) Confianza en el servicio
d) Diferenciación de los productos
e) Ubicación del local
f) Precio
g) Marcas Exclusivas
h) Calidad
i) Otros especificar

10.¿Cómo se entera del servicio de venta de productos de lujo dermatológicos ?
a) Mediante Internet
b) Mediante Prensa Escrita
c) Mediante Radio
d) Mediante Contactos (Boca Oreja)
e) Mediante Televisión
f) otros especificar

11.¿Cuánto personal le gustaría que le oriente para adquirir productos dermatológicos?
a) Uno
b) Dos
c) Tres
d) Mas de tres

12. Enumere del 1 al 5 los factores que determinan la elección de un local para compra de producto (Siendo 5 el más importante y no se puede repetir la calificación)
a) Variedad y novedad del servicio
b) Exclusividad del servicio
c) Precio
d) Ubicación y accesibilidad del local
e) Calidad de los productos

13. ¿Dónde preferiría que funcionara el local?

a) Miraflores

b) San isidro

c) Otros especificar

14.De acuerdo con el siguiente concepto

Somos una farmacia exclusiva personalizada que brinda una alternativa para la generación de bienestar del cuerpo del usuario mediante productos exclusivos médicos y de belleza en un solo lugar de Lima Metropolitana

Compraría usted en este lugar productos de lujo ? 

a) Definitivamente compraría
b) Probablemente compraría
c) Podría o no comprarlo
d) Probablemente no lo compraría
e) Definitivamente no lo compraría

\section{5.¿Cómo le gustaría pagar el servicio?}
a) Efectivo
b) Tarjeta de Crédito/Debito
c) Deposito en Cuenta
d) Cheque

16.¿Qué tipo de promoción le gustaría recibir?
a) Servicios Adicionales gratuitos
b) Transporte Gratuito al local
c) Servicio personalizado a domicilio
d) Precios especiales por la compra de productos adicionales
e) Viajes y/o retiros de belleza
f) Participación en activaciones exclusivas

\section{7.¿Cómo le gustaría enterarse del servicio de America Deluxe Health}
a) Mediante Internet
b) Mediante Prensa Escrita
c) Mediante Radio
d) Mediante Contactos (Boca Oreja)
e) Mediante Televisión
f) Mediante invitación
g) Otros Especificar

¡Muchas gracias por su valioso tiempo! La información brindada es confidencial y será de gran ayuda para el proyecto. 


\section{Anexo 11 Distribución de Productos y Márgenes de venta ADH}

Anexo 13 A Cremas ADH

\begin{tabular}{|c|c|c|c|c|c|c|c|}
\hline \multirow{2}{*}{$\begin{array}{l}\text { Cremas } \\
\text { Clinique }\end{array}$} & \multirow[t]{2}{*}{ Presentación } & \multicolumn{2}{|c|}{ costo mayor } & \multicolumn{2}{|c|}{ Precio venta } & \multirow{2}{*}{$\frac{\text { Margen }}{260 \%}$} & \multirow{2}{*}{$\begin{array}{l}\text { Participación } \\
\text { en ventas }\end{array}$} \\
\hline & & $\$$ & 25 & $\$$ & 90 & & \\
\hline Isdn & \multirow{11}{*}{ cremas de $100 \mathrm{ml}$} & $\$$ & 22 & $\$$ & 50 & $127 \%$ & $5 \%$ \\
\hline Estee Lauder & & $\$$ & 60 & $\$$ & 100 & $67 \%$ & $19 \%$ \\
\hline Cetaphil & & $\$$ & 22 & $\$$ & 60 & $173 \%$ & $5 \%$ \\
\hline Eucerin & & $\$$ & 14 & $\$$ & 30 & $114 \%$ & $11 \%$ \\
\hline Chanel & & $\$$ & 32 & $\$$ & 90 & $181 \%$ & $8 \%$ \\
\hline Bioderma & & $\$$ & 15 & $\$$ & 40 & $167 \%$ & $8 \%$ \\
\hline Givenchy & & $\$$ & 34 & $\$$ & 90 & $165 \%$ & $3 \%$ \\
\hline Dior & & $\$$ & 34 & $\$$ & 90 & $165 \%$ & $9 \%$ \\
\hline $3 \mathrm{Lab}$ & & $\$$ & 11 & $\$$ & 30 & $173 \%$ & $2 \%$ \\
\hline Orlane & & $\$$ & 42 & $\$$ & 70 & $67 \%$ & $2 \%$ \\
\hline La Roche Posay & & $\$$ & 18 & $\$$ & 50 & $178 \%$ & $4 \%$ \\
\hline
\end{tabular}

Anexo 13 B Maquillajes

\begin{tabular}{|c|c|c|c|c|c|}
\hline Maquillajes & presentación & costo mayor & Precio venta & margen & $\begin{array}{l}\text { Participación } \\
\text { en ventas }\end{array}$ \\
\hline Clinique & & $\$ 65$ & $\$ 130$ & $100 \%$ & $28 \%$ \\
\hline MAC & & $\$ 20$ & $\$ 70$ & $250 \%$ & $21 \%$ \\
\hline Dior & & $\$ 52$ & $\$ 100$ & $92 \%$ & $16 \%$ \\
\hline Estee Lauder & & $\$ 26$ & $\$ 60$ & $131 \%$ & $13 \%$ \\
\hline Chanel & & $\$ 28$ & $\$ 75$ & $168 \%$ & $12 \%$ \\
\hline Lositam & & $\$ 26$ & $\$ 70$ & $169 \%$ & $9 \%$ \\
\hline Anastasia & Bases de $100 \mathrm{mg}$ & $\$ 110$ & $\$ 180$ & $64 \%$ & $2 \%$ \\
\hline
\end{tabular}


Anexo 13 C Colonias

\begin{tabular}{|c|c|c|c|c|c|}
\hline Colonias & presentación & costo mayor & Precio venta & Margen & $\begin{array}{l}\text { Participacion } \\
\text { en ventas }\end{array}$ \\
\hline Carolina Herrera & & $\$ 75$ & $\$ 160$ & $113 \%$ & $33 \%$ \\
\hline Chanel & & $\$ 78$ & $\$ 170$ & $118 \%$ & $23 \%$ \\
\hline Dolce Gabanna & & $\$ 220$ & $\$ 350$ & $59 \%$ & $14 \%$ \\
\hline Imperial Majesty & & $\$ 300$ & $\$ 450$ & $50 \%$ & $10 \%$ \\
\hline Eau d Hadrien & & $\$ 51$ & $\$ 120$ & $135 \%$ & $7 \%$ \\
\hline Bulgary & & $\$ 48$ & $\$ 100$ & $108 \%$ & $6 \%$ \\
\hline Ninna Ricci & & $\$ 43$ & $\$ 110$ & $156 \%$ & $5 \%$ \\
\hline Calvin Klein & frascos $100 \mathrm{ml}$ & $\$ 49$ & $\$ 120$ & $145 \%$ & $3 \%$ \\
\hline
\end{tabular}


Anexo 12 Proyección de ventas ADH 2020

\begin{tabular}{|c|c|c|c|c|c|c|c|c|c|c|c|c|c|}
\hline & ENERO & FEBRERO & MARZO & ABRIL & MAYO & JUNIO & JULIO & AGOSTO & SET & OCTUBRE & NOVIEMBRE & DICIEMBRE & TOTAL \\
\hline CREMAS & $\$ 13,344$ & $\$ 13,344$ & $\$ 16,681$ & $\$ 16,681$ & $\$ 26,689$ & $\$ 20,017$ & $\$ 40,033$ & $\$ 40,033$ & $\$ 36,697$ & $\$ 33,361$ & $\$ 30,025$ & $\$ 46,705$ & $\$ 333,610$ \\
\hline MAQUILLAJES & $\$ 4,448$ & $\$ 4,448$ & $\$ 5,560$ & $\$ 5,560$ & $\$ 8,896$ & $\$ 6,672$ & $\$ 13,344$ & $\$ 13,344$ & $\$ 12,232$ & $\$ 11,120$ & $\$ 10,008$ & $\$ 15,568$ & $\$ 111,203$ \\
\hline PERFUMES & $\$ 4,448$ & $\$ 4,448$ & $\$ 5,560$ & $\$ 5,560$ & $\$ 8,896$ & $\$ 6,672$ & $\$ 13,344$ & $\$ 13,344$ & $\$ 12,232$ & $\$ 11,120$ & $\$ 10,008$ & $\$ 15,568$ & $\$ 111,203$ \\
\hline VENTAS & $\$ 22,241$ & $\$ 22,241$ & $\$ 27,801$ & $\$ 27,801$ & $\$ 44,481$ & $\$ 33,361$ & $\$ 66,722$ & $\$ 66,722$ & $\$ 61,162$ & $\$ 55,602$ & $\$ 50,042$ & $\$ 77,842$ & $\$ 556,017$ \\
\hline
\end{tabular}

De acuerdo al estudio de mercado el público objetivo adquiere el $60 \%$ de cremas y el $20 \%$ para los maquillajes y perfumes durante el primer año por lo que en la proyección de ventas se realiza dicha distribución. Asi mismo se consideran ventas masivas en mayo (por el día de la madre) junio (día del padre), julio, agosto y diciembre por ser meses de fiesta. 
Anexo 13 Inversión Inicial

\begin{tabular}{llll}
\hline & cantidad & inversión & Total \\
\hline Acondicionamiento & 1 & $\$ 20,000$ & $\$ 20,000$ \\
Mostradores & 6 & $\$ 1,000$ & $\$ 6,000$ \\
aires acondicionados & 3 & $\$ 1,500$ & $\$ 4,500$ \\
Equipo computo & 6 & $\$ 700$ & $\$ 4,200$ \\
\hline total & & & $\$ 34,700$ \\
\hline
\end{tabular}


Anexo 14 Gastos Administrativos ADH

\begin{tabular}{llll}
\hline $\begin{array}{l}\text { Gastos } \\
\text { Administrativos }\end{array}$ & Mensual & Anual & Fuente \\
\hline sueldos & $\$ 7,041$ & $\$ 142,641$ & Planilla \\
Gasolina & $\$ 200$ & $\$ 2,400$ & Referencial \\
Agua & $\$ 120$ & $\$ 1,440$ & Sedapal (2019) \\
Internet + Teléfono & $\$ 150$ & $\$ 1,800$ & Movistar (2019) \\
Luz & $\$ 250$ & $\$ 3,000$ & Luz del Sur (2019) \\
& & & Municipalidad San \\
IMPUESTOS & $\$ 25$ & $\$ 300$ & Isidro \\
Depreciación & $\$ 204$ & $\$ 2,450$ & Inversión en Activos \\
Total & $\mathbf{\$ 7 , 9 9 0}$ & $\mathbf{\$ 1 5 4 , 0 3 1}$ & \\
\hline
\end{tabular}




\section{Anexo 15 Transcripción del focus}

\section{FOCUS1}

Buenas noches con todos, gracias por haber aceptado nuestra invitación al focus group, mi nombre es Nathalie Rivera y soy alumna de USIL, que está preparando su tesis para graduarme en un master.

Este Focus group tiene como objetivo conocer las percepciones en torno a la implementación de un Retail que ofrezca productos premium dermatológicos con el fin de detectar oportunidades de mejora y fortalecer los aspectos necesarios que impulsen a ofrecer un servicio exclusivo y personalizado

La reunión tendrá una duración aproximada de 40 minutos y será grabada con fines de recopilación de información. Por lo anterior, no se preocupen ya que dicho material sólo será utilizado por el equipo y lo que ustedes opinen dentro de esta sala no será transmitido a terceros. Todo lo que digan es importante. Díganlo cuando quieran, Las opiniones más sencillas, que quizá consideren demasiado simples o poco interesantes, a veces suelen ser las más importantes.

Siéntanse en la libertad de discutir y defender sus ideas con confianza. No hay respuestas buenas, ni respuestas malas ya que todas permitirán definir las características del negocio.

Moderadora: ¿Qué productos de belleza/salud exclusiva utiliza?

Andrés: Cetaphil.

Hessy: Estee lauder.

Stephany: bueno usualmente de belleza Lancome, es una de mis marcas preferidas.

Moderadora: ¿Dónde compra dichos productos en el Perú?

Martin: yo compro mis productos en el jockey plaza. 
Hessy: si yo también.

Stephany: yo en saga, ripley.

Moderadora: ¿utilizan productos dermatológicos para su piel?

Todos: si

Claudia:De todas maneras hay que hacer la limpieza en la mañana y en la noche sobre todo en la noche.

Moderadora: ¿cuáles son las marcas que más frecuentes compran para el cuidado de la piel?

Martin: Estee lauder.

Hessy: Clinique.

Moderadora: ¿Cuál fue la experiencia en dichos locales, de dichos productos?

Martin: yo en uno de los módulos del jokey plaza no me gustó mucho la atención porque demoran mucho.

Hessy: no es personalizada.

Stephany: si tiene sus problemas si hay mucha gente dependiendo las horas tienes que esperar o tú mismo está viendo que producto quieres y que no.

Hessy: no te recomiendan no te ven tu piel, entonces debería haber alguien especializado en cada uno que pueda decirte que es lo mejor

Claudia: todos tenemos poco tiempo y cuando vamos hay mucha gente como que toma esto y aquello y no te dan más variedad.

Moderadora: ¿con que frecuencia compran los productos de belleza o salud? 
Hessy: depende, si es maquillaje es diferente tiempo, puede durar más que si es una crema puede ser dos meses y un labial 6 meses o un año.

Andres: las mujeres creo que más usan en verano maquillaje y cosas para el producto de la piel

Moderadora: bueno hombres y mujeres en realidad bloqueador, ese tipo de cosas.

Hessy: bloqueador se debería usar todo el año

Martin: yo compro cada dos meses.

Stephany: pero ahora las cremas te vienen con protección ósea no necesariamente que te pongas bloqueador, una crema de cara hidratante también tiene bloqueador.

Claudia: la base también tiene.

Moderadora; ¿Porque prefieren comprar en dichos locales?

Hessy: yo creo que personalmente dentro del jocckey encuentro de todo dentro del centro comercial no es que tenga que ir de una tienda a otra tienda dentro del jockey tengo donde estacionar y se hace todo más fácil.

Moderadora ¿qué es lo que más valoran del establecimiento en el que ustedes mencionaron que compran? Me dijeron el estacionamiento..

Hessy: claro, es importante.

Andres: la variedad.

Oscar: Si sobre todo la variedad.

Andres: no solo vas a comprar algo en específico. 
Hessy: claro siempre es bueno que tengas la opción de ver otro producto, si, hay mucha gente que utiliza un producto y va siempre ahí a comprar ese producto pero a mi por ejemplo me gusta probar, y si me enseñan un nuevo producto que me llama la atención lo voy a probar y comprar, también me gustaría por ejemplo una persona que te diga puedes comparar este producto con eso y esto sería bueno.

Moderadora: ¿el servicio que te brindan en estos locales es personalizado?

Hessy: no.

Andres: no.

Oscar: no.

Martin: no.

claudia: no como debería ser, esperamos eso uno va a qué te brinden algo personalizado, pero no, tienes que ir a comprar lo que ya utilizas siempre.

Hessy: también hay personas que quieren venderte cualquier cosa por ganar su comisión.

Andres: yo creo que debería existir un tema de premios o de bonos por una mejor atención.

Stephany: de repente gente especializada porque obviamente te quieren vender y ya está, pero esa persona no tiene mucho conocimiento.

Hessy: debería haber alguien que conozca del tema un dermatólogo.

Andrés: también por venderte te venden cualquier cosa te llevas algo con una expectativa y al final empeora tu experiencia de compra.

Bueno ahora podemos pasar para que degusten lo que podemos ofrecerles. 
Moderadora: bueno ahora les voy a mostrar unas fotos para conversar un poco de la idea de negocio que tenemos vamos a pasarla en la pantalla.

El nombre es América Deluxe health

Esta es la idea del negocio como pueden ver en esta imagen, la parte de atrás va a ser la farmacia y en el segundo nivel va estar la parte dermatológica, acá pueden ver dividido cada sector, por marcas creamos un concepto distinto en farmacia una tienda especializada en el cuidado de la salud...

La idea es dar a conocer la marca como una tienda personalizada de lujo, nuestro lema es un pequeño tesoro en un mismo lugar, contamos con espacios eficientemente distribuidos donde podrás encontrar diversas marcas en medicina, cosméticos perfumería y dermatología de alta gama, tuvimos una buena idea que fue implementar un derma truck como punto de venta el cual servirá para hacernos conocidos en lugares cercanos donde vamos a estar ubicados también vamos a ser pioneros en el delivery gratis en productos dermatológicos especializados el derma truck se va usar para cocteles, festivales ese tipo de cosas, bueno ahora hablemos un poco de esto.

Moderadora: ¿Qué es lo que entiendes del concepto de la idea que les mostré?

Andrés: exclusividad.

Claudia: dar a conocer el producto porque lo están probando en uno mismo, entonces eso es lo que uno quiere.

Stephanny: variedad de productos porque va a estar super diversificados la cantidad de productos y marcas de repente marcas que no hay en Perú estaría muy bueno.

Moderadora: ¿Qué tanto les agrada la idea presentada? 
Martin: a mí me agrada la idea, está muy bien implementada y el local se ve muy amplio, sobre todo es personalizado y es muy importante porque no se encuentra eso.

Stephany: especializado por lo que se ha presentado entonces ...

Claudia: es un muy buen punto

Moderadora: ¿qué ventajas o desventajas tiene esta idea de negocio y por qué?

Martin: bueno en ventajas sabemos que es personalizado y además la idea del delivery gratis, me pareció super chévere.

Andrés: tiene bastante diferenciación de otros locales que ofrecen los mismos productos de repente.

Moderadora: ¿qué es lo que más valoran de la idea?

Andrés: la calidad del servicio y los productos.

Moderadora: y lo que menos valoran.

Andrés: Creo que deberían implementar personal que conozca generalmente todos los productos y todas las marcas, no solo de su marca porque si tú vas a consultarle a una persona de una marca va a vender su producto y no te abre el panorama de otros.

Moderadora: Es por eso que vamos a tener un dermatólogo...

Moderadora: ¿en general como imaginarían que sería el servicio ideal del lugar?

Stephany: bueno a mí me encantaría llegar a la tienda que alguien se acerque y me pregunte que estoy buscando de acuerdo a eso voy paseando y que me muestre esos productos y que esa persona sepa de todo, las preguntas que tengo.

Moderadora: ¿qué piensan del nombre? 
Andrés: si creo que está acorde a lo que están ofreciendo-

Martin: si yo estoy de acuerdo.

Moderadora: y el logo...

Andrés: A mí sí me causa intriga porque tiene tres colores distintos tu resaltas health porque es de cuidado, pero veo que América es blanco y Deluxe gris, y lo veo más como un lugar donde venden productos farmacéuticos no tanto como cosméticos, belleza.

Martin: a mí no se me quedo tan grabada tampoco creo que debería ser algo que resalte un poquito más.

Moderadora: ¿qué servicios exclusivos debería tener esta idea de negocio para que usted considere preferirlo?

Martin: lo principal es que sea personalizado como ya lo mencionaron, y también que tenga una salita de espera en caso este muy lleno eso a mí me resalta en comparación con otras tiendas.

Hessy: y creo que también podrían hacer tipo una limpieza facial.

Stephany: o dar tester de repente.

Hessy: ósea podrían decirte en tu piel podríamos usar tal y tal producto, no es algo que te prueban con un algodoncito si no te vas habiendo probado los productos bien probados.

Moderadora: ¿Qué productos exclusivos les gustaría encontrar?

Hessy: hay una marca que no se si la venden acá que es She said it, podrian traerla.

Moderadora: Que otros productos aparte de lo que menciono la señorita Hessy les gustaría. 
Andrés: como productos que tienen THC es un mercado muy reducido, pero tiene gran acogida en el público.

Moderadora: ¿Cuál es el precio que estarían dispuestos a pagar?

Hessy: yo creo que varía bastante depende si es un producto, o que, yo por ejemplo cada dos meses puedo gastar 800 soles o puedo gastar depende de lo que cueste cada crema, hay una que cuesta 400 soles y ora que te puede costar 1000 soles y varia bastante de acuerdo el tipo de piel que tenga la persona porque también eso cambia.

Moderadora: ¿qué medio de pago utilizaría para pagar?

Andrés: tarjeta

Hessy: tarjeta.

Martin: tarjeta

Oscar: si tarjeta.

Moderadora: ¿les gustaría participar en nuestros eventos que podamos tener?

Todos: si

Moderadora: ¿a través de qué medios justamente les gustaría ser invitados?

Andrés: redes sociales

Sthephany: si, también correo electrónico

Moderadora: ¿entre san isidro y Miraflores que distrito prefieren para la ubicación del local?

Andrés: san isidro.

Hessy: san isidro. 
Oscar: san isidro

Martin: san isidro.

Claudia: Miraflores.

Moderadora: ¿qué opinan de esta propuesta de negocios?

Andres: que es muy innovadora

Stephany: si, no hay algo así a mí me gusta bastante la verdad

Claudia: es algo interesante y llamativo.

Moderadora: ¿Cuáles debe usted que deben ser los principales diferenciadores de este servicio para que tenga éxito en el mercado?

Andrés: que se preocupen más en el cliente y no en la venta

Martin: que sea realmente personalizado porque hay locales que dicen ser personalizados pero el local no cumple

Stephany: la experiencia que tienen los clientes más que nada.

Moderadora: ¿saben si otros lugares tienen estas características?

Martin: no

Hessy: no

Andrés: No hay ninguno.

Stephany: en Perú no.

Moderadora: ¿qué otra cosa te gustaría encontrar en el local?

Claudia: que tenga un dermatólogo, y que te ofrezcan el servicio de limpieza bien hecho. 
Hessy: a mi si me gustaría que tenga todos los productos de belleza de alta gama en un solo lugar.

Stephany: si para no estar de un lado a otro a comprar otra cosa.

Moderadora: ¿habría algo que cambiarían, añadieran que cosa y por qué?

Andres: que sea pet frendly.

Stephany si eso.

Christian: a mí me parece todo ok.

Moderadora: muchas gracias por su tiempo agradecemos sus respuestas que permitirán la cristalización de nuestro proyecto, gracias.

\section{FOCUS 2}

Buenas noches con todos, gracias por haber aceptado nuestra invitación al focus group, mi nombre es Nathalie Rivera y soy alumna de USIL, que está preparando su tesis para graduarme en un master.

Este Focus group tiene como objetivo conocer las percepciones en torno a la implementación de un Retail que ofrezca productos premiun dermatológicos con el fin de detectar oportunidades de mejora y fortalecer los aspectos necesarios que impulsen a ofrecer un servicio exclusivo y personalizado

La reunión tendrá una duración aproximada de 40 minutos y será grabada con fines de recopilación de información. Por lo anterior, no se preocupen ya que dicho material sólo será utilizado por el equipo y lo que ustedes opinen dentro de esta sala no será transmitido a terceros. Todo lo que digan es importante. Díganlo cuando quieran, Las opiniones más 
sencillas, que quizá consideren demasiado simples o poco interesantes, a veces suelen ser las más importantes.

Siéntanse en la libertad de discutir y defender sus ideas con confianza. No hay respuestas buenas, ni respuestas malas ya que todas permitirán definir las características del negocio.

Moderadora: ¿Qué productos de belleza/salud exclusiva utiliza?

Guísela: bueno, todo lo que es el cuidado para la piel cremas hidratante humectantes, lociones para el cuerpo todo lo que ayude a cuidar la piel, a mantenerla...

Rolando: veo que yo soy el mayor entre todos acá, y lo que yo puedo decir es que ahora me doy cuenta el daño que ahora ha sucedido conmigo, porque nunca me eh preocupado por el cuidado de la piel, soy una persona que eh trabajado en el campo, me gusta ir a la playa, eh viajado por varios lugares y nunca me he preocupado por el cuidado de la piel y ahora tengo una a ficción a la piel que se llama soriasis, y uso algunos productos que me recomienda el dermatólogo no son necesariamente de belleza si no es más por salud , y después uso una crema a base de urea.

Patty: claro ahora recomienda protector solar para todas las edades

Laura si, incluso en invierno porque dicen que toda la luz el reflejo igual $t$ afecta

Rolando: Los rayos ultravioletas pasan las nubes en invierno y verano

Guisela: Todas las épocas del año

Luis: yo uso una crema de día que también tiene un protector UV que es Eucerin si no me equivoco.

Moderadora: ¿Dónde compra dichos productos en el Perú? 
Patty: A mí el dermatólogo, bueno yo tengo un poco de manchas a mí el dermatólogo me recomendó el Biocare gel, es un buen producto, yo lo utilizo de día, en invierno, verano, otoño, y si me lavo la cara tengo que volver a aplicarlo.

Moderadora: ¿y donde lo compra?

Patty: en farmacias, pero en cadenas, ¿en cualquier farmacia no?

Laura: yo compro normalmente en saga los productos que son de belleza, y otros como la marca Bioderma en Aruma o en las farmacias de las clínicas

Carlos: yo, utilizo lo que actualmente usamos todos, hasta los jóvenes como dice el señor muy poco lo use antes son las cremas para protegernos del sol, pero la crema que si utilizo es para fortalecer los parpados que la compro en Herbalife.

Luis: yo lo compro en saga o en los dutty free cuando viajo.

José: Es que depende hay cremas que no consigues en cualquier lado y otras que si, por ejemplo, para los tatuajes yo utilizo Bepanten que lo consigo en cualquier lado pero hay otras que no consigo en cualquier farmacia

Laura: Hay unas que tienes que mandar a traer de USA porque acá solo las encuentras en algunos sitios y a veces no las tienen.

Moderadora: ¿Cuál fue la experiencia en dichos locales, de dichos productos?

Luis: aceptable, no excelente pero aceptable.

Patty : como comprar cualquier cosa

Laura: En algunas te hacen probarlo en algunos sitios te explican mejor que en otros también 
Carlos: En el caso de Herbalife uno no va a la tienda a comprarlo si no un representante va a la casa.

Jose: Depende si es tienda departamental por lo general te hacen una prueba, y es un poco más personalizado dependiendo de lo que estás buscando cual es el tipo de piel, si es una piel grasa, te hacen probar diferentes productos que están dirigidos a tu perspectiva

Patty: eso pasa con la marca Mac, yo compro la base, aparte también ojos y ahí te hacen la prueba, y que tipo de piel tienes, no es única para todos

José: yo por ejemplo no puedo utilizar cualquier crema porque mi piel es grasa, entonces si yo utilizo una piel que es grasa no me va a servir, necesito una crema que me ayude a secar la piel.

Guisela: la crema tiene que ser adecuada al tipo de piel y creo que una vez que probamos una marca y vemos resultados, nos quedamos con esa Luis: es que tampoco no hay mucho chance de probar varias a la vez porque no hay en un solo lugar variedad

Carlos: Claro, una vez que compraste una, a mitad del producto que te queda en casa no vas a ir a comprar otra.

Rolando: a menos que te haga daño

Carlos: claro.

Guísela: por ejemplo, una de mis cuñadas vive en Francia y una vez me trajo unos productos marca Clinique y como que las probé y me gustaron entonces eso es lo que me eh acostumbrado a comprar últimamente, en saga. 
Moderadora: ¿cuáles son las marcas que más frecuentes compran para el cuidado de la piel?

Laura: Bioderma, Estee lauder, clinique también es buena

José: bioderma, Abene hay una espuma limpiadora que es muy buena

Rolando: lo que yo uso para mi tratamiento es productos de ac farma y iq farma son tres cosas distintas para este tratamiento y me va bien, son de laboratorio

José; es que para cuidar la piel medicada de repente cuando se trata de maquillaje, pero también si es solo para confort es bath and body

Luis; Yo utilizo Eucerin y Clinique y me va bien

Patty; pero ahora la mayoría de las cremas tiene protector UV.

Moderadora: ¿con que frecuencia compran los productos de belleza o salud?

Guísela;A penas se acaban

Patty;A mí me duran 8 meses

Laura; las cremas de mano y de cuerpo se acaban más rápido, las usas a diario, por ejemplo hay algunas que se ponen en la cara cada vez que te lavas.

Patty pero s esa poco

Guísela; Claro pero por ejemplo la crema de manos se usa más seguido

José: Por lo general son 3 meses maso menos

Laura: un serum te puede durar cuatro meses.

Patty; Mientras más caras más chiquitas pero son mejor

Moderadora; ¿Porque prefieren comprar en dichos locales? 
Carlos; Bueno como te dije en el caso de las cremas de herva life no es que yo voy a comprar si no me la traen, pero es porque vino una persona y me explico para que servía cada crema

Moderadora; algo personalizado quiere decir

Carlos; si exacto me explico y me enseño unos productos y uno de ellos me pareció interesante por eso lo compre

Laura; en saga también tú le dices más o menos lo que estás buscando y de acuerdo al tono de piel te recomiendan lo que es mejor.

José: También porque tienen variedad si vas a un lugar no tienen muchas cosas y si te pueden recomendar es para tu tipo de piel, pero solo tienes esa marca no tienes variedad, entonces muchas veces te recomiendan otra marca que no tienen en ese lugar entonces necesitas un lugar que sepas que estén todas las cremas.

Laura: o a veces quieres comprar dos y tienes que ir primero a un sitio y luego al otro porque no tienen todo en el mismo lugar

Luis: si es verdad nunca hay todo en un mismo lugar.

Guísela: todo lo que necesitas no está en un solo lugar

Laura: Tienes que comprar por parte.

Guísela: Tienes los sitios específicos donde compras cada uno Moderadora ¿qué es lo que más valoran del establecimiento en el que ustedes mencionaron que compran?

Laura: La calidad, servicio

Luis: la comodidad el servicio 
José: servicio

Luis: El estacionamiento creo yo

José: Eso también es cierto

Moderadora: ¿el servicio que te brindan en estos locales es personalizado?

Patty: si, en el caso de Mac es personalizado tu entras te hacen sentarte te prueban te maquillan te desmaquillan, tu sal hermosa, pero tienes que comprar jaja

José: para todo tiene que ser personalizado porque uno está el tipo de piel que de repente cuando vas a bath and body que es algo más de uso diario igual tu sabes lo que estás buscando de repente una crema con un olor diferente igual te preguntan maso menos que es lo que estás buscando.

Moderadora bueno ahora pueden pasar a servirse los bocaditos.

Moderadora: bueno ahora les voy a mostrar unas fotos para conversar un poco de la idea de negocio que tenemos vamos a pasarla en la pantalla.

El nombre es América Deluxe health

Esta es la idea del negocio como pueden ver en esta imagen, la parte de atrás va a ser la farmacia y en el segundo nivel va estar la parte dermatológica, acá pueden ver dividido cada sector, por marcas creamos un concepto distinto en farmacia una tienda especializada en el cuidado de la salud...

La idea es dar a conocer la marca como una tienda personalizada de lujo, nuestro lema es un pequeño tesoro en un mismo lugar, contamos con espacios eficientemente distribuidos donde podrás encontrar diversas marcas en medicina, cosméticos perfumería y dermatología de alta gama, tuvimos una buena idea que fue implementar un derma truck 
como punto de venta el cual servirá para hacernos conocidos en lugares cercanos donde vamos a estar ubicados también vamos a ser pioneros en el delivery gratis en productos dermatológicos especializados el derma truck se va usar para cocteles, festivales ese tipo de cosas, bueno ahora

Moderadora: ¿Qué es lo que entiendes del concepto de la idea que les mostré?

José: bueno la idea es tener la mayoría de marcas de alta gama asociadas a un solo lugar que es lo que hablábamos hace un momento que no siempre se encuentran todas en un solo lugar y tener la comodidad de encontrarlas en un mismo lugar, aparte de darte a conocer por ejemplo con el derma truck para que la gente pueda conocer nuevas marcas Carlos: lo que yo dije fue que a mí me gustaba comprar lo de herbalife porque me lo ofrecían como algo personalizado y me explicaban cada producto, me doy cuenta que acá no solo me lo van a explicar si no un experto me va a dar las pautas de lo que realmente necesito, me parece muy bien

Guísela: me parece interesante lo que más me gusta es que voy a tener todas las marcas en un mismo sitio

Laura: si porque por ejemplo en saga te hacen probar un producto tu sientes también que te está tratando de vender esa marca, pero acá tienes todas las marcas y acá te va a explicar un experto que conoce todas y puede recomendarte la que es mejor para ti.

Luis: además que tienes el delivery gratis.

Guísela: interesante lo del delivery porque así no mas no hay delivery de productos de belleza.

Patty: a mí me parece que lo del truck es algo innovador ninguna marca lo tiene

Guísela: ninguna cadena ni marca lo tiene. 
Patty: porque la idea de todo negocio es que sea algo innovador

Diego: también depende de un ambiente, donde sea fácil encontrar las cosas

Moderadora: ¿Qué tanto les agrada la idea presentada?

Laura: a mí me gusta

Guisela: a mí me encanta porque la idea según entiendo vas a tener todas las marcas en un solo sitio no vamos a tener que movernos a diferentes sitios para encontrar lo que queremos.

Laura: Si es mucho más fácil encontrar lo que necesitas.

José: lo único es que cuando hiciste la presentación mencionaste que iba a estar por marca yo creo que sería mejor por área específica de la piel de repente cara y otra de cuerpo, y ahí tienes todas las marcas porque por ejemplo si vas al lugar y dices voy por una crema para la cara y la chica tiene que buscar por un lado y luego por el otro porque está por marca creo que es mejor tener todas las marcas.

Moderadora: ¿qué ventajas o desventajas tiene esta idea de negocio y por qué?

Guísela: yo creo que un poco de lo que estábamos hablando, las ventajas es que vas a tener todas las marcas en un solo sitio, el delivery es otra ventaja

Laura: otra es que es especializado para el área dermatológico porque en otros sitios mesclan varias cosas y no es personalizado, en otra farmacia puedes encontrar pastillas, pero también bioderma pero no es personalizado.

Patty: ¿eh visto que al costado de la tienda también hay una farmacia es un todo no?

Rolando: lo que no se visualiza es un área para estacionar los vehículos

Moderadora: no, si tiene estacionamiento si va a tener 
Patty: que haya una sala de espera

José: eso es lo que iba a mencionar porque en la presentación veíamos un área de farmacia que es nada más que como para entrar y al fondo el área dermatológica se ven como unos muebles para poder sentarse me parece importante esa diferenciación.

Patty: claro, con su cafecito.

José: porque cuando uno va a una farmacia estas de pie estas esperando.

Laura: a veces demora mucho porque tienen que buscar si es algo medicado a veces demora.

Diego: además las cremas las pruebas en cambio en una farmacia tu entras compras y te vas en cambio acá tienen que mostrar que cosa es y explicarte sobre eso.

Laura: claro.

Moderadora: ¿qué es lo que más valoran de la idea?

Todos: Que este todo en un solo lugar.

Moderadora: ¿Y lo que menos valoran de la idea?

José: yo creo que nada

Carlos: no vimos cosas negativas

Moderadora: ¿en general como imaginarían que sería el servicio ideal del lugar?

Laura: bueno tienen que tener personal super capacitado, que te atiendan de una buena manera, que sean amables y que tengan paciencia para explicar sobre todo si van hacer pruebas de repente te quieres probar todo y tienen que ser pacientes. 
Carlos: yo me pondría en el caso de que este negocio va a funcionar muy bien por lo tanto va haber mucha gente entonces deberían estar preparados para atender las personas que están en espera

José: claro eso es importante porque si te vas a tomar el tiempo de aplicarle a alguien va haber gente que va estar esperando.

Carlos: el que espera va a tener que tener algo para entretenerse relacionado claro, a un producto que va a poder comprar ver ejemplos, para poder llegar y ser atendido más rápido.

Patty: que todos tengan la misma capacitación porque a mí me ha pasado que voy a una tienda me dicen para tu piel es esto, me voy a la otra porque se me acabo y me dicen que esa no era y es Mac ah es una empresa americana yo creo que eso no debe pasar a mí me disgusta, que me estén dando para usar esto este mes y a los 5 o 6 meses me dicen esto no he lo que tenía que usar entonces que uso.

José: sientes que te están paseando todo el tiempo. El área de derma tiene que tener gente capacitada, porque no solo es el hecho que va a querer comprar todo si no que también va a ir gente que de repente no conoce lo que quiere o necesita para la piel y hay que explicarle con paciencia, y la gente tiene que eta capacitada y con devoción para el servicio al público.

Moderadora: ¿qué piensan del nombre?

Luis: a mí me gusta porque asocia lo que es salud, y Deluxe me imagino que son marcas top por ende deben ser las mejores.

Laura: me gusta que diga Deluxe healt porque son producto para la salud, pero las mejores marcas es lo que s eme viene a la mente. 
Moderadora: ¿Qué piensan del logo?

José: yo no lo entendí, ósea no logro asociarlo al cuidado de la piel.

Patty: bueno son los colores de las letras.

José: Si claro, es un nombre sobrio, serio, formal creo que va con el nombre estas ofreciendo un producto de lujo es serio.

Carlos: pero si yo lo miro y no veo lo que dice me parecería que es algo relacionado con la vista

Patty: pero yo creo que una marca para que se posicione tiene que ser corto

José: también.

Laura: también podría decir skill health es más especializado para la piel de repente sería una idea más clara de lo que ofrece

Patty: de repente las iniciales.

Carlos: claro tiene razón.

Guísela si

José: sí, claro.

Patty: porque si te pones a pensar no te vas a acordar todo en cambio sí son tres letras rapidito la captas.

Laura: A,D,H.

Moderadora: ¿qué servicios exclusivos debería tener esta idea de negocio para que usted considere preferirlo? 
Luis: como dijimos antes la atención personalizada y que también en la zona de espera tenga comodidades y bocaditos, un servicio de calidad.

Laura: también podría tener valet parking.

Carlos: hay que tener en cuenta que por lo general va una persona acompañando a la otra entonces insisto que el área de espera debe ser entretenida.

Patty: también hay video juegos ah

Por decir va una mama joven mientras ella va comprando el niño va jugando.

Laura: si se puede dar bastante porque por ejemplo puede estar comprando para el niño pero a él no le interesa.

José: Si el niño esta entretenido la mama puede comprar tranquila, por ejemplo mi hermana es alérgica al jabón y tiene que utilizar Eucerin y cuando iba con mi mama a comprar no quería ir, entonces si me parece una buena idea

Moderadora: ¿Qué productos exclusivos les gustaría encontrar?

Luis: No solo un producto las marcas a las que estamos acostumbrados y si hay mejores conocer de ellas y probarlas.

Patty: jabones dermatológicos.

José: más de otros productos creo que tiene que ser de la piel estrictamente por ejemplo cremas astringentes para limpiar la cara ese tipo de cosas.

Laura: también podría ser maquillaje porque la mayoría de marcas tienen su idea de maquillaje cosas que son antialergicos.

Guísela: algunas marcas las que dicen especial cuidado en que no se dañen la piel.

Moderadora: ¿Cuál es el precio que estarían dispuestos a pagar? 
Carlos. Eso depende.

José: depende de la marca y el producto.

Patty: 100 soles 120 depende

José: dependiendo del producto

Laura: 300 soles un poco más dependen

Patty: si un labial no más estos 90 soles

Laura depende los contornos de ojos son caros los bloqueadores ha de varios precios.

Moderadora: ¿qué medio de pago utilizaría para pagar?

Luis visa

Carlos: visa

Laura: depende de lo que vas a comprar, si no vas a comprar muchas cosas de repente en efectivo

Diego: bueno yo creo que efectivo y tarjeta porque hay productos que te pueden cosatar 200 soles una crema 200 más y que cojas algo más entonces nadie lleva 400 soles en la billetera

Patty: mínimo en una compra 400 o 500 soles.

Luis: te animas por otras cosas y va sumando

Patty: tú vas por una cosa y al final vas pagando 600 soles eso pasa.

Guísela: cuando mencionabas lo del delivery también podría haber una especie de historial del cliente porque de repente yo me compre la crema que me gustaba y desaparece la caja y dices cual era la crema. 
Laura: si eso pasa

Guísela: entonces llamas y dices hace dos meses compre y no me acuerdo el nombre

Patty: Que tengas un código de cliente

Laura: También eso es bueno porque digamos se agotó el producto y te avisas cuando llega el producto como tienen tus datos.

Diego: de alguna forma eso obliga al cliente a volver a la tienda porque hay muchísimas personas que no se acuerdan que cremas compraron exactamente y a todos le pasa eso.

Guísela: si tú sabes que en tu tienda exclusiva tiene la línea que tu compra dices ahí tengo que ir ya no voy a ir a otro sitio.

Moderadora: justamente vamos a tener un plan que se llama embajadores donde van a junto a todo lo que compras, tus datos y de acuerdo a eso se van a poder enviar regalos a los clientes frecuentes, bueno ¿les gustaría participar en nuestras activaciones?4

Todos: si

Patty: que nos envíen las invitaciones jaja

Moderadora: ¿a través de que medios justamente les gustaría ser invitados?

José: por correo electrónico.

Patty: el correo ya no se lee por whatsapp.

Carlos: si la opinión está dividida podría ser ambos.

Moderadora: ¿entre san isidro y Miraflores que distrito prefieren para la ubicación del local?

Todos: san isidro. 
Patty: bueno para donde estamos san isidro.

Diego: yo creo que en san isidro hay más fluido de personas que trabajan.

Luis: hay más oficinas, y la gente pasa por ahí caminando.

Guísela: mientras la zona no sea de tanta congestión

Patty: en san isidro está el centro empresarial ya mayor cantidad de gente que trabaja en oficina gente que puede pagar.

José: Miraflores se ha vuelto más turístico San isidro sería la mejor opción.

Moderadora: ¿qué opina de la propuesta de negocio?

Interesante y es innovadora porque no hay un lugar así

No hay ah

José; no hay lo más cercano es pharmax y aun así no es igual venden juguete chocolates de todo, competencia directa no hay

Moderadora: ¿Cuáles debe usted que deben ser los principales diferenciadores de este servicio para que tenga éxito en el mercado?

Laura: La calidad

Luis: El servicio

Moderadora: ¿saben si otros lugares tienen estas características?

Todos: no

Luis que sea algo para piel no existe

Patty: no hay 
Moderadora: ¿qué otra cosa te gustaría encontrar en el local?

José: hablamos de maquillaje, yo creo que más se perdería la idea

Guísela: lo que tiene relación con la piel es maquillaje.

Rolando: la limpieza también de piel

Laura. Cremas limpiadoras las que son para el acne por ejemplo.

Moderadora: ¿habría algo que cambiarían, añadieran que cosa y porque?

José: yo creo que todo está bien no cambiaría nada todas las ideas me parecen innovadoras y con bastante potencial, no creo que tengas algo negativo

Patty: la salita de espera

Guísela: estaba la salita de espera lo que hablamos fue tener algo para niños

Carlos: bocaditos

Laura: De repente videos que sean educativos que explican características de los productos.

José: también un área de cosas nuevas, una pequeña islita, para que sea lo primero que vez cuando entras.

Patty: una buena forma de venta, lo que yo veo por ejemplo cuánto cuesta que me maquillen por decir 350 soles ya no te lo cobro, pero llevas eso en productos es un gancho, entonces si o si te llevas los 350 soles.

Laura: se podría aplicar algo así por ejemplo para limpiezas faciales con la misma modalidad. 
Moderadora: muchas gracias por su tiempo agradecemos sus respuestas que permitirán la cristalización de nuestro proyecto, gracias.

Todos: aplausos. 
1.Distrito de residencia

En la Tabla 1 se muestra los resultados

\section{Tabla 1}

Lugar de residencia de los encuestados

\begin{tabular}{lll}
\hline \multicolumn{2}{l}{ distrito procedencia } & Puntaje \\
\hline a) Miraflores & 81 \\
b) San Isidro & 185 \\
c) Surco & 43 \\
d) San Borja & 51 \\
e) La Molina & 20 \\
Otros & 5 \\
\hline
\end{tabular}

Fuente: Investigación de Mercado (2019)

En la figura 1 se muestra la distribución porcentual

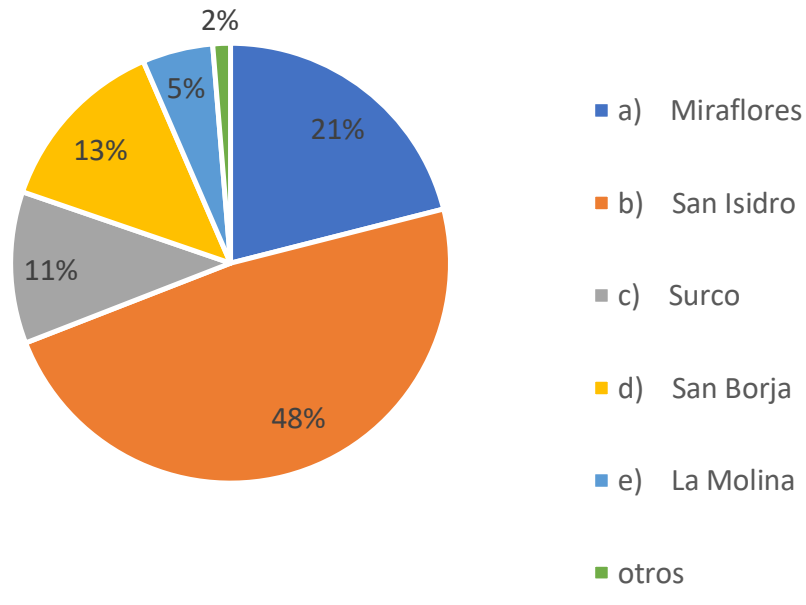

Figura 1 Distribución porcentual del lugar de residencia

Fuente: Investigación de Mercado (2019)

2. Ingresos Promedio

En la Tabla 2 se aprecian los ingresos promedio de los encuestados

Tabla 2 
Ingresos Mensuales de la Muestra

\begin{tabular}{ll}
\hline Ingresos mensuales & \\
\hline 13,105 soles a 17,000 soles ( de $\$ 3854$ a $\$ 5000)$ & 222 \\
$17,000$ a 27,200 soles (desde $\$ 5000$ a $\$ 8000)$ & 124 \\
$27,200$ a 40,800 soles (desde $\$ 8000$ a $\$ 12000)$ & 29 \\
Más de 40,800 soles (Más de $\$ 12,000)$ & 10 \\
\hline
\end{tabular}

Fuente: Investigación de Mercado (2019)

En la figura 2 se muestra la distribución porcentual de los ingresos de los encuestados

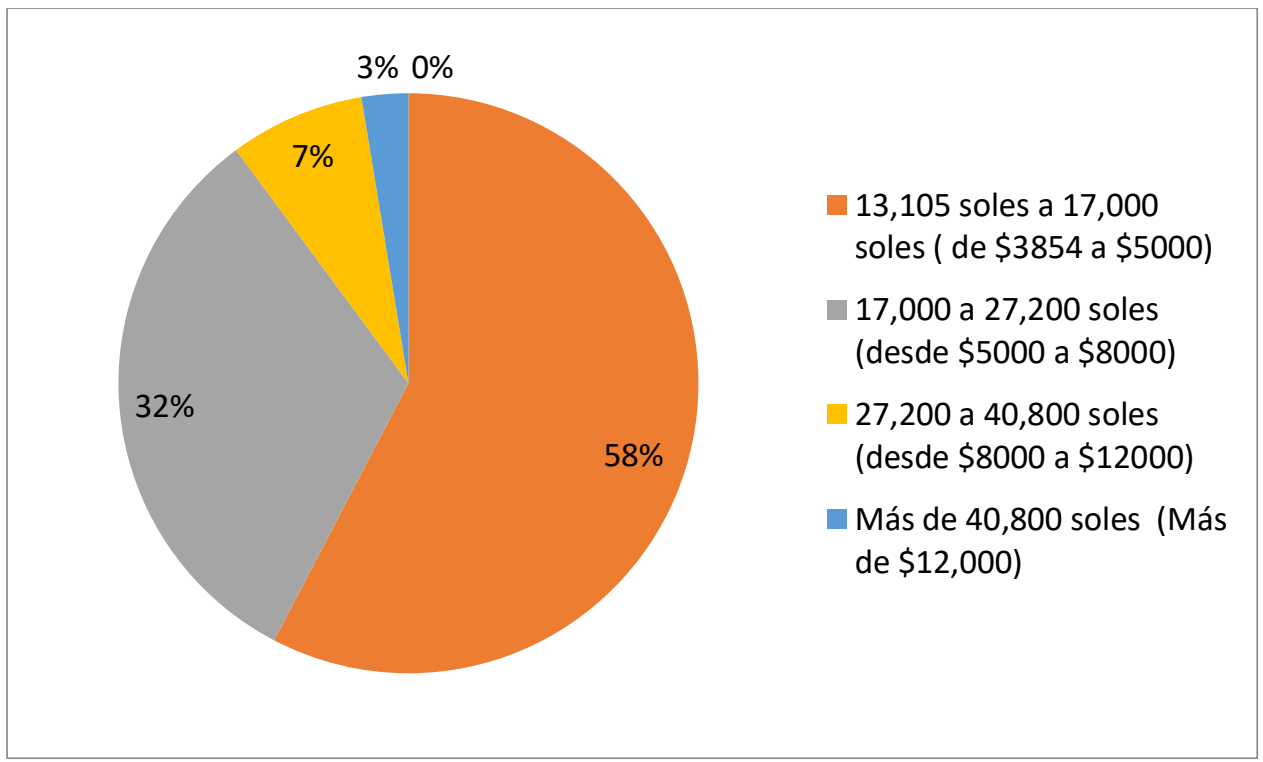

Figura 2

Distribución porcentual de los ingresos de los encuestados

Fuente: Investigación de Mercado (2019)

3. Tipo de producto de belleza

En la Tabla 3 se muestra los tipos de productos que adquieren los encuestados

Tabla 3 
Tipo de Producto consumido por el público objetivo

\begin{tabular}{lll}
\hline \multicolumn{2}{c}{ productos que consume } \\
\hline a) Dermatológicos & 240 \\
b) Perfumes y colonias & 67 \\
c) Maquillajes & 68 \\
d) Aditivos/Naturales & 9 \\
e) Otros & 1 \\
\hline
\end{tabular}

Fuente: Investigación de Mercado (2019)

En la figura 3 se muestra la distribución porcentual de los productos

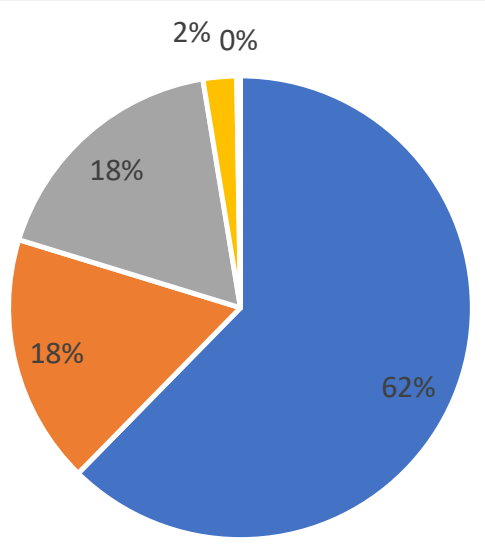

- a) Dermatológicos $\quad$ b) Perfumes y colonias $\square$ c) Maquillajes

- d) Aditivos/Naturales - e) Otros

Figura 3

Distribución del tipo de muestra

Fuente: Investigación de Mercado (2019)

\section{Marcas Preferidas Cremas}

En la Tabla 4 se muestran las marcas de cremas preferidas por la muestra.

\section{Tabla 4}




\begin{tabular}{clc}
\hline \multicolumn{2}{c}{ Cremas dermatológicas que consume la muestra } \\
\hline a) & Clinique & 88 \\
b) & Isdn & 21 \\
c) & Estee Lauder & 72 \\
d) & Cetaphil & 20 \\
e) & Eucerin & 41 \\
f) & Chanel & 29 \\
g) & Bioderma & 31 \\
h) & Guerbin & 13 \\
i) & Dior & 36 \\
j) & 3Lab & 9 \\
k) & Orlane & 8 \\
l) & La Roche Posay & 17 \\
\hline Total & & 385
\end{tabular}

Fuente: Investigación de Mercado (2019)

En la figura 4 se muestra la distribución de dichas cremas

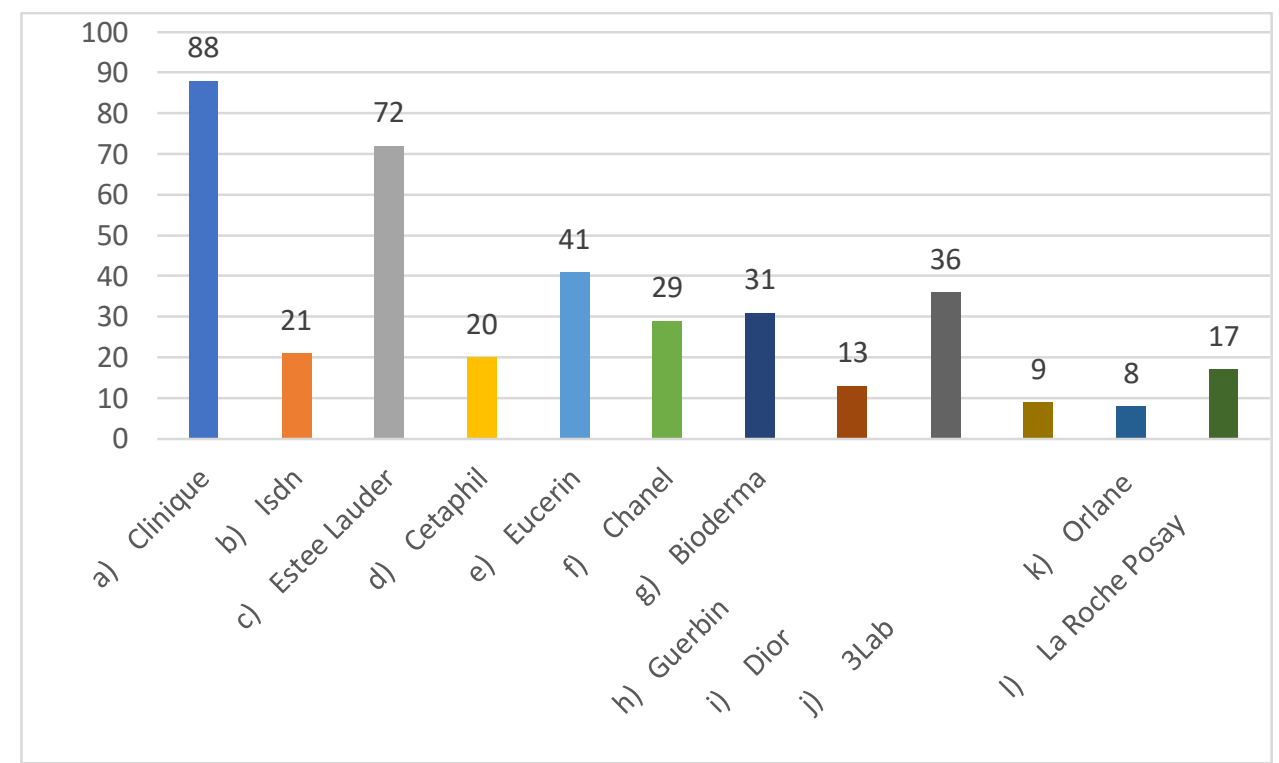

Figura 4

Cremas Dermatológicas preferidas

Fuente: Investigación de Mercado (2019)

5. Marca de Maquillajes 
En la tabla 5 se muestran las marcas de maquillajes dermatológicos preferidos por la muestra

\section{Tabla 5}

Marcas de Maquillajes preferidos por la muestra

\begin{tabular}{cll}
\hline \multicolumn{3}{c}{ Maquillajes dermatológicos } \\
\hline a) & Chanel & 46 \\
b) & Dior & 63 \\
c) & Estee Lauder & 49 \\
d) & MAC & 80 \\
e) & Clinique & 107 \\
f) & Lositam & 33 \\
Otras & & 7 \\
\hline
\end{tabular}

Fuente: Investigación de Mercado (2019)

En la figura 5 se muestra la distribución de dichos maquillajes

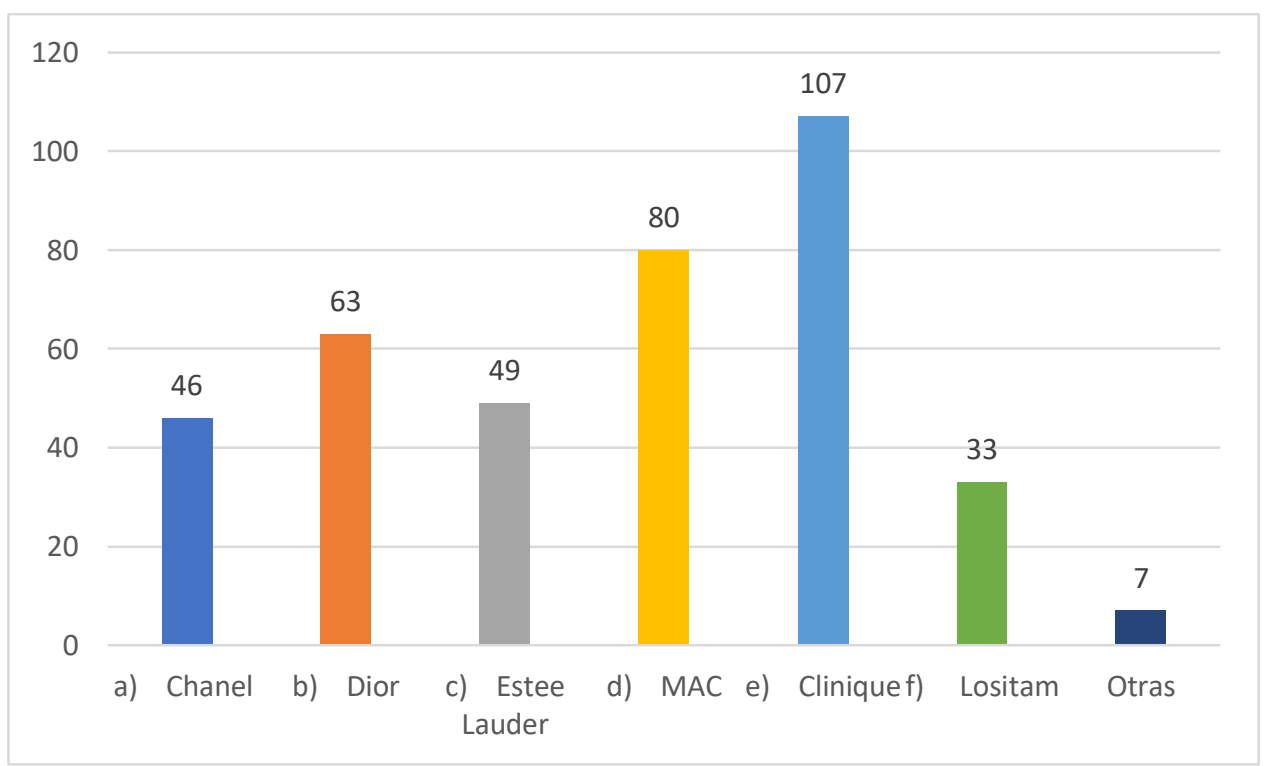

\section{Figura 5}

Distribución de Maquillajes dermatológicos

Fuente: Investigación de Mercado (2019) 
6. Marca de Perfumes

En la Tabla 6 se muestran las marcas de perfumes preferidos por la muestra.

Tabla 6

Marcas de Perfumes/Colonias preferidas de la muestra

\begin{tabular}{lll}
\hline \multicolumn{3}{l}{ Perfumes y/o colonias que consume } \\
\hline a) & Chanel & 88 \\
b) & Carolina Herrera & 127 \\
c) Eau d Hadrien & 26 \\
d) Imperial Majesty & 38 \\
e) Dolce Gabanna & 52 \\
f) Ninna Ricci & 21 \\
g) Bulgary & 22 \\
Otros & 11 \\
\hline
\end{tabular}

Fuente: Investigación de Mercado (2019)

En la figura 6 se muestra la distribución de dichas colonias

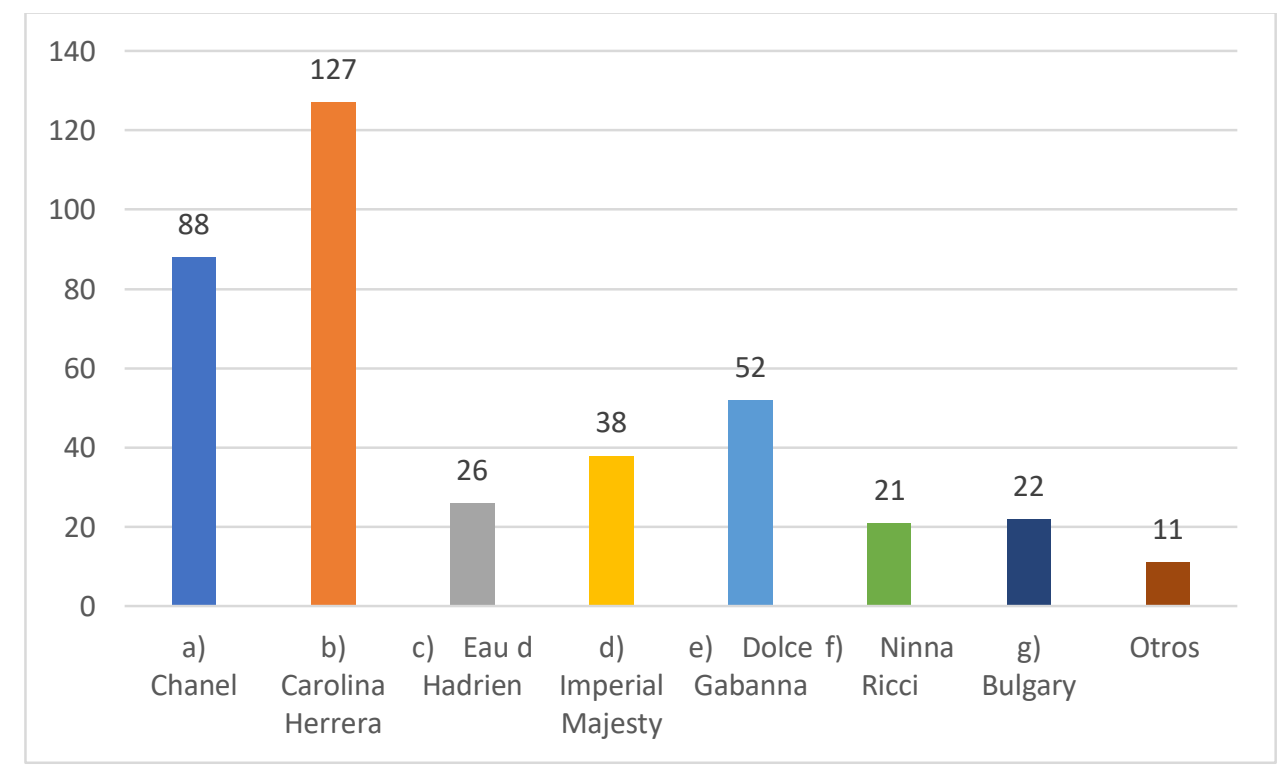

Figura 6

Distribución de Colonias/Perfumes preferidos

Fuente: Investigación de Mercado (2019)

3 Frecuencia de Compra 
En la Tabla 7 se muestra la frecuencia de compra de los productos

\section{Tabla 7}

Frecuencia de Compra de los Productos

\section{Tiempo de Compra}

a) Semanalmente 8

b) Quincenalmente 21

c) Mensualmente $\quad 72$

d) Bimensualmente 262

e) otros

22

385

Fuente: Investigación de Mercado (2019)

En la figura 7 se muestra la distribución porcentual de dicha frecuencia

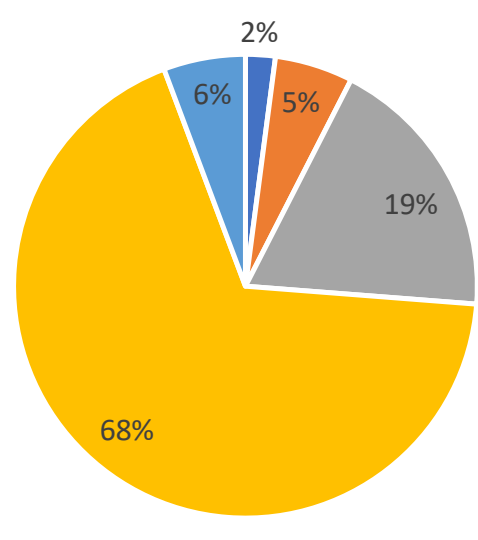

a) Semanalmente

b) Quincenalmente

- c) Mensualmente

d) Bimensualmente

e) otros

\section{Figura 7}

Distribución de la frecuencia de compra

Fuente: Investigación de Mercado (2019)

8.Ticket de compra

En la tabla 8 se muestra el promedio de gasto por visita para la compra de cremas, maquillajes y colonias por parte de la muestra 


\section{Tabla 8}

Promedio de Inversión por compra

\section{Ticket de compra}

\begin{tabular}{ll}
\hline a) Menos de 1000 soles (Menos de \$294) & 129 \\
b) Entre 1001 y 2000 soles (Entre \$294 y \$588) & 205 \\
c) Entre 2001 y 3500 soles (Entre \$588 y \$1030) & 47 \\
d)Más de 3500 soles (Mas de \$1030) & 4 \\
\hline
\end{tabular}

Fuente: Investigación de Mercado (2019)

En la figura 8 se muestra la distribución porcentual de los tickets de compra
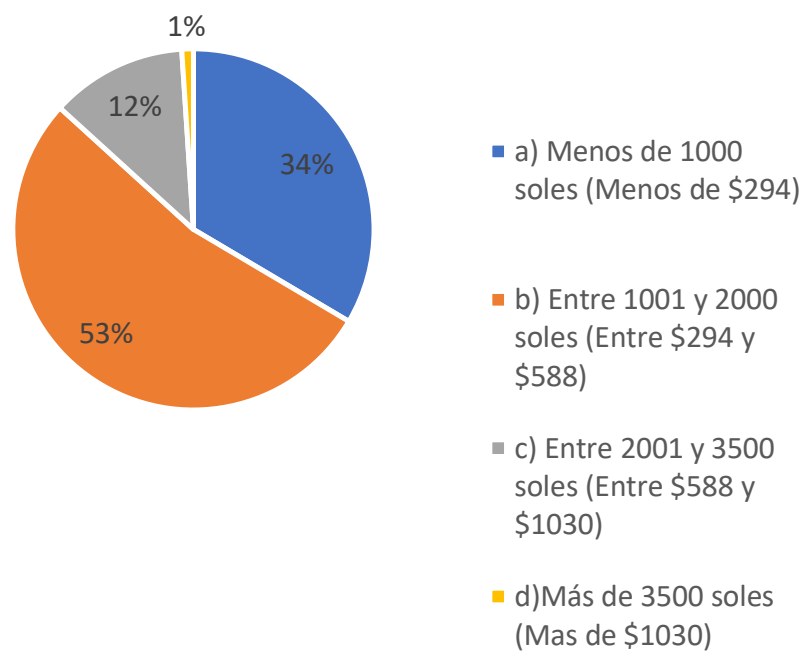

Figura 8

Porcentaje de Distribución de la inversión por compra de artículos de belleza

Fuente: Investigación de Mercado (2019)

9. Factores para Acudir a una determinada tienda para adquirir cremas

En la Tabla 9 se muestra la valorización que le da la muestra a una tienda que venda productos dermatológicos. 


\section{Tabla 9}

Factores de Preferencia

\begin{tabular}{lc}
\hline $\begin{array}{l}\text { Factor más importante por los que adquiere productos dermatológicos de } \\
\text { lujo }\end{array}$ \\
\hline Variedad de promociones & 64 \\
Profesionalismo del proveedor & 60 \\
Confianza en el servicio y los productos & 78 \\
Diferenciación de los productos & 70 \\
Ubicación del local & 43 \\
Precio & 13 \\
Marcas Exclusivas & 53 \\
Otros & 4 \\
\hline
\end{tabular}

Fuente: Investigación de Mercado (2019)

En la figura 9 se muestra la distribución porcentual de los factores de preferencia.

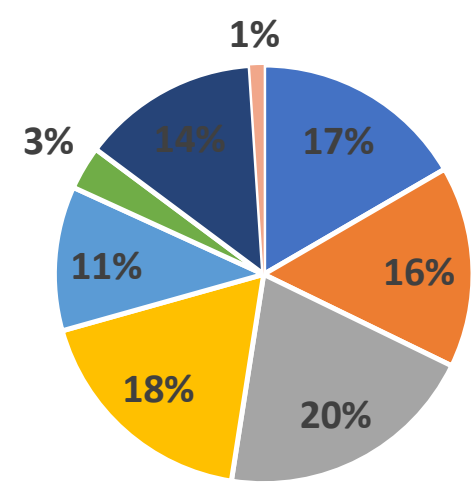

- a) Variedad de promociones

a) Profesionalismo del proveedor

- c) Confianza en el servicio

d) Diferenciación de los productos

- e) Ubicación del local

f) Precio

- g) Marcas Exclusivas

h) Otros

\section{Figura 9}

Valorización Porcentual de los Factores de Preferencia

Fuente: Investigación de Mercado (2019) 
10. Comunicación del Servicio

En la Tabla 10 se muestra la manera como el público objetivo se entera de la existencia de la tienda.

\section{Tabla 10}

Medios de Comunicación utilizados por el Público Objetivo para informarse

\begin{tabular}{ll}
\hline \multicolumn{1}{c}{ Como se entera del servicio } & \\
\hline a) Mediante Internet & 236 \\
b) Mediante Prensa Escrita & 47 \\
c) Mediante Radio & 17 \\
d) Mediante Contactos (Boca Oreja) & 72 \\
e) Mediante Televisión & 11 \\
f) otros & 2 \\
\hline
\end{tabular}

Fuente: Investigación de Mercado (2019)

En la figura 10 se muestra la distribución porcentual de los medios de información utilizados para enterarse del servicio

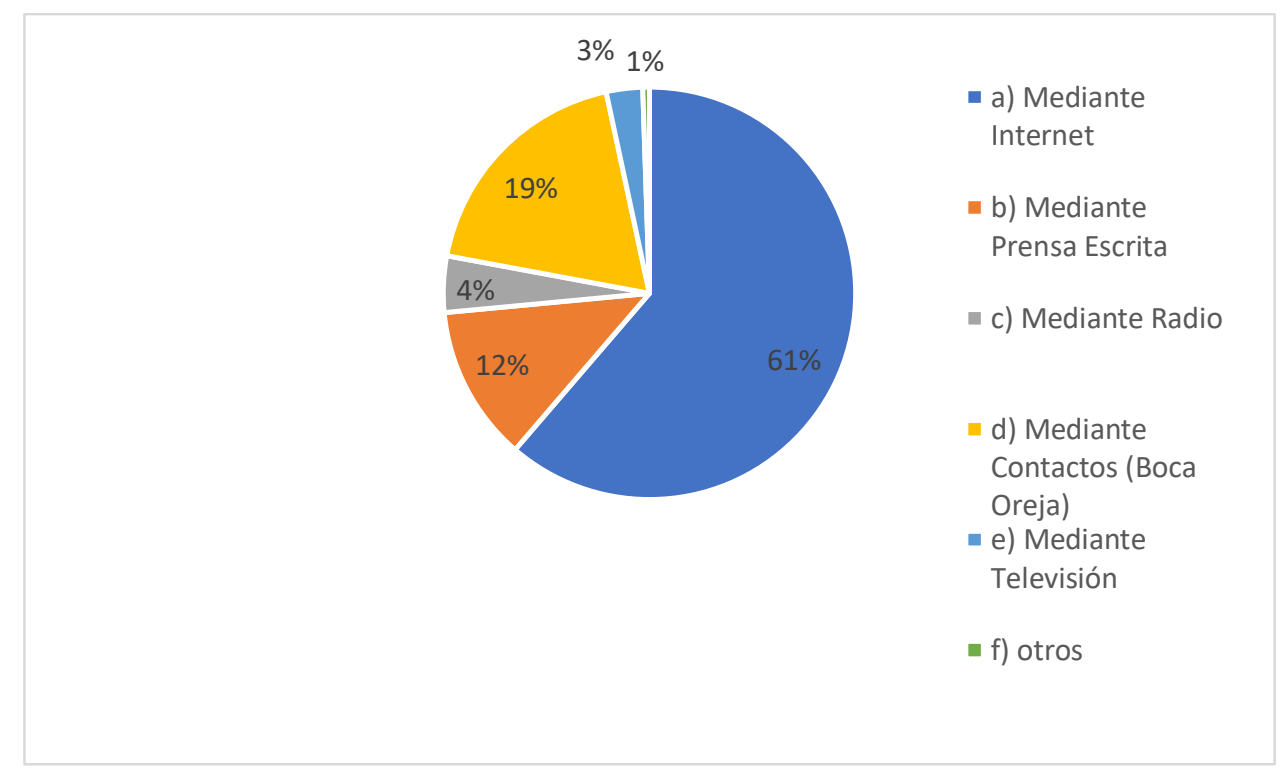

Figura 10

Distribución porcentual de los medios de comunicación que utiliza el Público Objetivo Fuente: Investigación de Mercado (2019) 


\section{Personal de Atención Requerido}

En la Tabla 11 se observa la preferencia del público objetivo sobre la atención que debe recibir en una tienda de lujo

\section{Tabla 11}

Cantidad de Personal Solicitada para Atención

\section{Personal de Atención}
a) Uno
190
b) Dos
175
c) Tres
14
d) Mas de tres
6

Fuente: Investigación de Mercado (2019)

En la Figura 11 se observa la distribución porcentual del público objetivo para ser atendido.

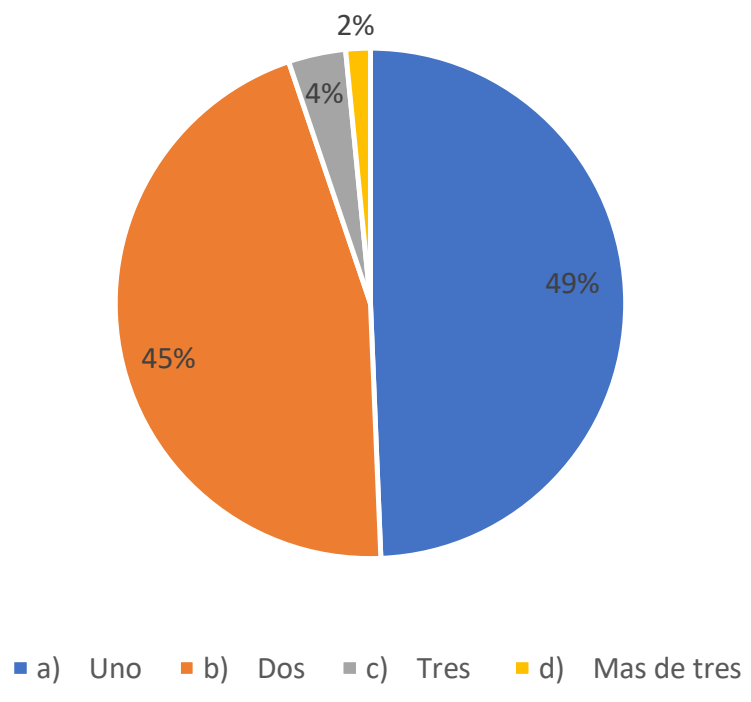

Figura 11 Distribución de la preferencia de Personal para atención

Fuente: Investigación de Mercado (2019) 
12. Valorización de factores de éxito

En la figura 12 se muestra el puntaje asignado a los factores de éxito donde cinco es el puntaje máximo y uno el puntaje mínimo otorgado por la muestra

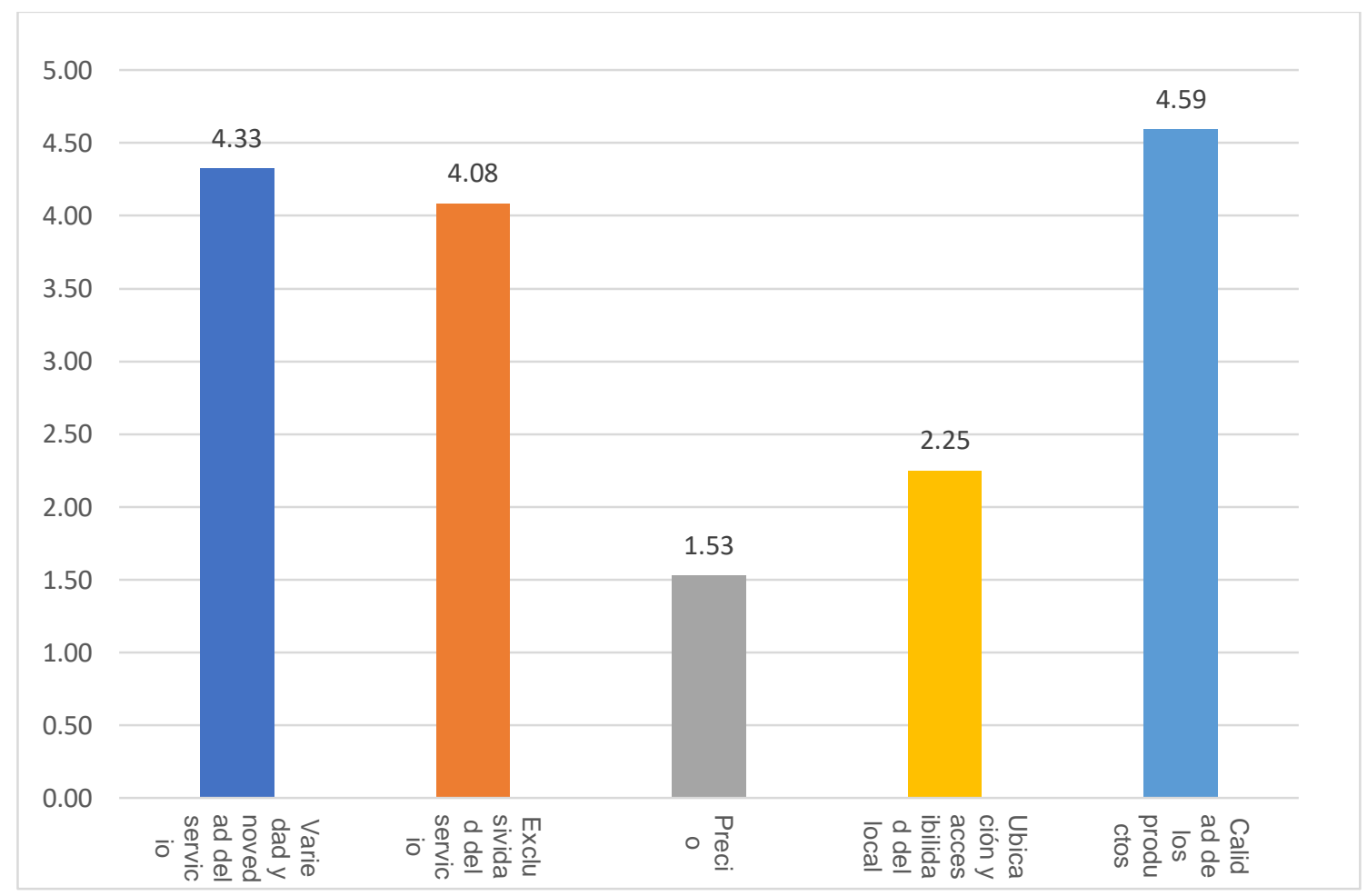

\section{Figura 12}

Valorización de Factores de Éxito para una Farmacia de Lujo

Fuente: Investigación de Mercado (2019)

13.Ubicación de la Farmacia

En la Tabla 12 se muestra la ubicación preferida por el público objetivo para la ubicación de la farmacia. 


\section{Tabla 12}

Ubicación Preferida por el público Objetivo

\section{Distrito localización del negocio}

Miraflores

San Isidro 301

Otro 6

385

Fuente: Investigación de Mercado (2019)

En la figura 13 se muestra la distribución porcentual de la preferencia del público objetivo por la ubicación

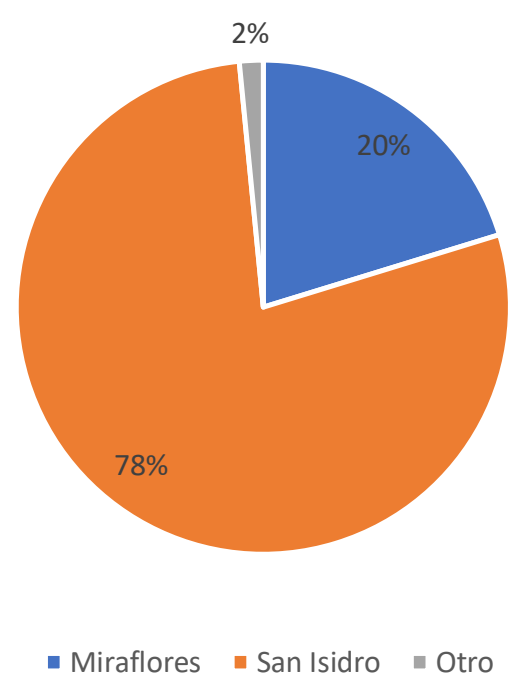

Figura 13

Ubicación de America Deluxe Health

Fuente: Investigación de Mercado (2019)

14. Medición de la Intención de Compra 
En la Tabla 13 se muestra la intención de compra por parte del público Objetivo

\section{Tabla 13}

Medición de la Intención de Compra

\section{Propuesta de Valor del Plan de Marketing}

Definitivamente lo compraría 252

Lo compraría

106

Probablemente lo compraría

Probablemente no lo compraría

8

Definitivamente no lo compraría

0

Fuente: Investigación de Mercado (2019)

En la figura 14 se observa el porcentaje de intención de compra por parte del público Objetivo

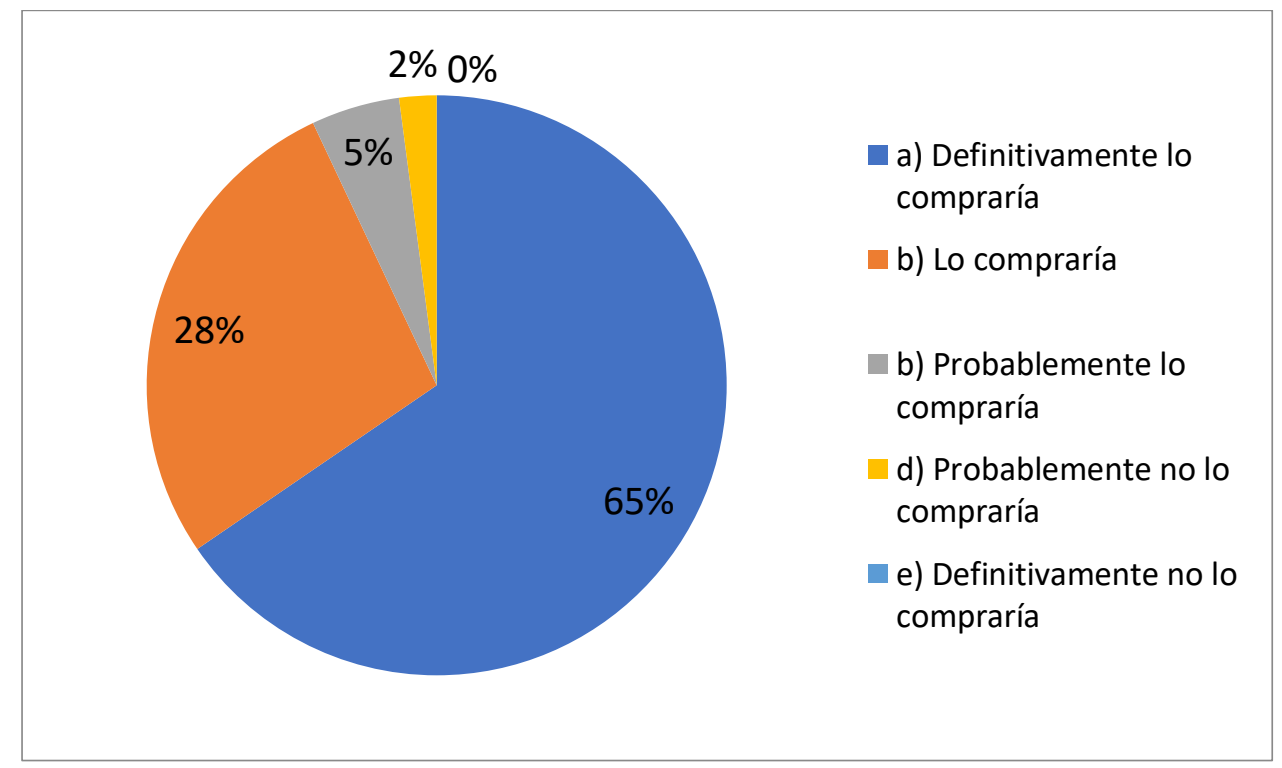

Figura 14 Distribución Porcentual de la Intención de Compra

Fuente: Investigación de Mercado (2019) 
15. Tipo de pago

En la Tabla 14 se muestra la forma de pago que prefiere el público Objetivo

\section{Tabla 14}

Forma de Pago Preferido por el Público Objetivo

\section{Pago del servicio}

\begin{tabular}{ll}
\hline a) Efectivo & 29 \\
b) Tarjeta de Crédito & 355 \\
c) Deposito en Cuenta & 0 \\
d) Cheque & 1 \\
\hline
\end{tabular}

Fuente: Investigación de Mercado (2019)

En este caso el 92\%del público objetivo cancela sus compras con tarjeta de crédito.

16. Actividades Promocionales

En la tabla 15 se muestra la preferencia del público objetivo para atender las actividades promocionales propuestas por $\mathrm{ADH}$.

\section{Tabla 15}

Preferencia por Actividades Promocionales América Deluxe Health

\section{Qué tipo de promoción le gustaría recibir}
a) Servicios Adicionales gratuitos

b) Transporte Gratuito al local

c) Servicio personalizado a domicilio

d) Precios especiales por la compra de productos adicionales

e) Viajes y/o retiros de belleza

f) Participación en activaciones exclusivas

Fuente: Investigación de Mercado (2019)

En la figura 15 se muestra la distribución porcentual de dichas preferencias 


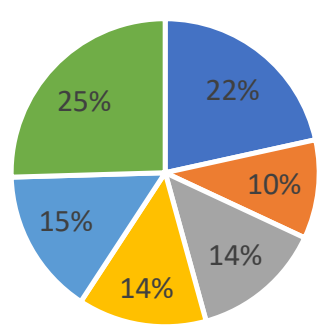

\footnotetext{
a) Servicios Adicionales gratuitos

a) Transporte Gratuito al local

a) Servicio personalizado a domicilio

- d) Precios especiales por la compra de productos adicionales

- e) Viajes y/o retiros de belleza

- f) Participación en activaciones exclusivas
}

\section{Figura 15}

Distribución Porcentual de Preferencias para las Actividades Promocionales de ADH Fuente: Investigación de Mercado (2019)

17. Medios Promocionales para comunicarse con Público Objetivo

En la Tabla 16 se muestran los tipos de medios que prefiere el público objetivo para ser invitado a las actividades de $\mathrm{ADH}$

\section{Tabla 16}

Tipos de Medios Preferidos por el público objetivo ADH

\section{Como le gustaría que lo contacten}

\begin{tabular}{ll}
\hline a) Mediante Internet & 222 \\
b) Mediante Prensa Escrita & 38 \\
c) Mediante Radio & 14 \\
d) Mediante Contactos (Boca Oreja) & 72 \\
e) Mediante Televisión & 16 \\
f) Mediante invitación & 23 \\
Total & 385
\end{tabular}

Fuente: Investigación de Mercado (2019)

En la figura 16 se muestra la distribución porcentual de los medios de comunicación preferidos por el Público Objetivo 


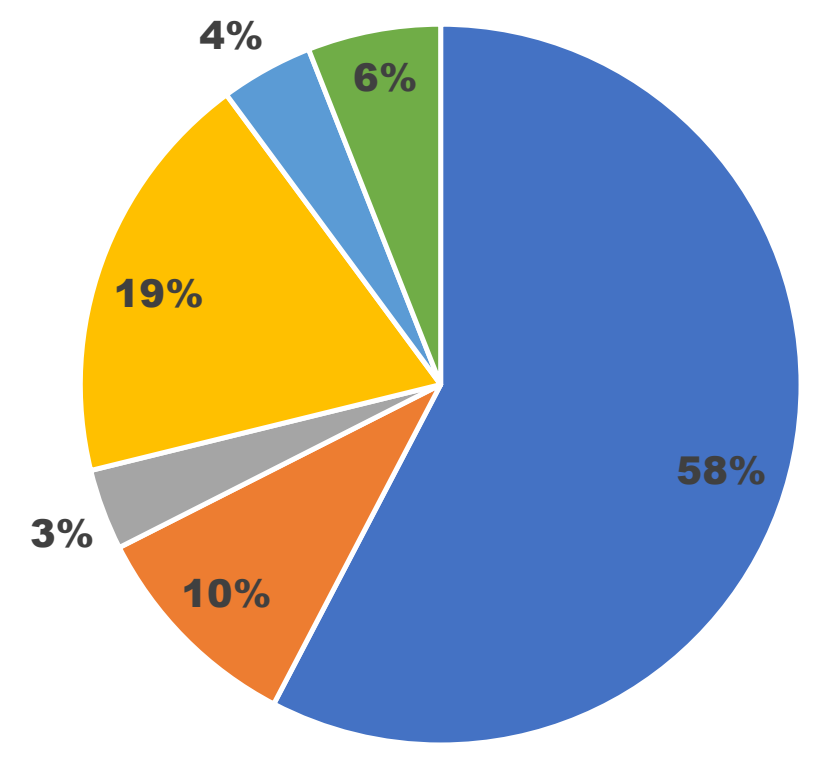
a) Mediante Internet
n b) Mediante Prensa Escrita
- c) Mediante Radio
d) Mediante Contactos (Boca Oreja)
- e) Mediante Televisión
- f) Mediante invitación

\section{Figura 16}

Distribución Porcentual de los Medios de Comunicación Preferidos por el Público Objetivo

Fuente: Investigación de Mercado (2019) 


\section{Objetivos}

\section{Anexo 17 Estudio de Mercado}

Determinar el tamaño del mercado objetivo

Evaluar la viabilidad del potencial del mercado

\subsection{Mercado Potencial}

El Mercado Potencial se determina con todos los habitantes que tienen entre 20 y 70 años y residen en la zona 7 de acuerdo a APEIM (2018)

\section{Tabla 1}

Estimación del Mercado Potencial

\begin{tabular}{lc}
\hline Distrito & Población Total 20-70 \\
\hline MIRAFLORES & 82,805 \\
LAMOLINA & 166,912 \\
SAN BORJA & 111,808 \\
SAN ISIDRO & 55,006 \\
SANTIAGO & DE \\
SURCO & \\
\hline TOTAL & 338,509 \\
\hline
\end{tabular}

Fuente: Datos Tomados de INEI (2013)

\subsection{Mercado Disponible}

El Mercado Potencial se determina con todos los habitantes que residen en la zona 7 que reúnen los requisitos determinados en la segmentación de mercado. Para ello se toman todos los pobladores de la zona 7 que pertenecen al Nivel Socio Económico A, tienen entre 20 y 70 años y según APEIM (2018) representa el 3.46\% de la población 


\section{Tabla 2}

Mercado Disponible ADH

\begin{tabular}{llll}
\hline & Población & Total & \\
Distrito & $20-70$ & NIVEL A & TOTAL \\
\hline MIRAFLORES & 82,805 & 0.346 & \\
LAMOLINA & 166,912 & \\
SAN BORJA & 111,808 & \\
SAN ISIDRO & 55,006 & \\
SANTIAGO & DE & \\
SURCO & 338,509 & \\
\hline TOTAL & 755,040 & & $\mathbf{2 6 1 , 2 4 3}$
\end{tabular}

Fuente: INEI y APEIM (2018)

Considerando el crecimiento de la población de Lima en 1.3\% anual (INEI,2018) se determina el mercado disponible para los próximos cinco años (Ver tabla 3)

Tabla 3

Determinación Mercado Disponible

\begin{tabular}{clllllll}
\hline & Año0 & $\%$ & Año1 & Año2 & Año3 & Año4 & Año 5 \\
\cline { 2 - 7 } $\begin{array}{c}\text { Mercado } \\
\text { Disponible }\end{array}$ & 261,243 & $1.30 \%$ & 269,080 & 277,153 & 285,467 & 294,031 & 302,852 \\
\hline
\end{tabular}

Nota: Año 1 Tomado de Estimaciones y proyecciones de población, Instituto Nacional de Estadística 2017, y Perú población 2017 Departamento de Estadística - CPI

\subsection{Mercado Efectivo}

Es una parte del mercado que está formada por el conjunto de consumidores que tienen la necesidad específica de comprar el producto o servicio que ofrece el nuevo negocio. Para determinar el mercado efectivo se utiliza las preguntas 2,7 y 8 de la encuesta de la investigación de mercado. 
Pregunta 2 Ingresos promedios mensuales

Menos de $\$ 50000.58 \quad$ Mas de $\$ \mathbf{5 0 0 0 0 . 4 2}$

Pregunta 7 ¿Con qué frecuencia utiliza el servicio?

Otros $0.02 \quad$ Semanal a bimestral 0.98

Pregunta 8 ¿Cuánto está dispuesto a gastar?

Mas de 1000 soles $\quad \mathbf{0 . 8 8} \quad$ Menos de 1000 soles 0.12

La cuantificación del mercado efectivo de mascotas se muestra en la Tabla 3.

Tabla 3

Cuantificación del Mercado Efectivo de Mascotas

\begin{tabular}{lcccc}
\hline & & & Decisión & \\
& Frecuencia & Ingresos & Gasto & Total \\
\hline Mercado Efectivo & 0.98 & 0.42 & 0.88 & 0.362 \\
\hline
\end{tabular}

De este resultado se obtiene que el mercado efectivo es de 94,624 personas.

\subsection{Mercado Objetivo}

En base al mercado efectivo, se determina, utilizando los resultados de la encuesta, la intención de compra. (Ver tabla 4)

Para calcular la proporción de penetración Pope (2002) propone un sistema de ponderación que permite calcular la intención de compra de los consumidores mediante el siguiente inductivo:

"Las ponderaciones en este caso suponen que solo alrededor de las tres cuartas partes (0.75) de las personas que dijeron que "definitivamente comprarían" el producto lo comprarían en realidad, que aproximadamente la cuarta parte (0.25) de los que dijeron que "probablemente compraría” y así sucesivamente (Pope, 2002, p. 183)”.

5: Definitivamente lo compraria

4: Lo compraria 
3: Probablemente lo compraria

2: Probablemente no lo compraria

1: Definitivamente no lo compraria

Los resultados de dichas respuestas obtenidas en el estudio de mercado realizado por el grupo se pondera con los porcentajes de la pregunta 14 de la encuesta realizada en el estudio de mercado y se aprecia en la Tabla 4

\section{Tabla 4}

Sistema de Ponderación de Intención de Compra

\begin{tabular}{|c|c|c|c|}
\hline $\begin{array}{l}\text { Escala de Intención } \\
\text { de Compra }\end{array}$ & Respuesta & Ponderaciones & Puntaje Ponderado \\
\hline $\begin{array}{l}\text { Definitivamente lo } \\
\text { compraría }\end{array}$ & 65.5 & 0.75 & $49.1 \%$ \\
\hline Lo compraría & 27.5 & 0.25 & $6.9 \%$ \\
\hline $\begin{array}{l}\text { Probablemente lo } \\
\text { compraría }\end{array}$ & 4.9 & 0.1 & $0.5 \%$ \\
\hline $\begin{array}{l}\text { Probablemente no lo } \\
\text { compraría }\end{array}$ & 2.1 & 0.05 & $0.1 \%$ \\
\hline $\begin{array}{l}\text { Definitivamente no } \\
\text { lo compraría }\end{array}$ & 0 & 0 & 0 \\
\hline
\end{tabular}

Adaptado de "Investigación de Mercado" Jeffrey Pope Editorial Norma (2002)

Fuente: Investigación de Mercado (2019) 


\section{Tabla 5}

Mercado Objetivo Plan de Negocio

\begin{tabular}{lccccccc}
\hline & Año0 & $\%$ & Año1 & Año2 & Año3 & Año4 & Año 5 \\
\cline { 2 - 7 } $\begin{array}{c}\text { Mercado } \\
\text { Potencial }\end{array}$ & 755,559 & $103.00 \%$ & 778,226 & 801,573 & 825,620 & 850,388 & 875,900 \\
\hline $\begin{array}{c}\text { Mercado } \\
\text { Disponible }\end{array}$ & 261,243 & $34.58 \%$ & 269,080 & 277,153 & 285,467 & 294,031 & 302,852 \\
\hline $\begin{array}{c}\text { Mercado } \\
\text { efectivo }\end{array}$ & 94,624 & $12.52 \%$ & 97,463 & 100,387 & 103,399 & 106,500 & 109,696 \\
\hline $\begin{array}{l}\text { Mercado } \\
\text { Objetivo }\end{array}$ & 33,743 & $4.47 \%$ & 34,755 & 35,798 & 36,872 & 37,978 & 39,117 \\
\hline
\end{tabular}

Fuente: Investigación de Mercado (2019)

De dicho mercado objetivo la empresa espera atender al realizar los esfuerzos y acciones de marketing de la empresa. Este mercado también es definido a través del porcentaje de mercado que se espera atender por lo que de acuerdo a la investigación de mercado se espera atender un $2.5 \%$ del mercado como escenario pesimista por lo que se cuenta con 845 personas que con seis atenciones anuales alcanzarían el objetivo de ventas. 